Portland State University

PDXScholar

Winter 3-14-2019

\title{
Physical and Emotional Sibling Violence and Child Welfare: a Critical Realist Exploratory Study
}

Katherine Elizabeth Winters

Portland State University

Follow this and additional works at: https://pdxscholar.library.pdx.edu/open_access_etds

Part of the Social Work Commons

Let us know how access to this document benefits you.

\section{Recommended Citation}

Winters, Katherine Elizabeth, "Physical and Emotional Sibling Violence and Child Welfare: a Critical Realist Exploratory Study" (2019). Dissertations and Theses. Paper 4808.

https://doi.org/10.15760/etd.6692

This Dissertation is brought to you for free and open access. It has been accepted for inclusion in Dissertations and Theses by an authorized administrator of PDXScholar. Please contact us if we can make this document more accessible: pdxscholar@pdx.edu. 
Physical and Emotional Sibling Violence and Child Welfare:

A Critical Realist Exploratory Study

by

Katherine Elizabeth Winters

A dissertation submitted in partial fulfillment of the requirements for the degree of

Doctor of Philosophy

in

Social Work and Social Research

Dissertation Committee:

Stephanie Wahab, Chair

Joan Shireman

Jana Meinhold

Eric Mankowski

Portland State University

2019 
(C) 2019 Katherine Elizabeth Winters 


\begin{abstract}
Sibling violence is a pervasive, yet poorly understood and substantially underreported phenomenon. Currently recognized as the most common form of intrafamilial abuse, various estimates suggest that 30 percent or more of children in the general population experience severe acts of violence inflicted by a sibling each year.

Given that many young people in the child welfare system experience the family conditions associated with abusive sibling violence, recent publications have implored child welfare to embrace the notion that it is a form of child maltreatment. Practitioners and policymakers have yet to reach agreement on what constitutes physical or emotional abuse between siblings, and the perspectives of young people with lived experience of abuse are largely absent from research and scholarship.

I designed the study, grounded in Critical Realism, to increase understanding of how sibling violence manifests in child welfare, contribute to theory development, and identify actions to protect children from harm. Based on in-depth interviews with eight foster care alumni, I offer a refined definition of sibling violence and four family conditions associated with sibling violence in child welfare. The findings also supported a systems-based theory reflecting four stable family member roles. My recommendations seek to leverage the infrastructure of the child welfare system while taking into consideration the limitations imposed by neoliberal social and economic policy.
\end{abstract}




\section{Dedication}

This dissertation is dedicated to FosterClub for their partnership in this project, the study participants who contributed so courageously to the interviews, and the foster care alumni who served as advisers and whose guidance and recommendations strengthened the study: Ashley Strange, Ke’Onda Johnson, TeAsia Hend, and Timothy Dennis. 


\section{Acknowledgements}

Utmost gratitude to my adviser, Stephanie Wahab - your encouragement, responsiveness, and pointed questions kept me steadily moving forward, with confidence. Joan Shireman, this project benefitted tremendously from your sage wisdom of child welfare and unwavering attention to its practice and policy implications. Janna Meinhold, I count myself lucky for having such an enthusiastic thought partner. Eric Mankowski, your gentle reminder to attend to my own heart was well-timed and did not fall on deaf ears. Beverly Parsons, your mentorship in systems thinking has beautifully altered the trajectory of my life. Amber Fletcher, your expertise in Critical Realism was my guidepost. Emily Lott and Lindsay Merritt, walking this path alongside you has been an honor and a privilege. And finally, to my family, thank you for giving me everything I needed to learn so much. 
Table of Contents

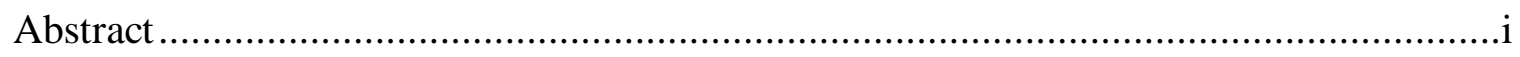

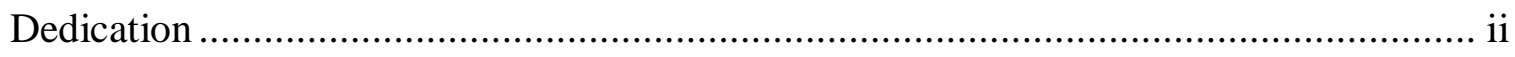

Acknowledgements .............................................................................................. iii

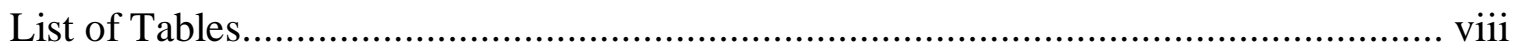

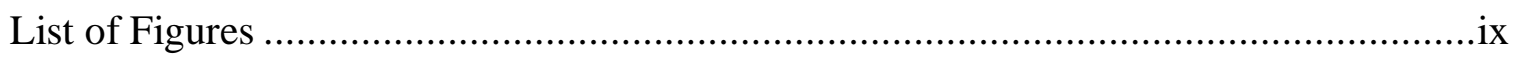

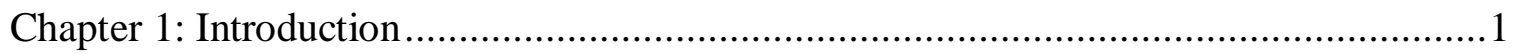

Social Problem Description and Definitions ......................................................

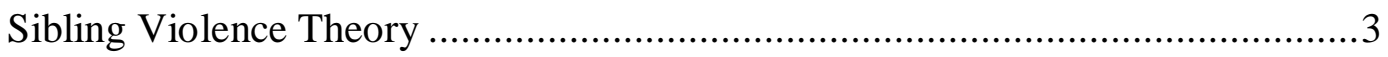

Sibling Violence Theory and Intervention in the Context of Child Welfare ...........4

Critical Realism for Sibling Violence Research in Child Welfare ..........................9

Study Purpose, Research Questions, and Significance to Social Science

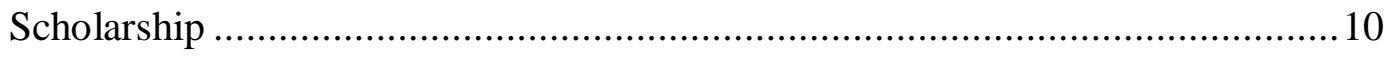

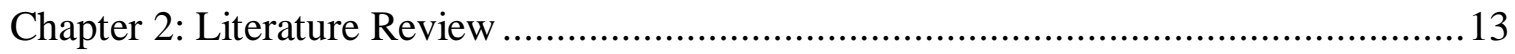

Defining Abusive Sibling Violence ....................................................................13

Abusive Sibling Violence in the Context of Child Welfare ..................................15

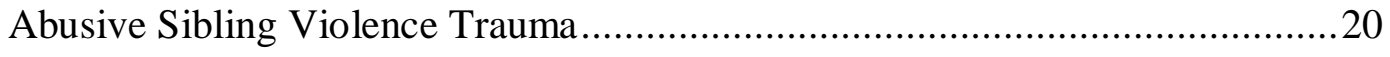

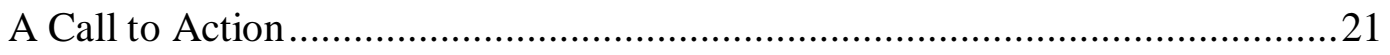

Family Conditions Associated with Sibling Maltreatment ...................................22

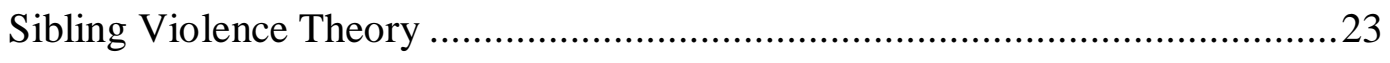

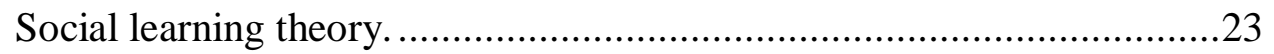


Radical feminist theory...................................................................25

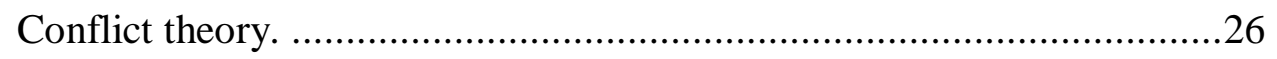

Coercive family process........................................................................29

Social ecological model of violence........................................................31

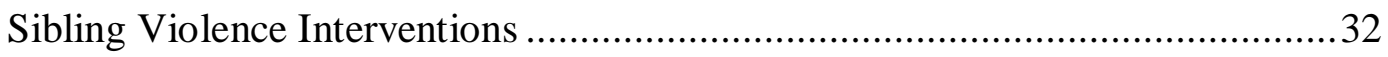

Micro- and meso-level interventions.......................................................32

Macro-level influences and interventions................................................37

Holistic, coordinated violence prevention intervention..............................39

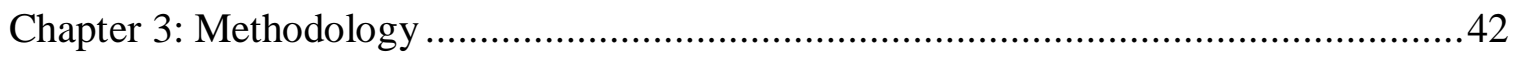

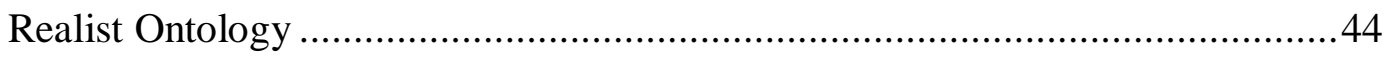

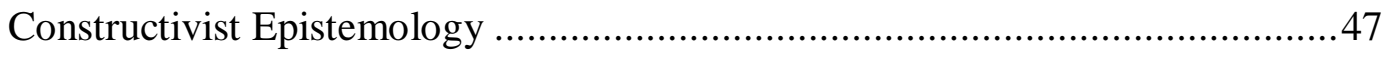

Methodology and Methods............................................................................48

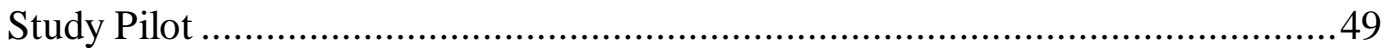

Study participant recruitment and consent process...................................54

Data collection.......................................................................................5

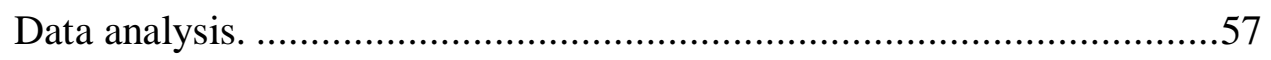

Establishing Trustworthiness............................................................................61

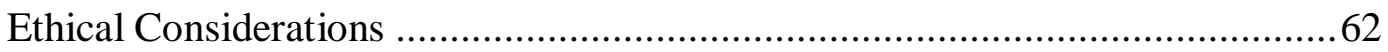

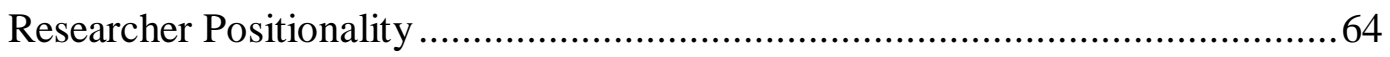

Chapter 4: Results................................................................................................66

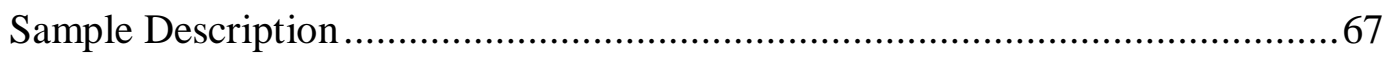


Research Question 1. How do foster care alumni describe their experiences with physical and emotional sibling violence? .............................................. 70

A nascent definition of abusive sibling violence in child welfare ............70

Family conditions associated with sibling violence ..........................77

Resonance of linear and non-linear theories ...................................87

Research Question 2. From the perspective of foster care alumni, how do adults who care for or work with young people involved in the child welfare system (e.g., foster parents, case workers, mental health providers, kinship caregivers,

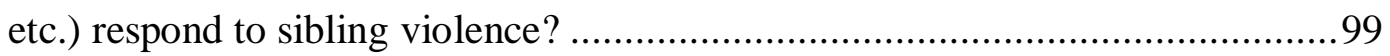

Inadequacy of adult responses to sibling violence in child welfare ..........99

Survivors' recommendations to address the problem ........................103

Results of CR Retroduction .................................................................... 104

Child maltreatment in political-economic context. ...........................106

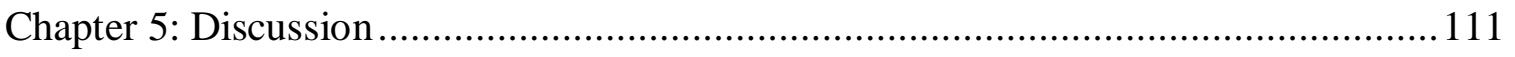

Raise Awareness and Provide Basic Training for Adults Charged with Ensuring

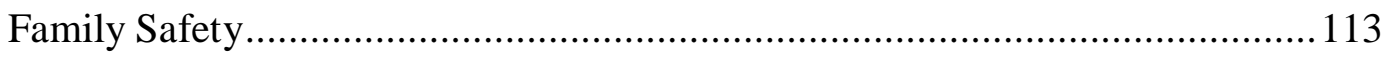

Refine and Adopt a Definition of Abusive Sibling Violence in Child Welfare..114

Systematically Assess and Track Abusive Sibling Violence Among Child

Welfare-involved Families ................................................................. 115

Revisit Child Welfare Co-Placement Policy ........................................... 116

Invest in Programs to Ensure Safe, Strong Sibling Relationships for Child

Welfare-Involved Youth ....................................................................... 116 


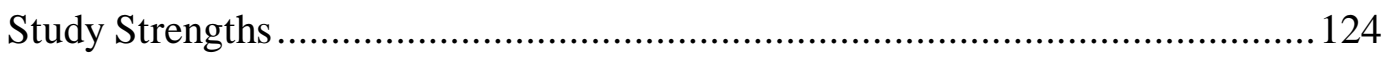

Youth Perspectives. ...............................................................124

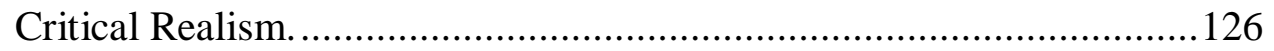

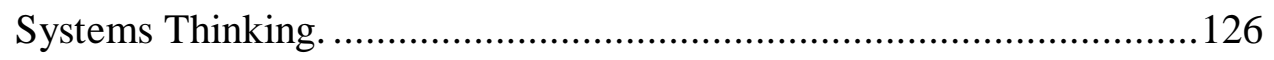

Implications for Future Research.................................................... 127

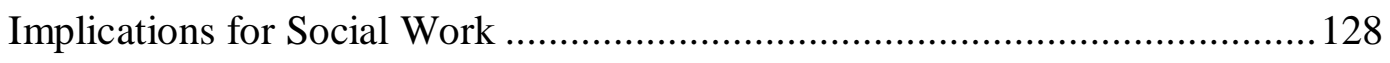

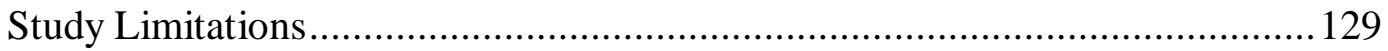

All female sample ...........................................................129

Individual perspectives. .....................................................130

Investigator limitations ........................................................130

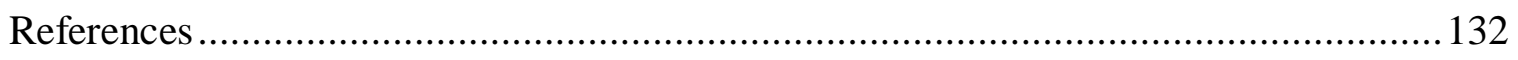

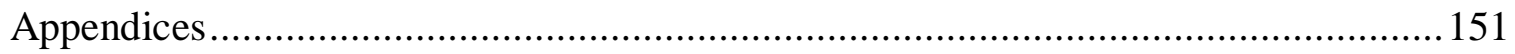

Appendix A: Recruitment Flyer ...................................................... 151

Appendix B: Participant Informed Consent Document ...............................153

Appendix C: Data Collection Instruments: Interview Protocol and Background

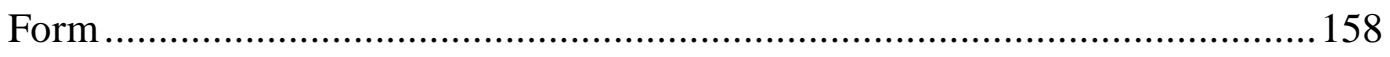

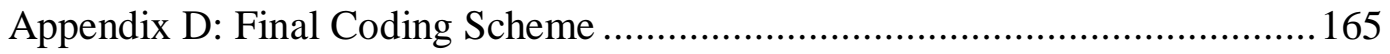

Appendix E: Family Map Example .................................................... 172

Appendix F: Human Subjects Application to IRB ....................................... 181 


\section{List of Tables}

Table 1. Characteristics of Sibling Rivalry and Sibling Violence .............................. 14

Table 2. NCANDS Child Maltreatment Perpetrator Categories and Percentages

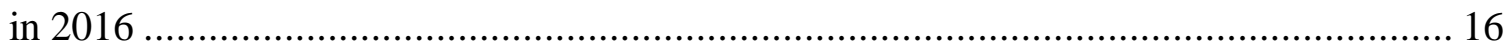

Table 3. Sibling Study Adviser Conference Call Summary ..................................... 52

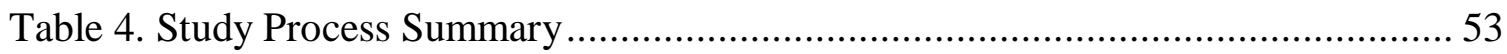

Table 5. Study Participants’ Reports of Physical and Emotional Sibling Violence ........ 68

Table 6. Family Conditions Associated with Sibling Violence ................................. 78

Table 7. Final Set of Family Conditions Associated with Sibling

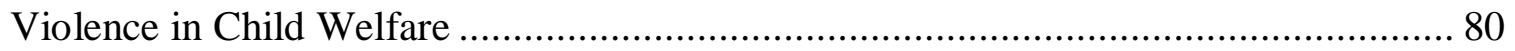

Table 8. Family Conditions Associated with Sibling Violence Overall and by

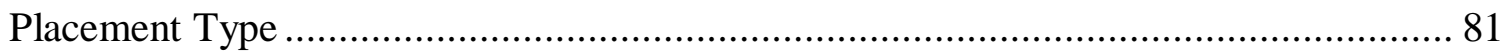

Table 9. Theory Code Descriptions .................................................................. 88

Table 10. Final Set of Primary and Secondary Family Conditions for Sibling

Violence in Child Welfare with Associated Linear Theories ..................................... 92 


\section{List of Figures}

Figure 1. Integrated theoretical model of sibling physical and psychological abuse (Hoffman and Edwards, 2004, p. 191).

Figure 2. Ecological model for understanding violence (adapted from the World

Health Organization, 2002, p. 12)

Figure 3. Ecological model for understanding violence (adapted from the World

Health Organization, 2002, p. 12).

Figure 4. Coordinated violence prevention model: Hypothetical common and specific elements (Hamby and Grych, 2013, p. 85).

Figure 5. CR domains of reality presented as an iceberg. 45

Figure 6. Instigator/retaliator escalating abusive sibling violence dynamic with reinforcing feedback loops.

Figure 7. Two biological siblings and their father. .95

Figure 8. Kinship care setting with two biological siblings and their foster sister.

Figure 9. Biological family with four siblings. .98

Figure 10. Retroduction results summarized in terms of the three domains of reality. .110 


\section{Chapter 1: Introduction}

\section{Social Problem Description and Definitions}

Sibling violence is a pervasive, yet poorly understood and substantially underreported phenomenon. Currently recognized as the most common form of intrafamilial abuse (Button \& Gealt, 2010), various estimates suggest that 30 percent or more of children in the general population experience severe acts of violence inflicted by a sibling each year (Caffaro, 2014; Finkelhor, Tuner, \& Ormrod, 2006; Straus, Gelles, \& Steinmetz, 2006; Tucker, Finkelhor, Shattuck, \& Turner, 2013). Common discourse continues to minimize the problem (e.g., sibling rivalry, rough housing), and the phenomenon is often treated as an accepted rite-of-passage. Yet differences in size and physique between siblings, the developmental immaturity of children, and everyday close contact within the household are likely to increase the frequency, intensity, and duration of violent sibling interactions (Finkelhor et al., 2006). These findings are cause for concern given robust evidence of numerous harmful effects of sibling violence across the lifespan (Button \& Gealt, 2010; Caffaro, 2011; Caffaro, 2014; Feinberg, Solmeyer, \& McHale, 2012; Finkelhor et al., 2006; Graham-Bermann, Cutler, Litzenberger, \& Schwartz, 1994; Kramer \& Bank, 2005; Straus et al., 2006; Tucker et al., 2013). In the absence of a caring adult who intervenes, chronic sibling violence may cause "toxic stress," which has been linked to physical and mental illness later in life (Shonkoff, Boyce, \& McEwen, 2009; Finkelhor et al., 2006).

Sibling violence theorists, practitioners, and researchers have attempted to define what constitutes abusive physical and emotional violence between siblings. Wiehe 
(1997), one of the first and more widely cited authors on the topic of sibling violence, aligned the phenomenon with parent-to-child maltreatment by using the word "abuse" when defining violent interactions between siblings. Caffaro (2014), a clinical psychologist and family therapist, effectively differentiated healthy sibling conflict (i.e., rivalry) and abusive sibling violence in terms of aims, frequency, power, change over time, and the role of caregivers. According to the author, abusive sibling violence is marked by stable victim and offender roles. Caffaro’s emphasis on repetition is notable, given that even low frequency peer violence (i.e., occurring less than four times per year) has been significantly associated with trauma symptoms in young children (Finkelhor et al., 2006). Meyers (2017) built upon the work of Caffaro and others in a qualitative study with adult survivors. She argued that a comprehensive definition of abusive physical and emotional violence between siblings should include the victim/survivor's lived experience/perception of what took place.

Despite commendable progress made over the course of more than three decades of sibling violence research and scholarship, a clearly-articulated and broadly accepted definition of "sibling abuse" is yet to be developed. In a review of more than 100 journal articles, books, chapters, and dissertations published between 1977 and 2008, Perkins (2014) found 16 different labels used to discuss emotional and physical violence between siblings: sibling abuse, sibling aggression, sibling agonistic behavior, sibling antagonism, sibling assault, sibling conflict, sibling fighting, sibling hostility, sibling maltreatment, sibling negativity, sibling psychological abuse, sibling psychological maltreatment, sibling quarreling, sibling relational aggression, sibling rivalry, and sibling violence (pgs. 
34-35). Definitional variation is problematic, limiting interpretation of individual sibling violence studies and the capacity of the field to draw comparisons among them.

\section{Sibling Violence Theory}

Theorizing about sibling violence is similarly nascent, traversing levels of the social ecology from the interpersonal to the global. Social learning theory positions sibling violence as a learned behavior which is fortified through reinforcement (Bandura, Ross, \& Ross, 1963; Hoffman \& Edwards, 2004). Radical feminist theory argues that the patriarchal organization of society and the related, pervasive acceptance of the use of power and control to achieve desired aims underlie the phenomenon (Button \& Gealt, 2010; Graham-Berman et al., 1994; Hoffman \& Edwards, 2004; Hoffman, Kiecolt, \& Edwards, 2005; Wiehe, 1997). With roots in Marxism, conflict theory assumes that humans are innately self-interested, and when located within a context of scarcity, will utilize any means available to obtain desired resources. Sibling violence is theorized to be a response to a child's perception that necessary resources (e.g., basic needs, parental attention) are scarce or inadequate (Hoffman et al., 2005; Smith \& Hamon, 2012). While these theories identify potential causal mechanisms underlying sibling violence, they rely on reductionist linear models and differentiations between violence and abuse are unclear.

Moving beyond linear, mechanistic models, a small subset of the literature discusses systems-based conceptions of sibling violence. Family systems theory (Milevsky, 2011), coercion theory (Granic \& Patterson, 2006; Patterson, 1982; Smith, Dishion, Shaw, Wilson, Winter, \& Patterson, 2014), and an ecological model 
(Bronfenbrenner, 1979) employ key systems concepts including holism, nesting, and non-linearity to examine interpersonal violence as a complex and dynamic process that spans local to global levels of a structurally violent society (Gil, 1996). In a comprehensive review of theories of sibling relationships across the lifespan, Whiteman, McHale \& Soli (2011) summarize the current state of sibling violence theorizing, acknowledging that:

...the processes that affect sibling relationship dynamics operate at a variety of levels, ranging from intrapsychic processes, such as attachment and social comparison, to relational dynamics, such as social learning and more distal forces beyond the family, such as sociocultural influences. (p. 135)

While a small number of systems-oriented scholars have explored these ideas, substantial additional effort is needed to understand the extent to which these conceptions approximate reality.

\section{Sibling Violence Theory and Intervention in the Context of Child Welfare}

The current definition of child maltreatment, per the most recent iteration of the Child Abuse Prevention and Treatment Act (CAPTA) states:

...the term 'child abuse and neglect' means, at a minimum, any recent act or failure to act on the part of a parent or caretaker, which results in death, serious physical or emotional harm... or an act or failure to act which presents an imminent risk of serious harm” (Administration for Children and Families, Division of Health and Human Services, 2016, p. 7). 
Though intentionally vague, the CAPTA definition of child maltreatment does not fit well with analysis of abusive sibling violence in that it assumes the perpetrator is a parent. However, the latter part of the definition, focused on "imminent risk of serious harm” can be employed given strong evidence that sibling-perpetrated physical and emotional violence produce negative outcomes across the lifespan (Button \& Gealt, 2010; Caffaro, 2011; Caffaro, 2014; Feinberg et al., 2012; Finkelhor et al., 2006; GrahamBermann et al., 1994; Kramer \& Bank, 2005; Straus et al., 2006; Tucker et al., 2013). Data on physical and emotional violence between siblings are not systematically collected in any of the three federally-maintained (i.e., national) child welfare data systems: National Child Abuse and Neglect Data System (NCANDS), Adoption and Foster Care Analysis and Reporting System (AFCARS), and National Incidence Studies of Child Abuse and Neglect (NIS) (Shireman, 2015). Moreover, many states exclude sibling violence from definitions of child abuse (Caffaro, 2011), leaving direct service practitioners ill-prepared to identify the problem among the children they serve (Kominkiewicz, 2004). Increased emphasis on sibling co-placement in child welfare is likely to further reduce attention to harmful sibling dynamics. This is notable given wellintentioned and often beneficial federal policy mandating co-placement for siblings in foster care. ${ }^{1}$ In a review of the peer-reviewed empirical social work and psychology literature published from 1988 through 2003, 17 studies addressing siblings in foster care

\footnotetext{
${ }^{1}$ The Fostering Connections to Success and Increasing Adoptions Act of 2008 (P.L. 110-351) requires that reasonable efforts be made to place siblings in the same foster home and with kin whenever possible, and over half of state child welfare systems prioritize sibling co-placement as a means of maintaining sibling bonds (Gustavsson \& MacEachron, 2010). For an in-depth discussion of legal protections accorded to siblings in foster care, see Shlonsky, Bellamy, Elkins, \& Ashare, 2005.
} 
or adoption collectively demonstrated that sibling co-placement can support placement stability and reduce symptomology among child welfare-involved youth (Hegar, 2005). A subsequent meta-analysis similarly concluded that "most children benefit significantly from living with their siblings” (Washington, 2007, p. 431). Juxtaposed with reports indicating that significant numbers of siblings were not co-placed (Staff \& Fein, 1992; Washington, 2007; Wulczyn \& Zimmerman, 2005), these findings powered a shift in federal and state legislation toward strong emphasis on co-placement and, when placed separately, the importance of ensuring regular visitation between siblings removed from biological caregivers, both in the United States and abroad (Hegar, 2005; Kothari et al., 2014).

The Fostering Connections to Success and Increasing Adoptions Act of 2008 was the first federal law to address the importance of sibling co-placement, requiring states to make reasonable effort to maintain sibling connections when in foster care. Over half of the states in the U.S. had established sibling placement or visitation policies prior to passage of the Act, whereas others developed state-based policies specific to siblings in foster care subsequent to its passage (Child Welfare Information Gateway, 2013). Yet neither the Act, nor its accompanying Program Instruction for Title IV-E agencies include the word "abuse" and the Act does not address cases where co-placement is not appropriate. Moreover, no standard protocol is available for caseworkers to use in making decisions about co-placement when sibling abuse is present. This "best practice” (Cohn, 2008) guides a nationalized approach to care in which siblings who should not be coplaced, or who should be co-placed only with strong supports, may be overlooked. In an 
effort to bring much needed nuance to co-placement policy, Linares, Li, Shrout, Brody, \& Pettit (2007) argued that separation of siblings during foster care placement may be beneficial, particularly for children with elevated levels of behavior and conduct problems.

The lack of attention to sibling violence in child welfare is concerning given that rates are likely high among maltreated children. Family conditions among children exposed to sibling violence include many which are common in child welfare: parental physical or emotional unavailability, lack of supervision, differential treatment of children in the same family such as scapegoating, inappropriate caretaking expectations placed on older sibling(s), parental acceptance of sibling violence as a normal part of family life, lack of parent intervention during acts of sibling violence, parental modeling of physically or emotionally abusive behavior, drug or alcohol abuse in the home, chronic mental or physical illness of parent(s), work or financial strain, and parental denial of the problem (Caffaro \& Con-Caffaro; 1998; Wiehe, 1997). Moreover, studies have demonstrated that sibling violence often co-occurs with other types of family violence (i.e., adult-perpetrated child maltreatment, interpersonal violence between adult caregivers) (Henning, Leitenberg, Coffey, Bennet, \& Jankowski, 1997; Spaccarelli, Sandler, \& Roosa, 1994; Wallace, 1999; Wiehe, 1997). A small number of studies support the notion that maltreated children are prone to sibling/peer violence (Linares et al., 2007; Linares et al., 2015; Shields \& Cincchetti, 1998, 2001). Linares et al. (2015) found that 82 percent of foster parents reported past-year physical aggression acts 
between siblings in their care; 14 percent of foster children had been "beat-up” by a sibling while in their care (p. 211).

While the causal mechanisms underlying sibling violence are tentative, various interventions have been devised to train both parents and children to more productively and peacefully navigate sibling disputes. As early as 1967, clinicians were testing approaches to reduce sibling aggression and increase cooperative play among general samples (Kramer, 2004). More recent interventions have recommended various combinations of individual, sibling, family, and group therapy and training sessions on topics such as mediation, to reduce sibling violence (Caffaro \& Conn-Caffaro, 2005; Caspi, 2008; Feinberg, Sakuma, Hostetler \& McHale, 2013; Kennedy \& Kramer, 2008; Kiselica \& Morrill-Richards, 2007; Reid \& Donovan, 1990; Thomas \& Roberts, 2009; Siddiqui \& Ross, 2004; Smith \& Ross, 2007). Two studies have tested interventions devised specifically for child welfare-involved siblings (Kothari et al., 2017; Linares et al., 2015). Both interventions employ skill-building to support siblings to cultivate relational and self-regulatory skills to enhance relationship quality. While initial testing generated statistically significant results, the study conducted by Linares et al. (2015) was subject to a small sample size and Kothari et al. (2017) did not include a measure of sibling violence. More work is needed to develop and test interventions to ameliorate violence between siblings within the context of child welfare and beyond.

Theory and intervention development for child-welfare involved siblings is promising, given a recent call for social workers and mental health practitioners to attend to physical and emotional sibling violence in their work with children and families and 
social work’s “Grand Challenge” to stop family violence ${ }^{2}$ (Kulkami, Barth, \& Messing

2016; Meyers, 2014; Perkins \& O’Connor, 2015; Perkins \& Stoll, 2016; Shadik, Perkins, \& Kovacs, 2013). Yet without holistic understanding of the causal mechanisms

underlying sibling violence, interventions for child welfare-involved siblings are likely to exclude potentially efficacious components or strategies. Moreover, the perspectives of young people with lived experience with sibling violence are absent from theory and research on the phenomenon in the context of child welfare. This lack of youth-informed research and practice is misaligned with a body of research which has demonstrated that young people have much to offer when it comes to social problems that affect them. When asked to describe their experiences, share their perspectives, and provide recommendations, young people can meaningfully contribute to efforts to parse complex interpersonal processes, develop accurate definitions and measures, capitalize on sources of resilience in intervention designs, and inform direct practice and policy-making (Horwath, Kalyva, \& Spyru, 2012; Hyde \& Kammerer, 2009; Riebschleger, Day, \& Damashek, 2015; Strolin-Goltzman, Kollar, \& Trinkle, 2010).

\section{Critical Realism for Sibling Violence Research in Child Welfare}

Critical Realism (CR) emerged in the 1970s and 1980s as an alternative paradigm to positivism and constructivism. CR opens space to investigate ontological questions about causation by employing constructivist epistemologies and methods by separating

\footnotetext{
${ }^{2}$ Led by the American Academy of Social Work \& Social Welfare (AAASWSW), the Grand Challenges for Social Work is an initiative to champion social progress through social science, collaboration, and shared projects. For more information about the Grand Challenges visit http://aaswsw.org/grandchallenges-initiative/about/. For information about the challenge to stop family violence, see Kulkarni, Barth, and Messing's (2016) policy recommendations.
} 
reality into three domains: the empirical, the actual, and the causal. According to this CR stratification, the empirical domain (where social science research takes place) consists of a subset of all events produced by an underlying causal mechanism. CR research embraces both intensive (i.e., in-depth interpretive data) and extensive (i.e., data on widespread trends, typically gathered with quantitative data) methods to identify empirically observable patterns of human behavior which are then subjected to theoryladen researcher-driven thought exercises to clarify causal processes (Lennox \& JurdiHage, 2017; Sayer, 2010). CR is a well-suited philosophy to guide the current project because its goal is to inform emancipatory action to dismantle system structures that cause human suffering. This project, grounded in the CR paradigm, aims to identify causal mechanisms underlying abusive sibling violence as it is described by foster care alumni. The long-term objective is to inform direct practice, intervention development, and child welfare policies that effectively reduce its prevalence. A more detailed discussion of CR as it relates to the methodology and methods for this project is included in Chapter 3.

\section{Study Purpose, Research Questions, and Significance to Social Science Scholarship}

This dissertation was designed to begin to fill gaps in theory, direct practice, and policy by asking foster care alumni to share their experiences with sibling violence and offer recommendations to address the problem. The study examined abusive sibling violence, employing a working definition based on the work of Caffaro (2011) and Meyers (2017): (1) a repeated, escalating pattern of physically and/or emotionally violent interactions; (2) with stable victim/offender roles (i.e., unidirectional, (Caspi, 2012)); (3) 
in which the offender is motivated by a need for power and control, and; (4) the victim experiences a chronic sense of terror and powerlessness. Specifically, the study investigated the extent to which such a definition was represented in the descriptions of physical and emotional violence provided by foster care alumni. ${ }^{3}$

The study was designed to generate information to clarify (i.e., better define) what constitutes abusive sibling violence and to assess the fit and utility of family conditions and theories of sibling violence discussed in the extant literature by incorporating the perspectives of foster care alumni who have experienced it in the context of child welfare. The research questions guiding the study included:

1) How do foster care alumni describe their experiences with physical and emotional sibling violence?

a) To what extent do their descriptions fit with Caffaro (2014) and Meyers’ (2015) definitions of abusive sibling violence?

b) To what extent are family conditions and theories of sibling violence discussed in the extant literature represented in their descriptions?

c) What additional/refined causal mechanisms do their descriptions suggest?

\footnotetext{
${ }^{3}$ The inquiry will intentionally exclude sexual abuse between siblings. While physical, emotional, and sexual abuse are likely to co-occur (Caffaro \& Conn-Caffaro, 1998; Wiehe, 1997), the latter is not subject to the definitional problems that physical and emotional abuse are. Sibling incest is a criminal behavior prohibited by law in every U.S. state (Myers, 1998 as cited in Perkins, 2014). The current study will focus on physical and emotional abuse since these types of sibling abuse are definitionally ambiguous and largely neglected in the child welfare literature.
} 
2) From the perspective of foster care alumni, how do adults who care for or work with young people involved in the child welfare system (e.g., foster parents, case workers, mental health providers, kinship caregivers, etc.) respond to sibling violence?

a) To what extent are adult responses perceived as helpful?

b) What do young people recommend to address sibling violence?

The goals of the study for Social Science scholarship, research, and practice were multifold:

1. increase understanding of physical and emotional sibling violence in the context of child welfare;

2. contribute to sibling violence theory development; and,

3. identify innovative ways to protect children from sibling violence and/or help foster children manage sibling violence.

The chapters that follow provide a comprehensive review of the sibling violence literature, both within and beyond the context of child welfare, describe the methods for the study including the ontology, epistemology and methodology guiding the project, the results of the study, and conclude with a discussion of the findings with emphasis on practical recommendations to address sibling violence in child welfare and beyond. 


\section{Chapter 2: Literature Review}

\section{Defining Abusive Sibling Violence}

Wiehe (1997), one of the first and more widely cited authors on the topic of sibling violence, aligned the phenomenon with adult-perpetrated child maltreatment by using the word "abuse" when defining violent interactions between siblings. According to the author, physical abuse includes "willful acts resulting in physical injury such as slapping, hitting, biting, kicking, or more violent behavior that may include the use of an instrument, such as a stick, bat, gun, or knife” (pp. 14-18). Emotional abuse was defined as “verbal comments aimed at ridiculing, insulting, threatening, or belittling. Emotional abuse is also inclusive of the destruction of personal property, such as a sibling who deliberately destroys a prized possession or pet of another sibling” (Wiehe, 1997, pp. 3334). In addition to providing a variety of tangible examples of acts which constitute physical and emotional abuse, both definitions highlight the intent of one sibling to harm another. Wiehe's definition of physical violence also specifies that injury must result from an act of violence to qualify as abusive.

According to Caffaro (2011), sibling violence is defined as "a range of behaviors including pushing, hitting, kicking, beating, and using weapons to inflict physical harm,” whereas psychological maltreatment includes "exposing a sibling to violence by peers or other siblings; comments aimed at ridiculing, insulting, threatening, terrorizing, and belittling a sibling; rejecting, degrading, and exploiting a sibling, and; destroying a sibling's personal property” (pgs. 8-10). The author differentiated healthy sibling conflict and abusive sibling violence in terms of aims, frequency, power, change over time, and 
the role of caregivers (Table 1). Most notably, abusive sibling violence is marked by stable victim and offender roles. A shortcoming of Caffaro's list of characteristics is that it largely neglects to describe the markers of psychological maltreatment between siblings.

Table 1

Characteristics of Sibling Rivalry and Sibling Violence (Caffaro, 2011, p. 91)

\section{Sibling Rivalry}

- Conflict between siblings in which the reward is possession of something that the other also wants

- Conflict between siblings that strengthens their relationship

- Fierce but balanced comparisons between siblings with regard to achievement, attractiveness, and social relations with peers

\section{Sibling Violence}

- A repeated pattern of physical aggression directed toward a sibling with the intent to inflict harm and motivated by an internal emotional need for power and control

- Physical aggression directed toward a sibling that aims to leave the other feeling humiliated, defeated, and/or unsafe

- An escalating pattern of sibling aggression and retaliation that parents seem unwilling or unable to stop

- Role rigidity resulting in the solidification of victim and offender sibling roles

More recently, Meyers (2017) conducted a qualitative study employing phenomenological and grounded theory methods to gather survivor accounts to develop a working definition of sibling abuse. Based on in-depth interviews with 19 survivors aged 25 to 65, analysis identified the unpredictable nature of the abusive incidents as an essential marker of sibling abuse. Survivors recounted violent interactions which occurred consistently over the course of years. Despite the long-term and frequent nature of the abuse, the perception that they could not anticipate or avoid the assaults resulted in 
a chronic sense of terror coupled with a perpetual state of powerlessness to self-protect. Meyers’ findings also confirmed intent, duration, and a power differential between siblings as key attributes of sibling abuse. A notable insight which can be garnered from the inquiry is the idea that a comprehensive definition of abusive sibling violence should include the victim/survivor's lived experience/perception of what took place. The current project assessed the extent to which there was resonance between the definitions of abusive sibling violence put forward by Caffaro and Meyers and respondents’ descriptions of sibling violence in the context of child welfare.

\section{Abusive Sibling Violence in the Context of Child Welfare}

While Caffaro and Meyers’ definitions position abusive sibling violence as a form of child maltreatment, state and federal entities charged with ensuring the safety and wellbeing of children have largely overlooked this form of family violence. In the United States, the Department of Health and Human Services Administration for Children and Families (ACF) is charged with promoting the economic and social well-being of families, children, individuals, and communities. ACF programs and services for children and youth include child abuse and neglect prevention and intervention and ensuring that children who are victims receive treatment and care. ACF includes the Children's Bureau

which collects case-level data on reports of child abuse and neglect via the National Child Abuse and Neglect Data System (NCANDS). Annual analyses of maltreatment data are summarized in publicly available reports that are also submitted to Congress (U.S. Department of Health \& Human Services, 2015). 
In Child Maltreatment 2016, the $27^{\text {th }}$ annual report on child abuse and neglect generated by the Administration and the most recent report available, child maltreatment was defined as "Any recent act or failure to act on the part of a parent or caretaker which results in death, serious physical or emotional harm, sexual abuse or exploitation; or an act or failure to act, which presents an imminent risk of serious harm” (U.S. Department of Health \& Human Services, 2016, p. viii). This definition is limited, given that many people other than parents can be abusers. Regardless, for fiscal year 2016, "there were a nationally estimated 676,000 victims of abuse and neglect...a rate of 9.1 victims per 1,000 children in the population” (U.S. Department of Health \& Human Services, 2016, p. x). The NCANDS does not capture sibling abuse rates, however, a significant shortcoming of the system. Children under the age of 18 constitute under one percent of perpetrators in the NCANDS (U.S. Department of Health \& Human Services, 2016, p. 65). Moreover, the system does not disaggregate siblings among the perpetrator categories captured, as shown in Table 2.

Table 2

NCANDS Child Maltreatment Perpetrator Categories and Percentages in 2016

\begin{tabular}{l|l}
\hline Perpetrator's Relationship to the Maltreated Child & Percentage \\
\hline Parent & $91.4 \%$ \\
Other relative & $4.6 \%$ \\
Unknown & $3.1 \%$ \\
Unmarried partner of parent & $3.0 \%$ \\
Other & $2.7 \%$ \\
More than one nonparental perpetrator & $1.1 \%$ \\
Friend or neighbor & $.8 \%$ \\
Child daycare provider or other professional & $.7 \%$ \\
Foster parent & $.2 \%$ \\
Legal guardian & $.2 \%$ \\
\hline
\end{tabular}


According to the NCANDS, sibling perpetrators comprise a very small proportion of substantiated child maltreatment cases; "other relatives”, who would include a variety of family members in addition to siblings, account for slightly more than six percent of perpetrators documented. Foster siblings are subsumed within the "other" category, which also includes nonrelated adult, nonrelated child, foster sibling, babysitter, household staff, clergy, and school personnel perpetrators (U.S. Department of Health \& Human Services, 2016, p. 23). ${ }^{4}$ These data contrast sharply with numerous other nationally-representative sources of family violence data. The National Family Violence Survey, The National Family Violence Resurvey, the Developmental Victimization Survey and, most recently, the National Survey of Children's Exposure to Violence reported rates of severe violence between siblings between 30 and 82 percent annually (Caffaro, 2011; Finkelhor, Ormrod, Turner, \& Hamby, 2005; Gelles \& Steinmetz, 2006; Tucker et al., 2013). While counting violent acts is an overly simplistic approach to investigating physical abuse and overlooks emotional abuse altogether, it does provide tangible evidence of the scope of the problem. These general population studies also support the notion that sibling violence crosses economic boundaries and position abusive sibling violence as a subset of family violence, comparable to interpersonal violence between adults and adult-perpetrated child maltreatment with regard to its need for both attention and intervention. The absence of sibling abuse cases in the NCANDS

\footnotetext{
${ }^{4}$ Data on physical and emotional violence between siblings involved in child welfare are not systematically collected in any of the three federally-maintained (i.e., national) data systems: National Child Abuse and Neglect Data System (NCANDS), Adoption and Foster Care Analysis and Reporting System (AFCARS), and National Incidence Studies of Child Abuse and Neglect (NIS) (Shireman, 2015).
} 
exposes a lack of alignment between the findings of rigorous, nationally representative sibling violence research and prevalence tracking conducted through child welfare.

The NCANDS is but one among numerous sources of information highlighting the lack of attention to abusive sibling violence in child welfare. Many states exclude sibling maltreatment from definitions of child abuse, or refer to it only indirectly, influencing both reporting practices and perceptions of what constitutes abuse (Caffaro, 2011). In a state-wide study of child protection service caseworkers conducted in Indiana in 2004, for example, almost one quarter of the child protection service caseworkers with an undergraduate degree in social work did not identify physical, sexual, verbal, or emotional violence when asked how they define sibling abuse (Kominkiewicz, 2008). ${ }^{5}$ Without clearly articulated definitions of what constitutes abusive sibling violence, direct service practitioners are ill-equipped to identify the problem among children they serve. A focus on the parent as the primary point of intervention may further influence caseworkers to discount the influence of sibling relationships.

Current child welfare policy recommends that siblings be placed together whenever possible to support foster youth to maintain sibling ties (McBeath et al., 2014). There is some evidence that co-placement mediates the relationship between adultperpetrated trauma and internalizing and externalizing symptoms among children in foster care (Hegar \& Rosenthal, 2011; Wojciak, McWey, \& Helfrich, 2013). At minimum, co-placement is generally assumed to do no harm (Hegar, 2005). While a

\footnotetext{
${ }^{5}$ This study should be interpreted with caution, as the results were based on a small sample size. It also appears that abuse was not defined in the survey that was administered to case workers.
} 
growing body of research has quantitatively assessed the relationship between sibling coplacement and placement stability, emotional adjustment, and foster children’s perceptions of their placement situations (Hegar \& Rosenthal, 2011), abusive sibling violence is not discussed (Pinel-Jacquemin, Cheron, Favart, Dayan, \& Scelles, 2013). Oversimplified co-placement policy in the absence of information about harmful sibling relationships may marginalize cases in which co-placement is not a good idea (Cohn, 2008). In a recent review of the literature on violence among siblings in joint placement, the authors note a need to refine methodologies and tools used to analyze the relationships between siblings across the continuum of care (Pinel-Jacquemin et al., 2013). Linares et al. (2007) argue that separating a foster child from their sibling(s) may be beneficial under certain conditions (i.e., behavioral or conduct problems).

The need to increase attention to abusive sibling violence in the context of child welfare is amplified by studies demonstrating high rates of co-occurrence with other forms of family violence. Children who witness domestic violence between their parents are more likely to engage in violent behavior with their siblings and peers (Button and Gealt, 2010; Spaccarelli et al., 1994; Wiehe, 1997). Noland, Liller, McDermott, Coulter, \& Seraphine (2004) found mother-to-father violence, father-to-mother violence, motherto-child violence, and father-to-child violence to be significant predictors of sibling violence perpetration. With regard to the effect of child abuse perpetrated by adult caregivers, Straus et al. (2006) documented a positive relationship between adultperpetrated violence toward a child and that child's likelihood of severely attacking a sibling. Children subjected to the most severe abuse from a parent were often intensely 
violent with a brother or sister (National Family Violence Resurvey). Sibling abuse is also more prevalent in families in which both spousal and child abuse are present (Wallace, 1999; Wiehe, 1997). Given these findings, it is likely that sibling violence rates are higher among youth served by the child welfare system than among general samples (Hamby \& Grych, 2013). In support of this notion, a recent study of foster youth found that acts of extreme sibling violence were commonplace (Linares, 2008).

\section{Abusive Sibling Violence Trauma}

The lack of attention to abusive sibling violence in child welfare is concerning, given that low frequency peer violence (i.e., occurring less than four times per year) has been significantly associated with trauma symptoms in young children (Finkelhor et al., 2006). The National Scientific Council on the Developing Child has defined "toxic" stress as “strong, frequent, or prolonged activation of the body’s stress management system. Stressful events that are chronic, uncontrollable, and/or experienced without children having access to support from caring adults tend to provoke these types of toxic stress responses” (2005/2014). As noted previously, Caffaro’s (2011) definition of abusive sibling violence describes a repeated, “escalating pattern of sibling aggression and retaliation that parents seem unwilling or unable to stop” (p. 91). This suggests that sibling violence may cause toxic stress, which has been linked to physical and mental illness later in life (Shonkoff et al., 2009). In a study cited by Caffaro (2011), "children who were repeatedly attacked by a sibling were twice as likely as others their age to demonstrate severe symptoms of trauma, anxiety, and depression, including sleeplessness, suicidal ideation, and fear of the dark” (Finkelhor et al., 2006). Deleterious 
outcomes also include mental health challenges, conduct disorders, neurotic traits, suicidal ideation and attempts, and decreased self-esteem (Button and Gealt, 2010; Caffaro, 2011; Feinberg et al., 2012; Finkelhor et al., 2006; Graham-Bermann \& Cutler, 1992, as cited in Caffaro, 2011). As evidenced by these studies, the harmful effects of abusive sibling violence manifest across the life course.

\section{A Call to Action}

Acknowledging that the phenomenon is often overlooked by social work practitioners, a recent article in Social Work, a National Association of Social Workers publication, advocated for the "necessary role for social work" in addressing physical and emotional sibling violence, arguing that "violence against a child, regardless of the individual perpetrator, is still violence against a child” (Perkins \& O’Connor, 2015, p. 91). When siblings are engaged in the child welfare system, and are removed from their original family, the state takes on the role of parent for those children and must conduct adequate assessment to determine whether they are demonstrating healthy conflict or abusive violence. Similarly, the state is responsible to intervene when abusive sibling violence is taking place, and to ensure that siblings are not co-placed when risk is eminent.

These findings point to a significant gap in the child welfare system, for the published literature contains little or nothing about sibling abuse. This is a new idea for child welfare. Apparently, little is currently being done, in either policy or practice, to address abusive sibling violence. A recent publication advocated for inclusion of sibling violence discussion in child abuse and neglect parent education curricula (Shadik at al., 
2013). This call for attention to abusive sibling violence in family-focused interventions is aligned with Perkins and O’Connor's recommendation that "social workers should evaluate and develop interventions aimed at preventing or ameliorating physical and emotional violence between siblings” (2016, p. 92). Yet without holistic understanding of the causal mechanisms underlying sibling violence, interventions for child welfareinvolved siblings are likely to exclude potentially efficacious components or strategies. The sections to follow present a synthesis of the literature on sibling violence theory and intervention.

\section{Family Conditions Associated with Sibling Maltreatment}

Two seminal, qualitative studies carried out in the late 1990s identified numerous individual characteristics and family conditions associated with sibling abuse including: parental physical or emotional unavailability, lack of supervision, differential treatment of children in the same family such as scapegoating, inappropriate caretaking expectations placed on older sibling(s), parental acceptance of sibling rivalry as a normal part of family life, lack of parent intervention during acts of inter-sibling violence, parental modeling of physically or emotionally abusive behavior, drug or alcohol abuse in the home, chronic mental or physical illness of parent(s), work or financial strain, and parental denial of the problem (Caffaro \& Con-Caffaro, 1998; Wiehe, 1997).

In addition to parent characteristics or behaviors, those embodied by perpetrators and victims were also explored. According to Caffaro and Con-Caffaro (1998), offenders are prone to thinking errors that minimize or distort their behavior, have suffered victimization themselves, and/or demonstrate deficiencies of impulse control, 
cognitive/developmental deficits, or an inability to empathize with others. Research psychologists conducting lab-based investigations similarly identified stable personality characteristics and cognitive processing deficits among aggressive children such as impulsivity, callous-unemotional traits, narcissism, and a tendency to inaccurately interpret social cues (Crick \& Dodge, 1994; Frick \& White, 2008; Kerig \& Stellwagen, 2009; Loeber \& Stouthhamer-Loeber, 1998). Large developmental, physical, or intellectual differences between siblings were similarly associated with sibling abuse (Caffaro \& Con-Caffaro, 1998). While emphatic that victim characteristics should not be used to place blame, Wiehe (1997) indicated that genetically determined physical and behavioral qualities may make a child more prone to abuse.

\section{Sibling Violence Theory}

Various sources of nationally-representative data indicate that 30 percent or more of children experience severe violence inflicted by a sibling (Caffaro, 2014; Finkelhor, Tuner, \& Ormrod, 2006; Straus, Gelles, \& Steinmetz, 2006; Tucker, Finkelhor, Shattuck, \& Turner, 2013). While these studies reveal the extent of the problem, the research community has yet to agree on the causal mechanisms underlying abusive sibling violence. Linear and non-linear (i.e., systems-oriented) theories are discussed in the literature.

Social learning theory. Numerous studies have documented the co-occurrence of various forms of family violence, drawing linkages between a child's exposure to violence and their propensity to inflict violent acts upon others. Children who witness interpersonal violence between their parents and/or experience adult-perpetrated abuse 
are more likely to engage in violent behavior with their siblings and peers (Button \& Gealt, 2010; Noland et al., 2004; Spaccarelli et al, 1994; Straus et al., 2006; Wallace, 1999; Wiehe, 1997). Social learning theory, based on the process of modeling or imitation in response to observation, has been offered as an explanatory theory for the multigenerational transmission of violence in families (i.e., aggression as a learned behavior). In a seminal study on the imitation process, Bandura et al. (1963) demonstrated that children who observed adults behaving aggressively toward a plastic Bobo doll later imitated this behavior in their own play, whereas a comparison group of children who did not observe aggressive behavior modeled by adults did not engage in aggressive play toward the doll. Parental demonstrations of aggression may surreptitiously communicate to children that violence is a morally-just means to resolve conflict and achieve desired ends in relationship with family members (Caffaro \& ConCaffaro, 1998; Straus et al., 2006).

Social learning theory also draws upon reinforcement principles in which a behavior results in receipt of desired rewards. Between siblings, reinforcement could occur by gaining control of a desired object, receiving parental attention, or through the pleasurable experience of power resulting from a sibling's fearful response (Hoffman \& Edwards, 2004). If behaviors are repeated without redirection or punishment, and continue to produce desirable effects, violence becomes a patterned response (Walker, 1986). In accordance with social learning theory, numerous researchers have proposed parental modeling as a salient explanation for sibling abuse (Hoffman \& Edwards, 2004; Kiselica \& Morrill-Richards, 2007; Straus et al., 2006). 
Radical feminist theory. According to radical feminist theory, male domination in all sectors of society reflects broadly accepted oppressive attitudes toward women which have resulted in various forms of gender inequality including male-female violence (Button \& Gealt, 2010; Hoffman \& Edwards, 2004; Hoffman et al., 2005; Weihe, 1997). Research supports the notion that the patriarchal organization of society contributes to abusive sibling violence. Studies have demonstrated that brothers have the highest rates of sibling violence, boys tend to commit more serious acts than girls, and male siblings are more likely to abuse female siblings (Hoffman et al., 2005; Wiehe, 1997). In Steinmetz and Straus’ seminal study of violence in the American family, those with only male children had consistently more sibling violence than families composed of only girls, a statistical relationship that increased markedly as children grew older (2006).

More recently, feminist theories have taken on greater breadth, theorized to include all power differentials between oppressors and oppressed, such as those based on race, ethnicity, socio-economic status, and age (Wiehe, 1998). This expansion of feminist theory is particularly useful when examining potential antecedents for violence within families in that it is more inclusive of the myriad exchanges that can take place among members. When applied to the problem of sibling abuse, feminist theory can account for oppressive dynamics occurring as the result of any source of power differential between children. In such exchanges the perpetrator is positioned as holding greater power and/or control such as via physical strength, intellectual/emotional maturity, or level of responsibility (Button \& Gealt, 2010; Hoffman \& Edwards, 2004). Wiehe (1997) described sibling violence as generally entailing an older/bigger/more powerful sibling 
abusing a younger/smaller/less powerful one in order to compensate for a perceived lack or loss of power. For example, an older sibling required to babysit his younger siblings might use excessive force to enforce bedtime rules (Wiehe, 1997).

Intersectionalities can create tenuous dynamics where the location of power is not clear cut. In cases where older female siblings advocate for themselves on the basis of age hierarchy, younger brothers may successfully challenge their authority with greater physical strength (Hoffman \& Edwards, 2004). Regardless of the characteristics of the individuals involved, the party holding more power within the conflicting dyad gains a sense of control through the act of overpowering another. Research supports blending these notions of feminist theory as an explanation for abusive sibling violence. Quantitative analysis has demonstrated that sibling pairs comprised of an older (and presumably larger/stronger) brother and younger (i.e., smaller/weaker) sister were at greatest risk for serious conflict (Graham-Berman et al., 1994).

Conflict theory. With roots in Marxism, conflict theory assumes that humans are innately self-interested and that societies are prone to scarcity of resources. In tandem, these human and societal conditions are posited to create dynamics in which people use violence to resolve conflicts that stem from competing interests (Smith \& Hamon, 2012). Jetse Sprey is the theorist credited with applying conflict theory to families, focusing on the conditions under which stability and instability occur (Smith \& Hamon, 2012). Sibling jealousy, competition for parental attention, the expectation that siblings share games, toys, or other valued items, and disagreements over assigned chores have all been discussed through the lens of conflict theory (Hoffman et al., 2005). Siblings subjected to 
differential treatment are likely to view each other as competitors for tangible resources and parental attention (Hoffman et al., 2005). Caffaro and Con-Caffaro’s (1998) determination that parental physical or emotional unavailability and differential treatment of children (e.g., scapegoating) were family conditions associated with abusive sibling violence is supported by conflict theory.

Hoffman and Edwards (2004) proposed a theoretical model of sibling violence and abuse that integrated social learning theory, feminist theory, and conflict theory, in addition to risk factors addressed in the extant literature (Hoffman and Edwards, 2004). Based on numerous linear relationships, the model organizes unidirectional lines of causation between parent and child characteristics, attitudes, and behaviors hypothesized to produce physical violence and psychological abuse between siblings. Figure 1 depicts the relationships between the components of the model.

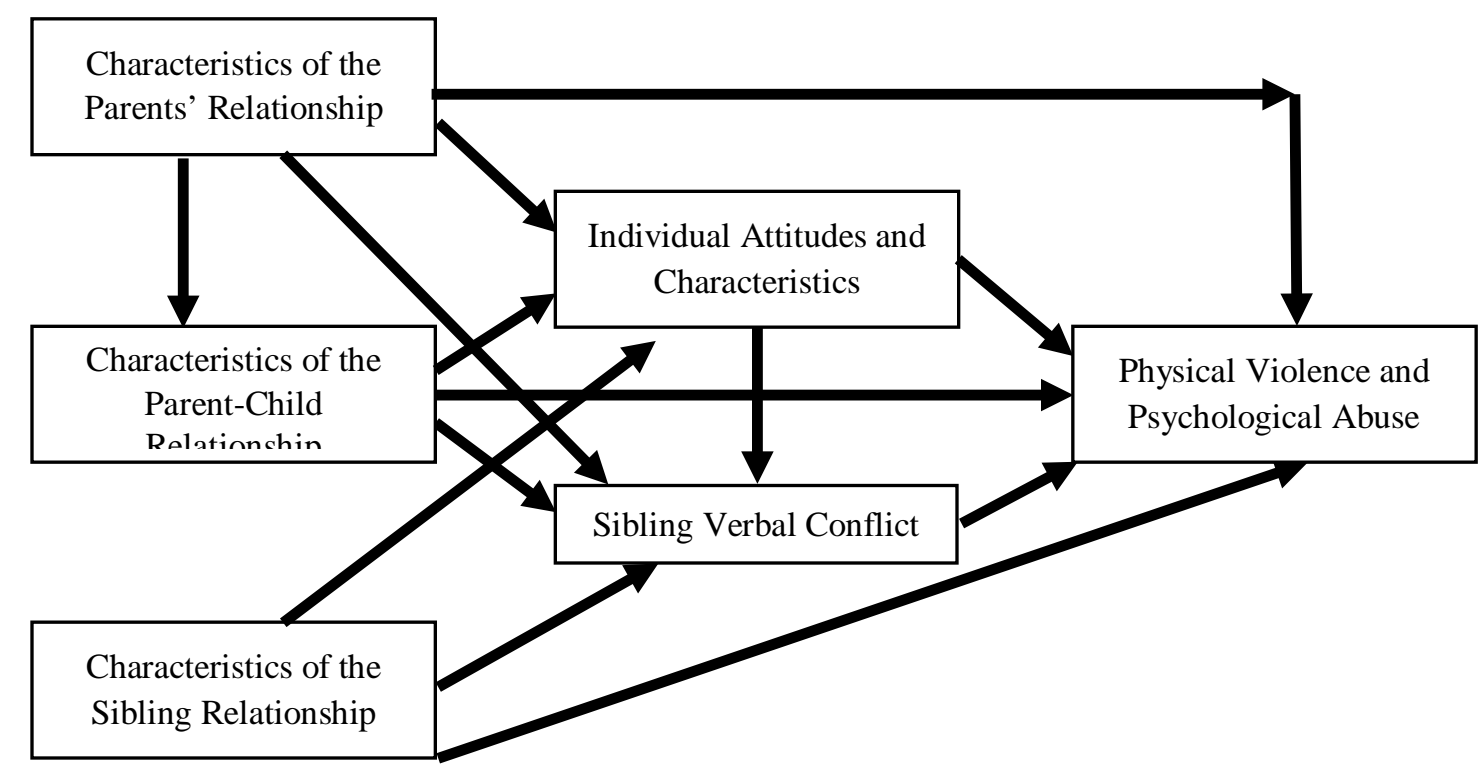

Figure 1. Integrated theoretical model of sibling physical and psychological abuse (Hoffman and Edwards, 2004, p. 191). 
The researchers tested the model with 651 university students via survey methods with measures of sibling violence were drawn from the Conflict Tactics Scale and additional variables operationalized by the researchers (Hoffman et al., 2005; Straus, 1979). At each stage of regression analysis gender was a significant factor. Males with brothers committed more types of sibling violence and more injurious behaviors (e.g., choking, using a weapon) than any other type of sibling pair. Favoring assigning chores to siblings according to traditional gender roles and approval of using physical force in sibling conflict were positively associated with sibling violence. The authors argued that the results were supportive of a feminist theoretical explanation for sibling violence. Social learning theory also garnered consistent empirical support in that arguments and interpersonal violence between caregivers and adult-perpetrated violence toward children were independently associated with sibling violence. Finally, parental favoritism was associated with heightened sibling violence, evidence that conflict theory was also supported by the model (Hoffman and Edwards, 2005).

An independent study implemented with a statewide sample of public school students tested the applicability of feminist and social learning theories to explain sibling abuse (Button and Gealt, 2010). Among more than $8,0008^{\text {th }}$ and $11^{\text {th }}$ grade students surveyed in 2007, 42 percent reported some form of sibling violence. Females were significantly more likely to report being victimized than males and youth who identified their parents as abusive to them or to have witnessed adult violence in the home were significantly more likely to report sibling violence. In addition to generating further evidence in support of feminist theory and social learning theory, victimization was 
significantly associated with reports of substance use and delinquency in middle and high school.

The work of Hoffman and Edwards (2004) and Button and Gealt (2010) makes useful progress, identifying variables in a linear model theorized to predict abusive sibling violence. While an essential preliminary step, their approach is based on the dominant methodological orientation of the social sciences, which is implicitly biased toward a reductionist perception of reality. Analysis seeks to break a construct or process down into its component parts. Understanding the relationships between them (which are assumed to be unidirectional and stable) is the focus of the inquiry. By analyzing abusive sibling violence in this way, the theories and models described in previous sections oversimplify a complex, synergistic, and dynamic socio-behavioral process. Subsequent sections discuss one systems-oriented theory and a systems-based model of sibling violence.

Coercive family process. Applying general systems theory to family behavior, family systems theory posits that individual members can be accurately understood only within the context of the whole family, including past generations. Rather than targeting individual members as the source of dysfunction, the locus of family problems is viewed as a function of struggle among members. Numerous forces are seen as moving in many directions simultaneously, with positive and negative feedback loops guiding behavior. Family members take on defined roles, repeatedly demonstrating a narrow set of behaviors across situations, resulting in a relative equilibrium of patterned rules of interaction (Smith \& Hamon, 2012). The family is also viewed as contained by a semi- 
permeable boundary with the environment (Crosbie-Burnett \& Klein, 2009). The family system is perceived as the nexus between structure and function (Zwick, 2015). The structure of the family system is the organization of members; function is the holistic behavior of the family, including how it relates to its context. The family system is hypothesized to engage in relatively stable patterns of behavior over time.

Coercion theory was developed by scientists at the Oregon Social Learning Center and has been the focus of numerous studies of childhood aggressive behavior. Based on principles of operant conditioning and negative reinforcement, coercion theory posits that learning occurs through interpersonal exchanges. Members of a dysfunctional dyad within the family mutually "train" each other in an ongoing process which reinforces difficult child behavior including aggression (Granic \& Patterson, 2006; Patterson, 1982). Research on coercion theory has largely focused on parents and their children, studying a process in which caregivers inadvertently reinforce difficult child behaviors through repeated, cyclical reactions of emotional withdrawal and giving in (Smith et al., 2014). Children with more frequent behavioral difficulties such as aggression (and who are therefore more challenging to parent) amplify coercive parenting practices which in-turn solidify aggression as a child develops (Granic \& Patterson, 2006).

Coercion theory can be applied to the whole family system to describe a coercive family process in which emotional, cognitive, and behavioral feedback loops manifest within and among multiple family members to produce multi-directional and synergistic coercive exchanges. Applying the theory in this way includes all dyadic subsystems; just 
as marital conflict is associated with compromised sibling relationship quality, the parental relationship, or relationships between caregivers and children, may become strained in the presence of ongoing sibling conflict (Milevsky, 2011). In a coercive family process, violence between dyads (or triads, etc.) becomes a stable, family-wide pattern.

Social ecological model of violence. Human behavior is typically discussed as generated through interactions among personal and contextual factors, such as by the “person in environment” orientation of social work. One of the more commonly applied systems-based models is the ecological framework originally developed by Bronfenbrenner (1979), which organizes society into a set of nested systems that interact in a synergistic fashion (Figure 2). ${ }^{6}$ When applied to the problem of violence, the values and actions of individuals, families, communities, and society are viewed as both reflective and generative of each other. Just as nations employ war tactics to secure global resources and gangs engage in acts of violence to control illegal drug sales within impoverished communities, family members and siblings use force to resolve disagreements. The "second wave” of interpersonal violence scholarship has begun to

\footnotetext{
${ }^{6}$ Figure 2 presents a limited set of concepts from Bronfenbrenner's bioecological theory of human development. The "mature" form of bioecological theory focuses on proximal processes at the center of the Process-Person-Context-Time model. According to the model, proximal processes of progressively reciprocal interaction between an individual and the persons, objects, and symbols in their immediate external environment are the "primary mechanisms" in development. The environment, or context, is comprised of the microsystem (e.g., home, school, or peer group in which the person spends a good deal of time engaging in activities and interactions), exosystem (i.e., contexts which have important indirect influences on development), macrosystem (i.e., the broad set of cultural values that encompass the group under study and influence the developing individual). In the mature model, time is also an essential element, which is also comprised of micro-, meso-, and macro- subcomponents. For a complete synthesis, see Tudge, Mokrova, Hatfield, and Karnik (2009).
} 
examine how mechanisms of violence perpetration co-occur across individuals and systems (Centers for Disease Control and Prevention, 2014; Hamby \& Grych, 2013). A recent study of preschoolers found that father-child physical aggression interacted with community violence to predict aggression between siblings (Miller, Grabell, Thomas, Bermann, \& Graham-Bermann, 2012).

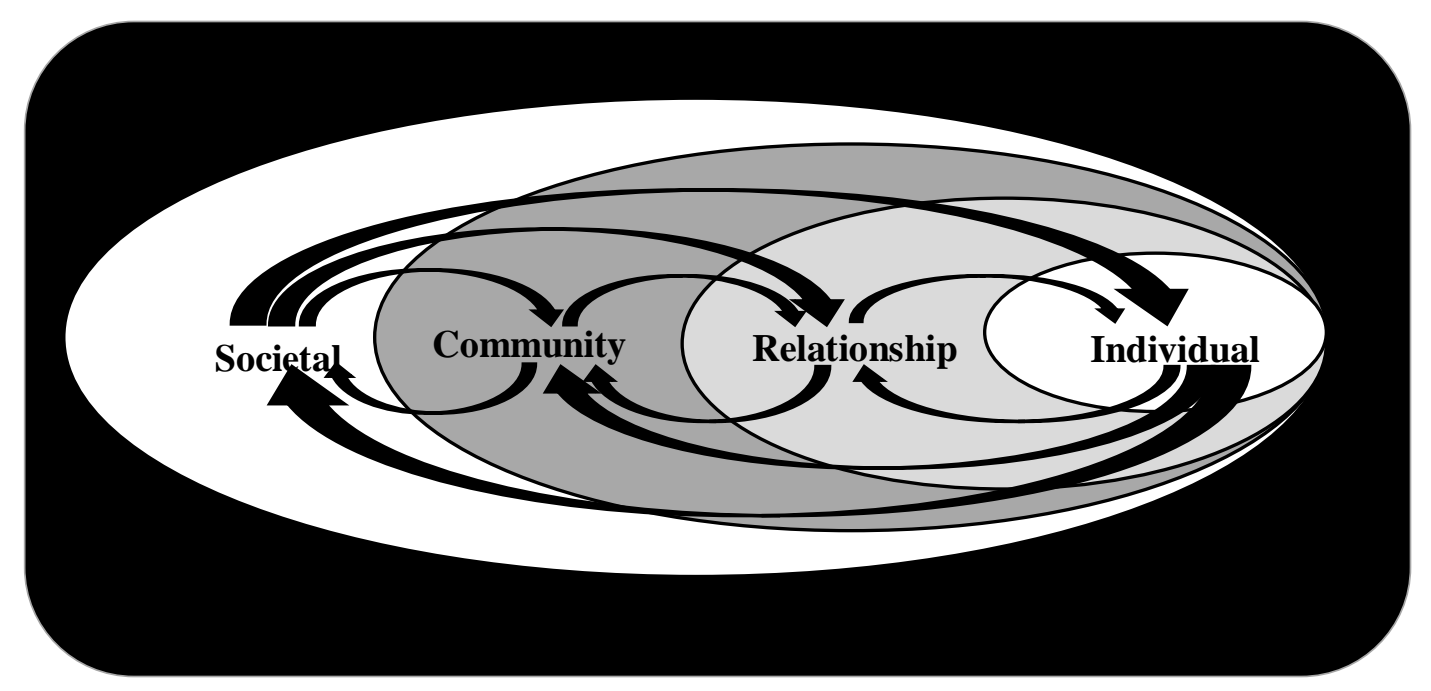

Figure 2. Ecological model for understanding violence (adapted from the World Health Organization, 2002, p. 12).

Subsequent sections will discuss interventions designed to address sibling violence at the micro-, meso-, and macro-levels of the social ecology.

\section{Sibling Violence Interventions}

Micro- and meso-level interventions. A variety of interventions have been developed to train both parents and children to more productively and peacefully navigate sibling disputes. As early as 1967, clinicians were testing micro-level approaches to reduce sibling aggression and increase cooperative play (Kramer, 2004). Early 
approaches were largely reactive rather than preventative, aimed at eliminating conflict by augmenting parent behaviors. Examples included training parents to utilize time-outs, overcorrection, verbal reprimands, logical consequences, token reinforcement systems, and other re-directive techniques. While intervention developers reported encouraging results in terms of reduced sibling aggression severity and frequency, the rigor of research assessing the effectiveness of these interventions was compromised by small sample sizes and single group designs (Kramer, 2004).

In response to evidence suggesting that sibling violence occurs as the result of systemic family problems, subsequent clinical interventions recommended a combination of individual, sibling, family, and group therapy sessions incorporating family rules for nonviolent behavior, guidance on incentive and consequence systems, role plays, identification of enjoyable sibling activities, perspective-taking, skill building, and/or facilitation of grieving over past trauma (Caffaro \& Conn-Caffaro, 2005; Kiselica \& Morrill-Richards, 2007). For example, the task-centered sibling aggression (TCSA) treatment model emphasizes helping parents and siblings to co-create rules for controlling conflict during problem solving sessions which engage siblings in direct negotiation processes (Reid \& Donovan, 1990; Caspi, 2008). In a single case design, Caspi (2008) describes three cases in which sibling aggression rates decreased and caregivers and children reported satisfaction with the intervention.

Based on the premise that constructive conflict interactions teach children to negotiate and take another's perspective, Canadian researchers identified mediation as a promising strategy that balances caregiver intervention with child autonomy (Siddiqui \& 
Ross, 2004; Smith \& Ross, 2007). Mediation-based interventions train parents to serve as facilitators who guide children through the conflict resolution process while concurrently allowing children to decide how the disagreement is resolved. Over the course of two experimental studies with general samples of siblings under the age of 11 and their female caregivers, mediation training resulted in increased discussion about emotions and the negotiation process by caregivers and children, increased reasoning dialogue among both caregivers and children, more accurate understanding of the other's perspective among siblings, increased rates of child-initiated resolution, and less authoritarian parenting practices (Siddiqui and Ross, 2004; Smith and Ross, 2007). The researchers did not measure types or rates of physical or emotional violence.

Based on the determination that healthy sibling relationships are defined by ambivalence (i.e., social interactions which rapidly shift between positive and negative behaviors), that moderate levels of conflict promote the acquisition of beneficial social and emotional competencies, and evidence suggesting that conflict-focused interventions often result in a shift toward disengaged sibling relationships, Kennedy and Kramer (2008) developed and tested a preventative intervention for siblings and their caregivers. More Fun with Sisters and Brothers (MFWSB) is a 5-week program for 4-8-year-old siblings that targets: initiating play with a sibling, methods for accepting and appropriately declining an invitation to play, perspective taking, identifying and discriminating among emotions, regulating emotions, problem solving, and conflict management. Caregivers observe trainer-led sessions for siblings; a subsequent home training session is designed to reinforce and transfer skill to the home environment. A 
randomized trial of MFWSB found a significant increase in demonstrations of warmth between siblings and a significant decrease in down regulation by caregivers in the treatment group. The researchers did not report data on violence rates.

A similar, though considerably more intensive preventative intervention was subsequently tested in a randomized trial of $1745^{\text {th }}$ grade children and their younger (i.e., $2^{\text {nd }}$ to $4^{\text {th }}$ grade) siblings (Feinberg et al., 2013). Designed to enhance siblings' interpersonal skills and increase parental involvement in the sibling relationship, Siblings are Special (SIBS) includes 12 90-minute afterschool sibling training sessions delivered by pairs of trained leaders and three 2.5-hour family nights where parents learn how to transfer the skills conveyed during the youth training sessions to the home environment. Significant, beneficial program effects for child adjustment and dimensions of sibling relationship quality were detected, as were gains in parent adjustment and parenting quality. Similar to the studies conducted by Siddiqui and Ross (2004), Smith and Ross (2007), and Kennedy and Kramer (2008), Feinberg et al. (2013) did not report on physical or emotional violence rates. While one could argue that a strength-based, positive focus on improving relationship quality is a viable approach to understanding sibling violence, their methodological choices also fortify the problematic notion that all sibling violence as normative.

In addition to interventions designed for the general population, two preventive interventions designed for siblings in foster care are discussed in the literature: Promoting Sibling Bonds (PSB), an 8-week program for maltreated sibling pairs ages 5-11 who are co-placed and, Supporting Siblings in Foster Care (SIBS-FC) for sibling dyads ages 7-15 
regardless of placement situation. PSB includes components for siblings and foster parents which are informed by MFWSB, Sibling Plus Parent Management, a social learning-focused intervention (Bank, Snyder, \& Prescott, 2002; Bank \& Kothari, 2013). The component for foster parents provides positive child management training for sibling aggression and mediation training for nonaggressive sibling conflict (Linares et al., 2015). SIBS-FC is a 12-session sibling intervention curriculum designed to support individual siblings' socially skilled behavior and reduce sibling dyad-based conflict (Kothari et al., 2014). The intervention engages siblings in 8 skill-building sessions, weekly home activities (with foster parent collaboration), and four community activities with project coaches. Other than supporting the home activities, the intervention does not train foster parents. Both PSB and SIBS-FC were tested with randomized trials that generated statistically significant results. Linares et al. (2015) measured sibling violence with the Sibling Aggression Scale, a measure modeled after the Conflict Tactics Scale-2. Foster parents in the intervention group reported lower sibling physical aggression from the older toward the younger sibling than foster parents in the comparison group, although the study was based on a small sample size. Kothari et al. (2017) did not include a measure of sibling violence.

Whether reactive or preventative, multi-component interventions point to an encouraging culmination of several decades of micro- and meso-level theory and intervention research aimed at supporting healthy sibling interactions. By educating both caregivers and youth in non-violent conflict resolution techniques these models have the potential to address coercion and aggression throughout the family system. 
Foster Parent Training (FPT) programs are another avenue for skill-building to support safe sibling relationships in foster care. This would be an addition to most FPTs in that they are largely focused on individual youth and/or their parents/families (Kothari et al., 2017). While a subset of FPTs have demonstrated efficacy to improve foster parent skill, many are not empirically supported, and they range widely in terms of their breadth and depth (Solomon, Niec, \& Schoonover, 2017). Improvement in FPTs, including training to manage sibling violence, would likely be well-received. Foster parents have expressed a need for skill building to address children's behavioral problems (Spielfogel, Leathers, Christian, \& McMeel, 2011). At minimum, foster parents could be trained to identify sibling abuse among foster children and provided with resources to access additional support. Subsequent sections will turn to macro-level analysis of antecedents and interventions to mitigate sibling violence.

Macro-level influences and interventions. Constraining consideration to the micro- and meso-levels of the social ecology excludes the broader social context in which children and families are nested. Feminist theory, initially conceived as a micro-level dyadic phenomenon in which the masculine overpowers the feminine (e.g., intimate partner violence), is now more broadly inclusive of all power differentials between oppressors and oppressed (Wiehe, 1998). Applied to the macro-level of the social ecology, feminist theory describes a process in which societal norms condoning the use of power and oppression to achieve desired ends are transferred to, replicated within, and maintained over time throughout all levels of the social ecology (Figure 3). 


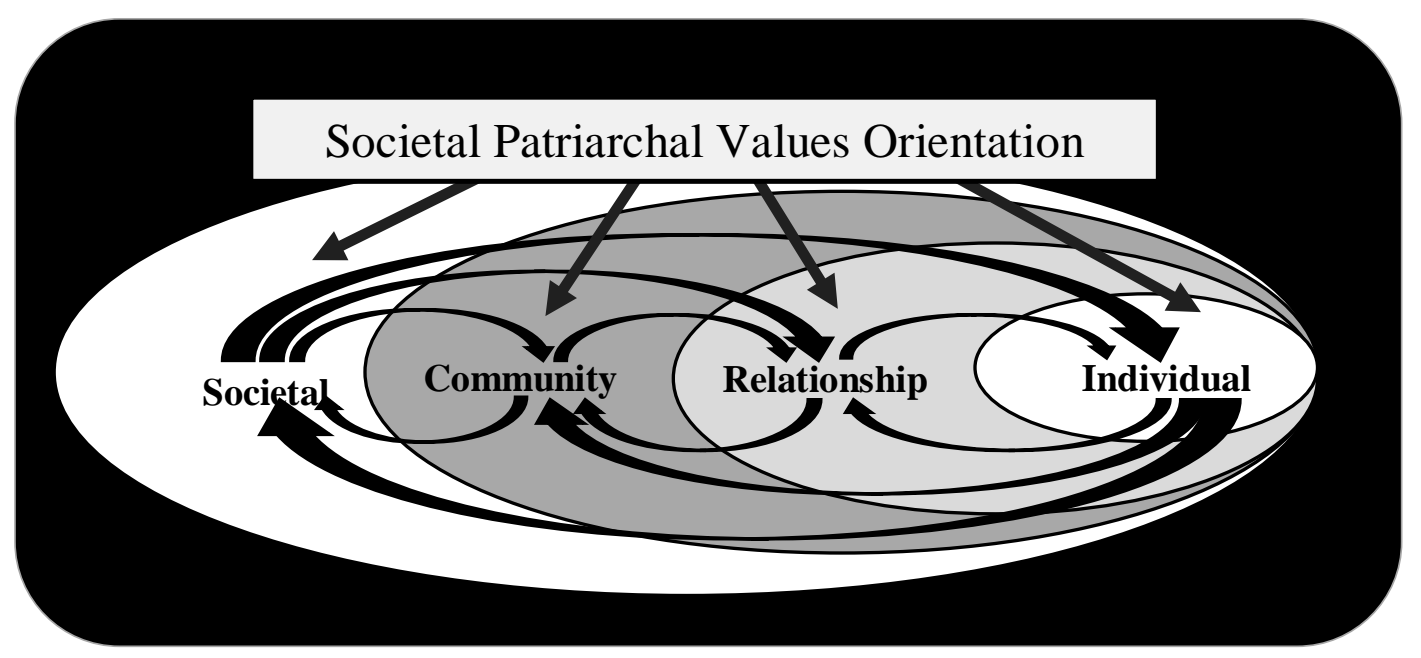

Figure 3. Ecological model for understanding violence (adapted from the World Health Organization, 2002, p. 12).

When examined from a macro-level perspective, interventions to address interpersonal violence, of which sibling abuse is a subset, are likely to be most effective if designed to change social and behavioral norms that support the use of force to resolve conflict at all levels of the social ecology. In 2009, the World Health Organization published a briefing which advocated for mass media campaigns as a promising approach for youth violence prevention. Mass media campaigns communicate information to broad populations via print, radio, and television to correct misperceptions about norms, attach a social stigma to unwanted behavior, or promote desirable behaviors through positive appeals (World Health Organization, 2009).

In a recent and exhaustive review of mass media campaigns to change health risk behaviors including tobacco use, sex-related behaviors, road safety, and child safety, the authors determined that campaigns can produce desired change across large populations (Wakefield, Loken, \& Hornik, 2010). The authors specify, however, that mass media 
campaigns are most effective when multiple marketing methods target non-habitual behaviors with concurrent access to key resources and policy-level support and enforcement. Additional recommendations to support mass media campaign effectiveness include ensuring sufficient exposure to messaging, drawing on social marketing theory to guide message development, and creating a supportive environment that allows the target audience to make the desired change (Randolph \& Viswanath, 2004). Creating an environment supportive of non-violence messaging would be particularly difficult given an overall culture in the United States which approves the use of power and sees power as a masculine prerogative. There are signs that this is changing, including the current \#MeToo social media hashtag, removal of prominent men, particularly in Hollywood, for widespread sexual misconduct allegations, and introduction of Senate and House bills to combat sexual harassment on Capitol Hill.

Holistic, coordinated violence prevention intervention. The recommendations accompanying evidence of the utility of mass media campaigns highlight the importance of incorporating social-ecological (i.e., systems-oriented) principles to their design and implementation. In alignment with this perspective, current violence prevention literature advocates for interventions that systematically address factors contributing to involvement in multiple forms of violence, account for developmental trajectories, and address history of violence exposure (Hamby \& Grych, 2013). As an example of a possible intervention model, Hamby \& Grych (2013) introduce a strategically coordinated and holistic school-based prevention initiative which begins in elementary school and is then "revisited, expanded, and tailored to different topics" as children 
develop throughout middle and high school (p. 83). Reproduced in Figure 4, the design combines numerous methods supported throughout the sibling abuse and interpersonal violence literature and intervenes at the micro-, meso-, and macro-levels of the social ecology. The center circle in the figure shows ongoing classroom curricula presented across grade levels, media campaigns, and therapeutic adjunct and community monitoring services. Peripheral circles in the diagram represent content-specific intervention subcomponents implemented at developmentally appropriate stages to address specific forms of interpersonal violence.

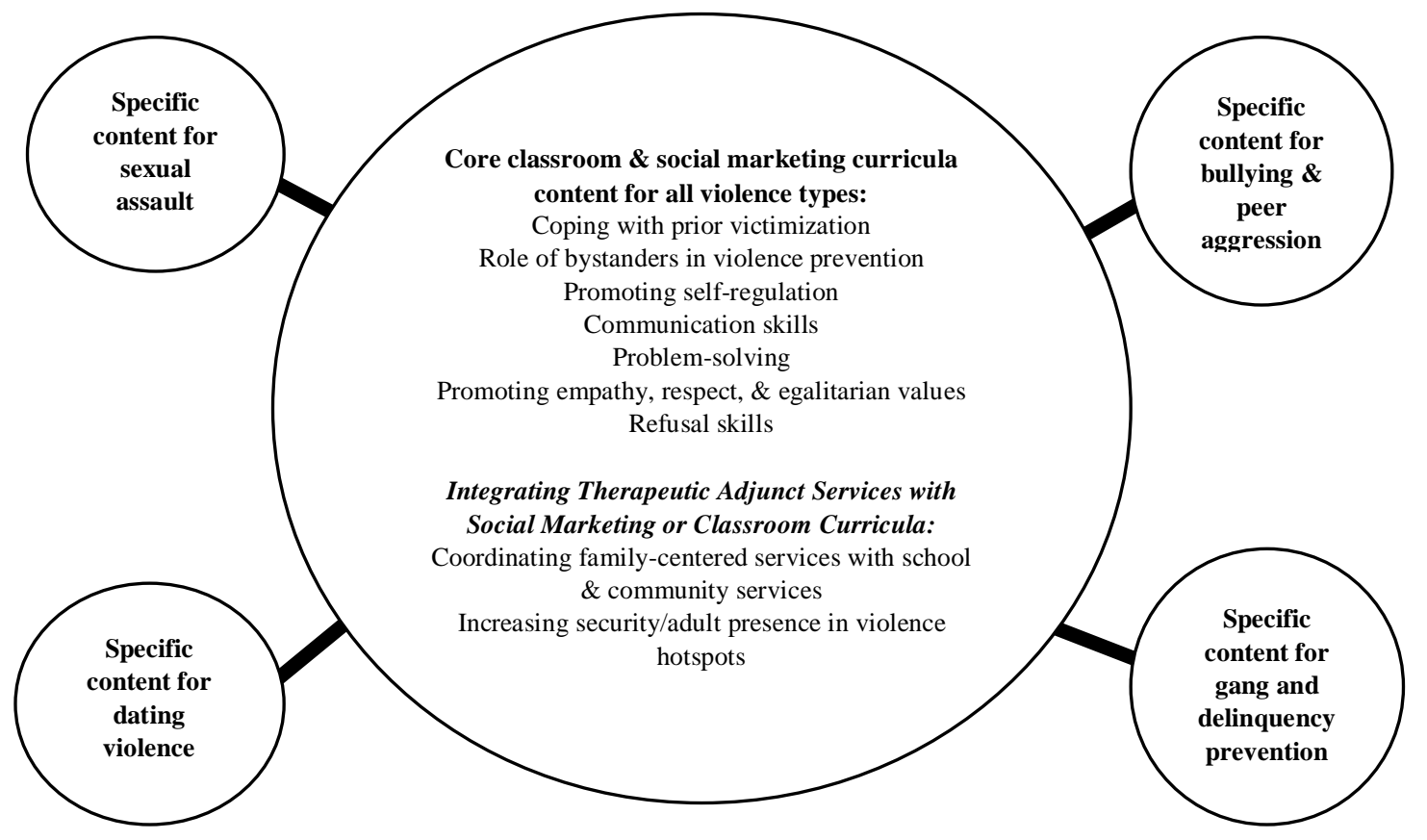

Figure 4. Coordinated violence prevention model: Hypothetical common and specific elements (Hamby and Grych, 2013, p. 85).

Although the model remains to be piloted, a similar though less-intensive school-based anti-violence intervention developed at Colorado State University demonstrated strong evidence of impact over a 2-year implementation period (Swaim \& Kelly, 2008). Resolve 
it, Solve it combines a mass media campaign developed by high school youth selected and trained as non-violence trainers/role models combined with middle school assemblies, classroom presentations, annual community events, and ongoing distribution of promotional items. When tested in a randomized trial in rural communities in five states, treatment site participants demonstrated statistically significant recall of media campaign messaging, a faster rate of decline in physical violence, a significant decline in verbal victimization, stable ratings of school safety (which declined for controls), and a near-zero change in intentions for violence (while controls increased). Resolve it, Solve it could generate stronger outcomes if expanded to reflect the recommendations made by Hamby and Grych (2013).

The anti-violence literature reviewed here provides a wealth of instructive guidance to ameliorate sibling abuse through both preventative and corrective intervention. None of the studies mentioned inclusion of youth voice in their development, however, a significant gap in efforts to address the phenomenon. Moreover, just two studies have endeavored to intervene into relationship quality between siblings in foster care, one of which focused specifically on sibling violence. Chapter 3 presents the philosophy and methodology for the study, designed to build sibling violence theory in the context of child welfare by incorporating the perspectives of foster care alumni. 


\section{Chapter 3: Methodology}

The study was grounded in critical realism (CR), a philosophy of science originating from the work of Bhaskar $(1979,1998)$ and then further developed by Sayer (1992), Archer (1995), and others (Fletcher, 2017). The sections to follow present two predecessors to CR, positivism and constructivism, with focus on their limitations in causal analysis. After positioning their limitations as rooted in the "epistemic fallacy" (Bhaskar, 1998, p. 27), CR is discussed as an alternative philosophy of science which effectively delimits ontological and epistemological inquiry and opens the study of causal mechanisms to qualitative methodology. The chapter concludes with the methodology for the current study which employed in-depth interview methods and deductive analytic techniques to investigate the causal mechanisms of abusive sibling violence and develop recommendations for ameliorative action in the context of child welfare and beyond.

As a philosophy of science, positivism relies on a realist/objectivist ontology which assumes the existence of an objective reality that is separate from our perceptions, theories, and constructions of it (i.e., Nagel’s argument that there is, indeed, “a view from nowhere in particular” (1989)). Based on Humean causal law, positivism employs reductionist methods to parse a theoretically knowable reality into discrete, measurable variables for statistical analysis (Fletcher, 2017; Lennox \& Jurdi-Hague, 2017). The researcher is positioned as objective and positivist study is presumed immune to researcher bias by employing "rigorous” methodologies impervious to external influence. Studies of this type are designed to describe associations or predict temporally bound, linear relationships (i.e., if event $x$, then event $y$ ). Positivist research may predict that an 
independent variable (or variables) predict dependent variables in a theoretical model, but the causal mechanisms underlying the relationship(s) (i.e., how one variable influences the other) remain elusive (Fletcher, 2017; Lennox \& Jurdi-Hague, 2017).

Constructivism followed positivism, ${ }^{7}$ a relativist/interpretivist ontology capable of augmenting the limitations of positivism by gathering descriptions via verbal and nonverbal symbol systems, primarily through qualitative research methodology. Based on individuals' lived experiences of social reality, constructivism proposes that human experience is time- and context-dependent and can only be understood subjectively (Morris, 2006); there are literally “different world versions” which are elicited during dialectic exchanges (Schwandt, 1994, p. 126). Emphasizing social actors, constructivism conflates individual experience with theoretical explanation, and as a result, largely avoids the realm of causation. According to a constructivist philosophy of science, child maltreatment "is more like pornography than whooping cough. It is a socially constructed phenomenon which reflects values and opinions of a particular culture at a particular time” (The British Department of Health, 1995 as cited by Houston, 2001, p. 848). Considering this example, the limitations of constructivism for the social sciences are obvious. The idea that many equally legitimate causes produce a given social phenomenon in an infinite number of unique contexts makes determination of corrective action extremely difficult.

\footnotetext{
7 This is an oversimplification. Numerous philosophies were generated in the time between positivism and constructivism, and afterward. For more in-depth discussion of the philosophies of science, see Kuhn's (1962) The Structure of Scientific Revolutions, Morris' (2006) Social Work Research Methods, and Brown and Strega's (2005) Research as Resistance: Critical, Indigenous and Anti-oppressive Approaches.
} 
More recently, critical realism (CR) has gained traction in the social sciences as a potentially generative alternative to positivism and constructivism. A key tenet differentiating CR from its predecessors is the clear delineation of ontology and epistemology. To the critical realist, reducing ontology to epistemology is a philosophical error that unnecessarily constrains the research endeavor. CR separates the two, employing a realist ontology and a relativist epistemology. Ontologically, CR holds that there is a "real world" that our perceptions, theories, and constructions refer to, yet epistemologically, our representations (which are also part of reality) are deemed fallible given the constraints of human sensory capacity to fully grasp the complexity of social systems. The notion of variant perspectives on reality (i.e., a constructivist epistemology) is compatible with this realist ontology. Leaning heavily on explanatory theory, the critical realist is free to employ constructivist, qualitative methodologies to investigate ontological questions to more fully develop causal explanations for what occurs in the "real” world. CR is emancipatory, with the goal of clarifying the causal mechanisms that produce human suffering and identifying logical, ameliorative actions (Fletcher, 2017; Maxwell, 2012).

\section{Realist Ontology}

According to CR, reality is stratified into three levels or domains, a “deep,” differentiated ontology capable of overcoming the epistemic fallacy. The empirical domain is comprised of observable events which are experienced with the five senses. These events may be causal and are understood through the filter of human interpretation. The actual domain is that in which all events occur, regardless of human sensory capacity 
to detect them. These events occur regardless of whether they are observed (i.e., Nagel's “view from nowhere”). Finally, the real domain is comprised of the causal structures or mechanisms underlying actual and empirically sensed events. These mechanisms are the causal processes underlying a given phenomenon occurring in the actual and perceived in the empirical domains. The three domains are not separate structures, but rather, comprise a singular reality. They interact synergistically such that human interactions at the empirical level can influence the causal mechanisms at the real level or vice versa (Bhaskar, 1979; Danermark, Ekström, Jakobsen, \& Karlsson, 2002). Fletcher (2017) represents the three levels metaphorically as an iceberg. The real and actual levels are below the waterline, unseen, whereas the empirical level is above the waterline, perceptible by the observer with one or more of the five senses (Figure 5).

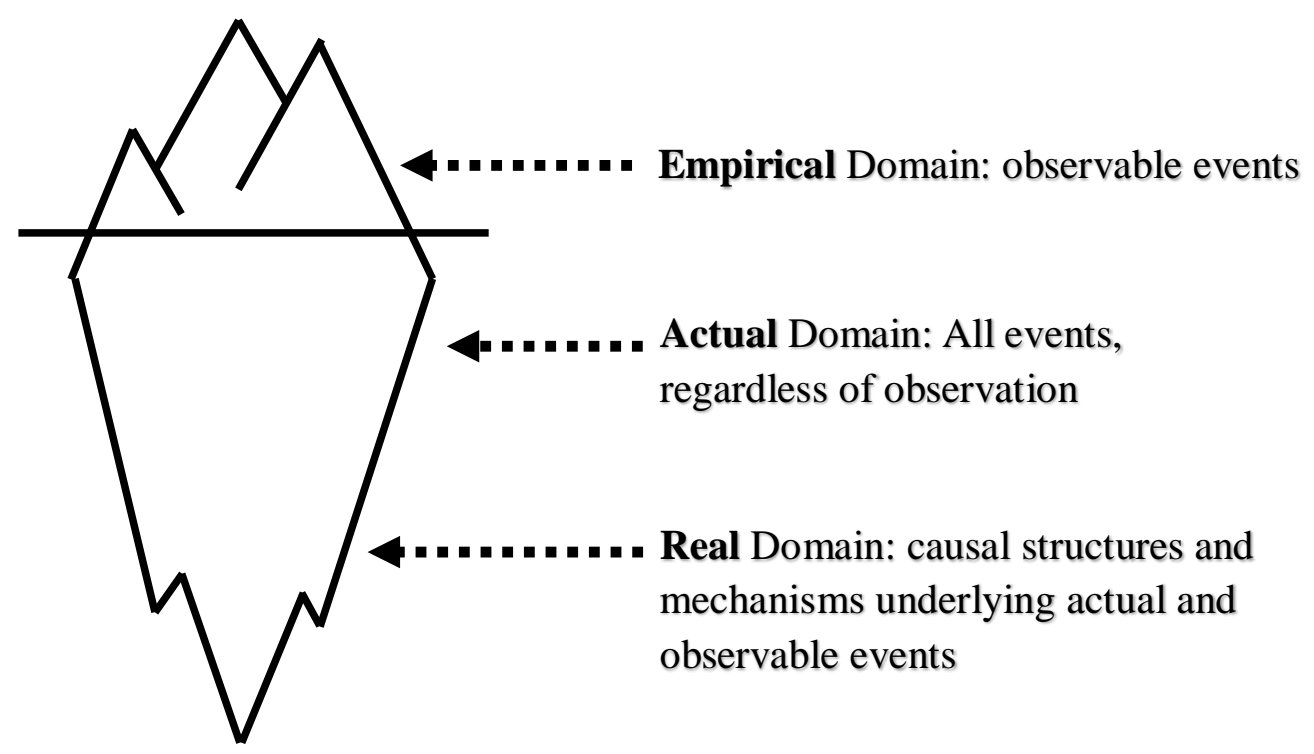

Figure 5. CR domains of reality presented as an iceberg.

In addition to the three domains of reality, a second key tenant of CR is the interplay between structure and agency, a concept widely discussed in the systems 
literature (Archer, 2010; Zwick, 2015). Bates (2006) represents this relationship as a double-helix in which one arm symbolizes human agency and the other social structure. The rods connecting the two arms of the helix are variant aspects of opportunity and constraint, which change over time (i.e., the turning of the helix). Human agency is seen as emergent and semi-autonomous from the underlying social structures that produce empirically determinable patterns, yet human agency may also influence the conditions that produce those patterns. Humans located within a given social system have choice in their behaviors, and yet those behaviors are constrained by system structures which limit their latitude of choice to some degree (Wright, 2011). Lennox and Jurdi-Hage (2017) effectively concretize these metaphoric and theoretic representations in a study of street harassment. Individual agents (i.e., women) are positioned as residing in a patriarchal social system structure that condones physical and verbal assault in public spaces. Returning to Bhaskar's three-domain representation of reality, patriarchy is theorized as the causal mechanism at the real level that produces gender socialization in the actual level and which is perceivable at the empirical level (e.g., cat calls, physical transgressions, etc.). Women's agency to respond to harassment is constrained by fear of retaliation but may also be amplified through new opportunities such as access to social media platforms used for anti-harassment activism. Lennox and Jurdi-Hage's example effectively conveys how constraints and opportunities vary across time and contexts. Once identified, they can inform emancipatory actions to dismantle oppressive system structures. 


\section{Constructivist Epistemology}

While constructivist ontology argues that reality is entirely socially constructed through and within human knowledge or discourse (Fletcher, 2017), CR employs constructivism as an epistemology to explore causal mechanisms in the real domain. The critical realist assumes that empirical observations are influenced by the observer's perceptual filters (e.g., positionality, theoretical stance) while concurrently engaging a realist ontology that assumes phenomena exist in the actual and real domains, beyond our ability to experience them directly. The critical realist is unwilling to allow empirical limitations to undermine the utility of the research endeavor to understand causal mechanisms and identify emancipatory actions. Constructivist representations are assumed to point to real things in a highly complex social world. Variation among human representations of a given phenomenon are not problematic, but rather, are helpful to identify patterns of action or behavior for a given object or structure (Danermark et al., 2002; Fletcher, 2017; Wright, 2011). Critical realists actively engage with theory in a dynamic analysis process which traverses the concrete and the metaphysical to develop increasingly representative theories of reality. Their understanding of current scientific knowledge on the topic is treated as both valuable and useful to explore multiple extant theories, all of which are assumed to be both feasible and fallible (Bhaskar, 1979; Fletcher, 2017). Empirical constructions can also challenge existing scientific knowledge and theory (Redman-MacLaren \& Mills, 2015 as cited in Fletcher, 2017). In the CR practice of rational judgement, the researcher may elaborate on or deviate from 
participants' interpretations to 'provide fuller or more adequate interpretations” (Parr, 2015, p. 10) of a given object or structure.

In summary, critical realists concern themselves with explaining what is occurring in the real domain, utilizing the interplay between empirical data and extant explanatory theory. By actively engaging with both the concrete (empiricism) and the abstract (theory), critical realists take tenets from both the positivist and constructivist philosophies of science without succumbing to their associated limitations (Lennox \& Jurdi-Hage, 2017). By describing not only what is taking place, but also how it manifests (i.e., employing theory to more and more accurately approximate reality), CR supports critique of the social conditions that produce empirical level patterns of human suffering including social, political, and economic causes (Fletcher, 2017; Houston, 2001; Wright, 2011). This aspect of CR fits well with the grounding ethos of Social Work given its potential to identify emancipatory solutions to social problems (Danermark et al., 2002; Houston, 2001). The sections to follow describe the methodology for the study, grounded in a CR philosophy of science.

\section{Methodology and Methods}

Critical Realism does not offer clear methodological guidance, but rather, tends to advocate for a mix of quantitative and qualitative methods (Danermark et al., 2002). Research questions should support empiricism that interrogates the utility of extant theory, which may be denied, supported, or elaborated upon within a particular context (Fletcher, 2017). The linear and non-linear theories examined in this project included: social learning theory, radical feminist theory, conflict theory, and coercive family 
process theory. A social ecological model was also incorporated into the analysis. ${ }^{8}$ The research questions guiding the study, replicated from Chapter 1, are presented below.

1) How do foster care alumni describe their experiences with physical and emotional sibling violence?

a) To what extent do their descriptions fit with Caffaro (2014) and Meyers’ (2015) definitions of abusive sibling violence?

b) To what extent are family conditions and theories of sibling violence discussed in the extant literature represented in their descriptions?

c) What additional/refined causal mechanisms do their descriptions suggest?

2) From the perspective of foster care alumni, how do adults who care for or work with young people involved in the child welfare system (e.g., foster parents, case workers, mental health providers, kinship caregivers, etc.) respond to sibling violence?

a) To what extent are adult responses perceived as helpful?

b) What do young people recommend to address sibling violence?

\section{Study Pilot}

In preparation for the study I engaged with a youth-driven advocacy and support program for youth in care with the goal of piloting the study and gaining assistance recruiting participants for the current project. ${ }^{9}$ The Executive Director was open to these

\footnotetext{
${ }^{8}$ The social ecological model locates an individual within a set of nested systems that interact in a synergistic fashion. The environment, or context, is comprised of the microsystem, exosystem, and macrosystem. In the mature model, time is also an essential element, which is also comprised of micro-, meso-, and macro- subcomponents (Tudge et al., 2009). Although not a theory, the model is helpful to interpret interactions within and across levels of the social ecology that are hypothesized to produce interpersonal violence. The model is also well aligned with the "person in environment" orientation of Social Work.

${ }^{9}$ I have concealed the name of the agency to maintain study participant confidentiality.
} 
ideas and after negotiating a contract with clearly articulated tasks, I worked with the Program Manager to plan a one-day site visit to carry out the pilot with young people participating in a summer internship program focused on leadership development. I

planned to use the pilot study to improve upon the design by testing the consenting process and data collection instruments and facilitating a group conversation to gather feedback about the research questions and data collection process.

The week prior to the scheduled pilot study date the Program Manager informed me that the interns had opted not to participate. While she alluded to events occurring within the program that were creating disruptive dynamics among the interns, she and the Executive Director also recommended that I enlist a group of study advisers from their national network of "young leaders" to improve the project (i.e., youth who had aged out of care and were achieving academic, professional, and social success in their lives). I embraced their recommendation and over the course of the subsequent year I advertised for the opportunity through the program's various social networks and other communication modalities, reviewed the resumes and interest statements of more than 20 candidates, conducted interviews with a subset of candidates whose background included physical and emotional violence with siblings, and ultimately enlisted four advisers to provide consultation on the study. In total the advisers participated in four conference calls, the content of which is summarized in Table 3.

As shown in the right-most column of the table, the advisers affirmed the utility of several aspects of the planned design (i.e., research questions, systems concepts, and the questions in the data collection instruments). However, I revised two key aspects of 
the study because of our conversations. First, it became clear that the advisers, who included both self-identified victims and perpetrators of sibling violence, were eager to talk about their experiences. The advisers demonstrated through their own sharing during the calls and their study design recommendations that I should ask directly about what had occurred during violent exchanges and allow ample time for study participants to share about their experiences in detail. This was particularly meaningful given that the Executive Director and Program Manager had communicated a strong concern about the study re-traumatizing study participants, recommending that I avoid asking young people to disclose the details of violent episodes.

Second, the advisers were very inquisitive about my interest in the subject, inviting me to discuss my experiences with sibling violence during the second call. I followed their lead, sharing about the types of violence I experienced and the ways they had impacted my life into adulthood. I did not dwell in the details of individual acts or events, nor share anything I was not ready to disclose, maintaining an interpersonal boundary that balanced courage and self-care. After I finished providing this information about my background, the advisers offered supportive condolences and appreciation for my choice to study the topic.

This early exchange with the advisers made it clear that creating a safe space to talk about sibling violence should begin with my own honest sharing about my background and interest in the topic, a conclusion that the advisers solidified during the final call by recommending that I build more information about myself into the introduction section of the interview protocol. While the young people did not state this 
explicitly, my takeaway was that personal disclosure could serve to disrupt the researcher-participant power imbalance (Ross, 2017), while concurrently allowing me to model a level of vulnerability appropriate to the research endeavor.

Because of these learnings, I determined that individual interviews, rather than focus groups, would be a more appropriate method of data collection for the project. This determination is in alignment with the peer-reviewed literature which offers numerous examples of in-depth interviewing to gather data on sensitive topics including bullying, high-stakes decision-making, and physical, emotional, and sexual sibling abuse (Allen, 2013; Cranley, Doran, Tourangeau, Kushniruk, \& Nagle, 2012; Keddell, 2011; Meyers, 2014; Rowntree, 2007).

Table 3

Sibling Study Adviser Conference Call Summary

\begin{tabular}{cll}
\hline Call & \multicolumn{1}{c}{ Agenda } & \multicolumn{1}{c}{ Study Implications } \\
\hline Call 1 & $\begin{array}{l}\text { Welcome } \\
\text { Introductions } \\
\text { Roles and responsibilities }\end{array}$ & N/A \\
\hline Call 2 & $\begin{array}{l}\text { Establish an agreement for our work together } \\
\text { Discuss our interest in the topic }\end{array}$ & $\begin{array}{l}\text { Young people want to share their stories } \\
\text { about sibling violence; retraumatization } \\
\text { is not a concern. Ask directly about } \\
\text { violent episodes. }\end{array}$ \\
\hline Call 3 & $\begin{array}{l}\text { Discuss the research questions for the study } \\
\text { Discuss systems concepts }\end{array}$ & $\begin{array}{l}\text { Research questions are on-target } \\
\text { Systems concepts resonate as applicable }\end{array}$ \\
\hline Call 4 & $\begin{array}{l}\text { Discuss the interview protocol } \\
\text { Discuss data collection logistics }\end{array}$ & $\begin{array}{l}\text { Importance of researcher self-disclosure } \\
\text { Individual interviews (not focus groups) }\end{array}$ \\
\hline
\end{tabular}

It is noteworthy that the timeline from my first contact with the agency through completion of the pilot spanned 18 months. This lengthy phase of engagement generated numerous benefits: (1) I was able to demonstrate my commitment to the project, gaining credibility as a student researcher with Executive Director, Program Manager, and foster 
care alumni; (2) I gained experience with youth-informed research; (3) I learned about the agency, including the Executive Director and Program Manager's interests and perceptions about research; (3) I brainstormed with the Executive Director and Program Manager about new ideas for the organization to support young people to gain leadership experience as research advisers and research-informed policy advocates.

After concluding engagement with the study advisers, I conducted a pilot study with four young people recruited through the agency’s summer internship program. I obtained IRB approval for the pilot study and the data were included in the analysis. The sections to follow describe the methods for the study, which were implemented successfully during the Summer 2017 pilot and applied in the same manner for the remaining interviews, completed the summer of 2018. Table 4 summarizes the study process, including the study event, date, the individuals involved, and the count. Eight interviews were included in the analysis, conducted during the "successful pilot" and “final data collection” events.

Table 4

Study Process Summary

\begin{tabular}{lllc}
\hline \multicolumn{1}{c}{ Event } & \multicolumn{1}{c}{ Date } & \multicolumn{1}{c}{$\begin{array}{c}\text { Individuals } \\
\text { Involved }\end{array}$} & Count \\
\hline Planned pilot & Summer 2016 & N/A & 0 \\
Study adviser engagement & Winter 2017-present & Study Advisers & 4 \\
$\begin{array}{l}\text { Successful pilot: Data } \\
\text { included in final analysis }\end{array}$ & Summer 2017 & Interview Participants & 4 \\
Final data collection & Summer 2018 & Interview Participants & 4 \\
\hline
\end{tabular}


Study participant recruitment and consent process. Study participants were recruited through the youth-driven advocacy and support program for foster youth described in the previous section, by disseminating a recruitment flyer through its ecommunication system and during two summer internship program sessions. To further increase the likelihood of a robust response, I included the contact information for three sibling study advisers on the recruitment flyer who agreed to serve as references for me. This gave interested respondents the opportunity to speak with a peer about their experience working with me prior to contacting me directly. A copy of the recruitment flyer is contained in the Appendix.

Study participants were recruited to meet the following criteria: (1) foster care alumni ages 18-24 years old; (2) with at least one (self-defined) sibling; (3) and for whom the study participant describes their sibling relationship as having been physically or emotionally violent in the period leading up to or during their involvement in foster care. I recruited a convenience sample of participants who reported emotional and/or physical violence within biological and/or foster family/kinship care settings. To accommodate the familial diversity represented among those served by child welfare, and to avoid erroneously privileging heteronormative, white, western family structures, self-defined siblings included biological full- and half-siblings, adoptive and step-siblings, as well as fictive kin and social siblings (Walker, Allen \& Connidis, 2005). The inquiry focused primarily on physical and emotional violence because sexual violence is already a widely acknowledged (and more clearly defined) form of abuse between children and youth. Alumni who reported sexual abuse in addition to physical and emotional violence were 
not be excluded, however, since the study pilot and previous research (Hamby \& Grich, 2013) have demonstrated that physical and emotional violence may co-occur with sexual violence.

The flyer initially directed alumni to contact me by telephone or email to express their interest and learn more about the study. One participant contacted me following dissemination through the agency’s e-communication network. I scheduled an initial telephone call with the potential participant to share more about the project and field her questions. After agreeing to participate, we identified a time and location to meet for the face-to-face interview. I recruited the remaining study participants during two sessions of the 2018 summer internship program at the youth-driven advocacy and support program for foster youth. I completed the final consent process for all the study participants immediately prior to conducting the interview. A copy of the consent form is contained in the Appendix.

Data collection. According to $\mathrm{CR}$, data collection occurs in the empirical domain of reality. Intensive data (i.e., in-depth interpretive data) are gathered from individual people to learn how particular mechanisms manifest within the specific contexts of their lives (Bhaskar, 1998). Intensive data for this study consisted of semi-structured interviews with foster care alumni to explore theories of sibling violence in the context of child welfare. CR also advocates for complementary collection of extensive data (i.e., data on widespread trends, typically gathered with quantitative data) to look for systematic differences across a population (Lennox \& Jurdi-Hage, 2017; Sayer, 2010). While collection of extensive data would be an ideal accompaniment to the primary in- 
depth interview methods described here, no such data are currently collected from child welfare-involved youth and to include such an approach in the current study was beyond the scope of a feasible dissertation. Ideally, the intensive data gathered in this project will inform a subsequent extensive approach.

Intensive data collection included three components: (1) creation of a family map; (2) a semi-structured interview, and; (3) completion of a background information form. The interviews began with the participant drawing a series of family maps, graphic representations of the family members present over the time period when the most pronounced sibling violence occurred (see Appendix). The purpose of the map was multifold. First, it helped me to understand the structure of the young person's family when they were experiencing the most significant sibling violence. For young people involved in the child welfare system, family organizations can be highly complex, including a variety of parents, step-parents, other adult caregivers such as grandparents, aunts and uncles, as well as full-, half-, fictive kin and social siblings. Participants drew multiple iterations of the map to represent various structures of biological and foster families over time. These visual representations helped me to quickly learn participants’ family formations. The maps also allowed me to easily refer to individuals by name or by pointing to their location on a map, and to probe about dynamics between/among dyads, triads, or other more complex combinations of family members with a focus on their influence upon violent exchanges. Once the participant had mapped the family structure(s), I carried out a semi-structured in-depth interview with questions designed to gather information on the following topics: 
1. Relationship(s) with sibling(s), including physical and emotional violence

2. Relationships with other family members, and their relationships with each other

3. The community/communities where the respondent lived when they experienced sibling violence

4. The things that adults did (or did not) do to address sibling violence

5. Ideas to help young people who experience sibling violence

A copy of the interview protocol is contained in the Appendix. With participant permission, the interviews were recorded to accurately capture the conversations. I transcribed the recordings to generate rich field texts (Butler-Kisber, 2010) for subsequent review and analysis.

After completing each interview, the participant was invited to complete a background form to gather basic demographic information (i.e., age, gender, sexual orientation, ability status, race/ethnicity) and determine their willingness to be contacted for future research (see Appendix). This information was collected for descriptive purposes only; establishing representativeness of the sample was an inappropriate goal given the constructivist epistemology grounding the study.

Data analysis. The data analysis process was based on the three key steps prescribed in CR: identification of demi-regularities, abduction, and retroduction (Fletcher, 2017). The process was non-linear, moving from the concrete, to the abstract, and then returning to the concrete (Sayer, 1992). Each step is described in more detail in the following sections. 
Identification of demi-regularities occurs through qualitative data coding (i.e., analytical resolution) (Danermark et al., 2002). The data are used to identify rough trends or broken patterns of common human behavior. Given the theory-laden CR grounding of the study, I employed Mayring’s (2000) deductive category application process, which works with theoretically derived codes to organize textual data. The codes for the initial coding scheme were derived from the sibling violence definitions, family conditions, and linear and non-linear theories discussed in the literature. Additional codes captured examples of physical and emotional sibling violence in biological and foster family contexts, the point at which sibling violence ended, actual and recommended interventions, and sources of resilience to navigate sibling violence. I conducted and coded interviews until I determined that the data corpus was adequate to generate information to extend and advance knowledge in relationship to the literature-derived definitions, family conditions, and theories in the context of child welfare. ${ }^{10}$ Applying Mayring’s coding agenda, each code included a clearly articulated definition, coding rules articulating the circumstances under which a given code was to

\footnotetext{
${ }^{10}$ Data saturation continues to be a contentious topic among qualitative researchers. An article by Morse (1995) positioned saturation as the hallmark of a valid qualitative study. To provide concrete guidance as to the number of interviews needed to achieve data saturation, Guest, Bunce, and Johnson (2006) documented the progression of theme identification after each set of six interviews in a study of 60 sex workers in Africa. The researchers concluded that 6-12 interviews would likely be adequate to identify meaningful themes and useful interpretations in studies with homogenous samples, high quality data, and a clearly defined domain of inquiry. O’Reilly and Parker (2012) argue that thematic saturation is not always an appropriate marker of quality assurance, but rather, that quality is inextricably linked to the epistemology undergirding the project. According to O'Reilly and Parker, quality should be determined with consideration for the nature of the topic and the resources available to conduct the study. In cases where saturation is not achieved, the authors cite the position of Morse (1995): this simply means that the construct has not been fully explored rather than that the findings are invalid. If a study generates rich information and extends or advances knowledge, it is deemed successful despite falling short of the saturation ideal. In such cases, transparency about any limitations to achieving saturation should be included with the findings.
} 
be applied to a text unit, and example text units. Through constant comparison analysis I identified areas of overlap/duplication among the family condition codes, reducing the set from seven to four. I then identified areas of overlap/duplication between the family condition codes and the linear theories, recoding text units representing aspects of the linear theories not subsumed within the family conditions. Finally, I worked back and forth between the family condition and linear theory codes and the non-linear theory and model codes, determining that the non-linear theory and model offered unique insight into sibling violence in the context of child welfare. As such, the non-linear theory and model codes were retained as separate codes. A copy of the final coding scheme (codes, definitions, and coding rules) is included in the Appendix. Example text units for the codes are presented in Chapter 4 (Results).

After identifying the demi-regularities I engaged in abduction and retroduction, two CR thought exercises designed to elucidate meaningful causal theory that incorporates not only underlying structures, but also the human actions that fortify or dismantle them. Abduction is a process of "inference or thought operation, implying that a particular phenomenon or event is interpreted from a set of general ideas or concepts” (Danermark et al., 2002, p. 205). In this study, abduction consisted of a holistic analysis process to determine how the demi-regularities (i.e., final codes) were represented within participants’ family systems with the goal of identifying patterns of interaction both within and across the families represented in the data. To do this, I recreated the family maps for each participant, identifying the gender of each member and their familial relationship to the study participant (mother, brother, nephew, etc.). I labeled three traits 
associated with the family conditions and theories (i.e., drug use, alcohol use, and mental health challenges) for individual members, and identified the presence and direction of physical and emotional violence between members. Beneath each family map, I summarized the key interview content associated with the time-frame (i.e., participant age range) represented in the map. These summaries included family member characteristics, examples of physical and emotional violence, patterns of interaction, and critical events, such as those that triggered reorganization of the family structure. I also drafted brief explanations of how the definitions and theories were represented in data, along with the text unit(s) associated with them. I concluded abduction by determining that a non-linear theory focused on the family level of the social ecology was the best representation of the phenomenon in the data. An example of a de-identified family map created during this phase of analysis is included in the Appendix.

The last phase of analysis was the CR process of retroduction, where I explored the "real” causal mechanisms necessary for abusive sibling violence to manifest at the empirical level. Retroduction focuses on theorizing about the social, cultural, and/or historical conditions in which a causal mechanism takes effect (Fletcher, 2017; Lennox \& Jurdi-Hage, 2017). Retroduction includes people's knowledge, and their reasons or motivations for doing things, which are treated as real causal mechanisms that can dismantle or fortify the objects or structures influencing their lives. I incorporated the key CR concepts of structure, agency, and open systems in the retroduction process, working to identify the causal mechanisms underlying abusive sibling violence (i.e., domain of the "real”) in the context of child welfare. I applied the questions developed by Danermark et 
al. (2002) in this phase of analysis: (1) What is fundamentally constitutive for the structures and relations of abusive sibling violence? (2) How is abusive sibling violence possible? (3) What properties must exist for abusive sibling violence to be what it is? (4) What causal mechanisms are related to abusive sibling violence? I applied this thought exercise to the child welfare system, with consideration for the broader system conditions (i.e., social, political, and economic) that bear upon its structure and function.

\section{Establishing Trustworthiness}

In this study I served as the "instrument" in that I devised and refined the research questions, conducted the interviews with the study participants, and completed the data analysis and synthesis. According to Finlay (2002), the practice of reflexivity, or “thoughtful, conscious self-awareness... encompass[ing] continual evaluation of subjective responses, intersubjective dynamics, and the research process itself” (p. 532) is essential to ensuring the integrity and trustworthiness of a study. To ensure trustworthiness, I engaged in a variety of activities in partnership with my academic advisers, colleagues, and peers.

After transcribing the data, I coded the interviews, preserving copies of data synthesis documents (i.e., participant-specific and aggregated text unit summary tables) to make it possible to follow the process of data analysis and synthesis back to the original transcripts. I engaged members of my committee as auditors who reviewed the coding scheme guiding the initial phase of analysis (i.e., identification of demiregularities). At appropriate junctures over the course of data collection and analysis, I again engaged members of my committee to review the intermediate synthesis documents 
(i.e., family map reproductions with text units). I drafted reflexive memos to explore how my own conceptions were influencing my interpretation of the data. I also debriefed with my committee members, student peers, and professional colleagues to discuss the preliminary findings and the issues that arose in the memos.

\section{Ethical Considerations}

By nature of being in the child welfare system, the foster care alumni who contributed to the study they have experienced significant trauma, including removal from their family of origin into out-of-home care. They represent a "vulnerable” population in that they are at increased risk for adverse social outcomes including homelessness, un-/under-employment, substance use/abuse, and physical and mental health challenges (Courtney, Piliavin, Grogan-Kaylor, \& Nesmith, 2001; Lenz-Rashid, 2004; Lopez \& Allen, 2007; Nicoletti, 2001; Reilly, 2003). Moreover, they may have experienced negative interactions with a variety of well-intentioned helping professionals who may have dismissed their allegations (McDonald \& Martinez, 2016), made seemingly illogical decisions about their care (Hyde \& Kammerer, 2009), unexpectedly severed interpersonal ties with them (Strolin-Goltzman et al., 2010), or subjected them to additional trauma (Riebschleger et al., 2015). Consideration for their sense of safety was paramount to ensuring that they were left no worse off for having taken part in the project and to increase the likelihood that the study would generate meaningful data. In addition to the oversight provided by the Portland State University Institutional Review Board (see Appendix for IRB Application) I addressed these concerns in ways which are informed by the literature and the guidance of the sibling study advisors. 
First, I built information about myself into the data collection instrument and I used this rapport-building process to foster a two-way relationship that modeled a safe level of self-disclosure with the hope that it would serve to disrupt the researchparticipant power imbalance (Ross, 2017; Oakley, 1981). Second, I explicitly conveyed that the interviewee held the power to guide the process in that they could decide where we would meet, which questions to answer, and that they could stop participating at any time. Third, throughout my engagement with each participant I emphasized an ethic of care that privileged empathy and mutual respect over capturing data. In one case I conducted an interview with a participant whose experience did not fit with the inclusion criteria. This became clear shortly after beginning the interview, but the participant was eager to talk about her experience losing touch with a foster sister whose relationship she valued. I chose to carry the conversation through to completion as a demonstration that her needs were important, valid, and equal to my own (Hoffman, 2007; Parr, 2015).

Despite my best efforts, some of the participants experienced psychological distress during the interviews. Three participants became tearful and two others took long pauses to regain their emotional composure following disclosure of particularly painful events. To avoid interrupting their experience or sending the signal that I was uncomfortable with their displays of emotion, I remained quiet and still until they regained their composure. Once calm, I expressed that I was sorry to hear about the painful experiences they had been through and asked if they would like to take a break or discontinue. In each case the participant communicated that they wanted to continue and appeared calm, so I proceeded with the remaining questions. 
At the conclusion of the interviews I observed each participant to be in a good emotional space; several expressed gratitude for having the opportunity to share their stories and thanked me for carrying out the project. Seven of the eight interviews took place at the residential internship program sight where participants had numerous peers and providers available for additional support. The consent form also included contact information for resources for individuals experiencing interpersonal violence, sexual abuse, or mental health challenges. Collectively, these cues and safeguards gave me confidence that I could conclude the interviews without additional assurances of safety or follow-up.

\section{Researcher Positionality}

I am a survivor of abusive sibling violence. In preparation to conduct this study, I completed a review of the literature and had many conversations with other survivors. I noticed a tendency to compare the literature to my own experience as I was preparing the proposal for this project, assessing the extent to which they fit or did not, and the associated feelings and judgements that arose in relation to those comparisons. Given the depth of my personal experience and reactions to the literature, I anticipated that some definitions, family conditions, or theories would resonate more deeply than others, and that I might focus on those similarities while missing other key findings in the data. I employed various methods (i.e., reflexive memos, adviser and peer consultation) to monitor the ways that my lived experience influenced the project, to strengthen the quality and usefulness of the research, and to assist me to manage the emotional labor required to sustain engagement with this sensitive topic. While these tasks were helpful, 
bi-monthly counseling sessions with a trauma-informed therapist were integral to maintaining my own wellbeing while completing the study. 


\section{Chapter 4: Results}

After obtaining committee and IRB approval, I worked with the youth-driven advocacy and support program to recruit participants for the interviews. The final sample included eight participants; I interviewed four individuals during the study pilot in 2017 and four additional participants in the spring and summer of 2018. As mentioned previously, the study pilot was conducted with IRB approval and the data were included in the final analysis. As each interview was completed, I transcribed the conversation verbatim from the recording, and entered the participants’ demographic information from the background information form into a spreadsheet.

I then applied the coding scheme, assigning text units to transcript passages that resonated with or were counter to the definitions, family conditions, and theories discussed in the sibling violence literature. Additional codes captured examples of physical and emotional sibling violence, the "break-point” at which sibling violence ended (if at all), and sources of resilience that supported participants to survive the violence they experienced. After coding the interviews, I electronically reproduced the family maps, adding more detail to the graphic representations and developing brief descriptions that identified linkages between the maps and the definitions, family conditions, and theories in the literature.

Working back and forth between the coded interviews and the family maps in a process of constant comparison, I identified demi-regularities (i.e., rough trends or broken patterns in the data (Danermark et al., 2002, p. 70)). The demi-regularities were comprised of the components of a nascent definition of sibling violence in the context of 
child welfare, a condensed set of key family conditions associated with the phenomenon, aspects of the linear and non-linear theories of sibling violence that resonated with the data, key perspectives about sibling violence among affected youth, and responses among the adults in their lives.

Finally, I engaged in abduction and retroduction, two CR thought exercises to elucidate meaningful causal theory. Abduction focused on causal mechanisms rooted in individual choice discernable from the interview data (i.e., at the empirical level).

Retroduction expanded the analysis to include the broader social, political, and economic conditions under which the causal mechanisms of sibling violence take effect, with focus on the child welfare system. The results of the analysis are presented in the sections to follow.

\section{Sample Description}

The final sample was comprised of eight women ages 19-24 who self-selected to participate. ${ }^{11}$ Five of the participants self-identified as white; three others self-identified as Black/African American, Hispanic/Latinx, and multi-racial (Black/African American, Hispanic/Latinx, and American Indian). Seven of eight participants were recruited through the youth-driven advocacy and support program's summer internship program. While the interviews were all conducted face-to-face in Oregon, the participants had traveled to the program site from seven U.S. states: California, Michigan, Nevada, Oklahoma, South Carolina, Texas, and Wisconsin. The eighth participant was recruited through the program's e-network and was from Oregon. One participant self-reported

\footnotetext{
${ }^{11}$ No males opted into the study. This is discussed in Chapter 5.
} 
multiple disabilities; others selected “none/prefer not to answer.” Seven of eight participants self-identified as heterosexual and one as bisexual.

Table 5 summarizes physical and emotional sibling violence data for the eight study participants. All were removed from their family of origin to out-of-home care. The out-of-home care settings where participants’ experienced the most pronounced physical and/or emotional sibling violence are listed. Four participants were placed in kinship care settings and three were placed in non-relative foster/adoptive care settings. One participant did not experience physical or emotional violence while placed in out-ofhome care. Rather, this participant was involved in the child welfare system for many years, during which time she transitioned between her original family and foster care. Each time she returned home, physically and emotionally abusive sibling violence resumed; she was under the care of the child welfare caseworker during this time. As shown, most participants experienced physical and emotional violence when living in their original home and after removal by child welfare.

Table 5

Study Participants’ Reports of Physical and Emotional Sibling Violence

\begin{tabular}{lc}
\hline Sibling Violence Out of Home Care Type & Count \\
\hline Kinship care & 4 \\
Foster/adoptive care $^{12}$ & 3 \\
No sibling violence in out-of-home care & 1 \\
\hline Sibling Violence Type & 6 \\
\hline Physical sibling violence - family of origin & 7 \\
Physical sibling violence - in care & 5 \\
Emotional sibling violence - family of origin & 6 \\
Emotional sibling violence - in care & \\
\hline
\end{tabular}

12 One study participant was fostered and then adopted by her foster parents. 
The study was guided by two research questions to learn how the foster care alumni experienced sibling violence and gather their perspectives on intervention into the phenomenon. The two research questions, and related sub-questions, are shown below.

1) How do foster care alumni describe their experiences with physical and emotional sibling violence?

a) To what extent do their descriptions fit with Caffaro (2014) and Meyers’ (2015) definitions of abusive sibling violence?

b) To what extent are family conditions and theories of sibling violence discussed in the extant literature represented in their descriptions?

c) What additional/refined causal mechanisms do their descriptions suggest?

2) From the perspective of foster care alumni, how do adults who care for or work with young people involved in the child welfare system (e.g., foster parents, case workers, mental health providers, kinship caregivers, etc.) respond to sibling violence?

a) To what extent are adult responses perceived as helpful?

b) What do young people recommend to address sibling violence?

I conducted the analysis with the overarching goals of:

1. increasing understanding of physical and emotional sibling violence in the context of child welfare;

2. contributing to sibling violence theory development; and,

3. identifying innovative ways to protect children from sibling violence and/or help foster children manage sibling violence. 
In the following sections I present the results of the thematic analysis and CR abduction for Research Question 1 and Research Question 2. Subheadings identify demi-regularities developed through constant comparison. The narrative describes each demi-regularity with additional synthesis generated through CR abduction.

\section{Research Question 1. How do foster care alumni describe their experiences with physical and emotional sibling violence?}

A nascent definition of abusive sibling violence in child welfare. The initial coding scheme identified text units that supported and challenged the definitions put forward by Caffaro (2014) and Meyers (2015) which were developed in studies with the general population of sibling violence survivors: a repeated, escalating pattern of violent interactions; stable victim/offender roles; perpetrator motivated by a need for power and control, and; victim experiences a sense of powerlessness/terror and perceives the behavior as abusive. The first demi-regularity, a refined, nascent definition of abusive sibling violence in the context of child welfare, supported the notion that abusive sibling violence is a repeated escalating pattern of violent interactions between two or more siblings that results in physical or emotional harm to a child. Stable roles were evident in the data, but the roles were that of instigators and retaliators, rather than victims and offenders. Instigator motivations were more nuanced than the previous definition suggests, and while some retaliators feared instigators, many did not and none of the participants described their interactions as abusive. Subsequent sections discuss these findings in greater detail. 
A repeated escalating pattern. When asked to describe their experiences with sibling violence, participants were able to easily recall examples due to their frequency and stable patterns of interaction. Participants used language such as “every week,” “daily,” “a lot,” “over and over,” and “common” when recalling the frequency of their violent interactions with siblings, which spanned five to 15 years. All but two participants experienced abusive sibling violence for six or more years. Many examples began with verbal arguing, “nitpicking,” or horseplay between siblings, but without adequate adult supervision or intervention, escalated until one or more children was physically and/or emotionally harmed. In the quote below, a participant describes the persistent, violent pattern of interactions with her older brother which began in early childhood and continued until age 12 when she was placed in foster care:

So it would start out with something like him flicking his boogers on me. I'd be like, “Stop,” even though I’d know he’d be joking. So I’d be like, “Stop, or I’m gonna hit you.” And he'd keep flicking his boogers at me and it would be frustrating, so I'd hit him like that [slaps with back of flat hand] because he'd be sitting next to me. And he'd take that seriously, and that was when we would actually get physical, and he'd shove me, and I'd get mad.... it always started out simple, but then it'd get to the point where my grandparents would have to intervene. They'd grab him and hold him back and my grandmother would have to pull me back and, “Okay, you guys need to calm down.” But we'd want to attack each other. I'd want to kick him. That was the thing I always wanted to do, is kick him. But he'd punch me. So it got pretty bad. We definitely would give 
bruises to each other. It would never get to the point where he'd punch me in the face, but he'd punch me in the arm, in my gut. I'd get bruises, or I'd be winded where I couldn’t breathe. And kicking him, I don’t know if I left bruises on him but I probably did. Kicking leaves bruises. So it got pretty physical at times. It never got to the point where we had to go to the hospital or anything. We definitely did get to the point where my brother had to go to juvi a couple of times. He would get a little bit too serious and he would go into the garage and he'd grab the chainsaw, I think that's what it's called, the chainsaw and he'd bring it in. My grandpa freaked out that one time, and he called the cops. And me, I ran to my room so scared. So it got to serious moments and he'd go away for a little while and then he'd come back and he'd be okay for a while but he was so easy to get elevated. Easier than me. I only got mad when he got mad at me.

Despite often beginning with relatively harmless interactions, participants described sustained patterns of violence that regularly escalated into abuse in that they experienced physical and/or emotional harm from the interaction. This was one of three examples in the data, each from a different participant, where the police were summoned to manage violence between siblings due to the extremity of the violence. The use of a weapon was also common - three participants reported that a sibling had threatened them with a knife. Participants' descriptions of their experiences with sibling violence strongly resonated with Caffaro’s defining abusive sibling violence as a repeated, escalating pattern of interaction. 
Sibling violence instigators and retaliators. Caffaro’s definition also includes stable victim and offender roles, a linear conceptualization of interpersonal violence between two siblings in which the victim does not retaliate. This type of interaction was represented in one of the interviews, but more common in the data were interactions where one child would instigate and another (or others) would retaliate. One pattern was that of an instigator employing emotional violence to engage a sibling. Examples spanned minor irritations like name-calling to emotionally abusive behavior such as degrading a sibling's sense of self-worth or destroying their possessions. The retaliator would respond with emotional or physical violence, which would then escalate until one or more of the children was physically and/or emotionally harmed. Describing the violence with her older sister, one participant recalled:

She would instigate it. She knew that was what I would turn to, physical violence. She was more like, verbal. Like she would abuse you verbally until you do something about it... she would run... that's what she does. She runs and then she does this thing where she falls on her back. She would like, kick, so you can't hit her. This one time she was doing that, and she kicked me hard, and I flew all the way down the stairs.

Figure 6 displays a nonlinear instigator/retaliator dynamic with stable roles. The arrows with plus signs represent reinforcing feedback loops (i.e., a repeated, escalating pattern). In cases of sibling violence between two siblings, participants’ descriptions resonated more strongly with the nonlinear representation displayed in Figure 6 than Caffaro’s unidirectional linear conceptualization. 


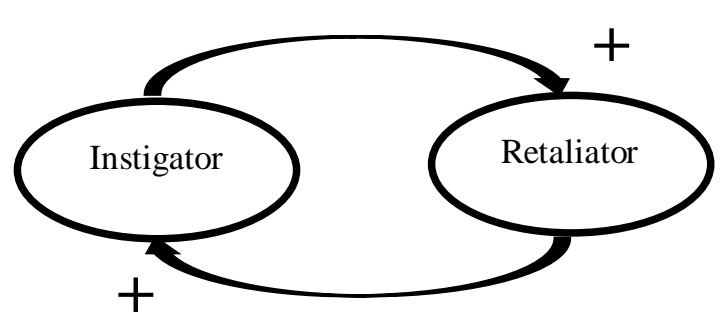

Figure 6. Instigator/retaliator escalating abusive sibling violence dynamic with reinforcing feedback loops.

In families with more than two children in the home, the stable instigator role was also represented in the data. For example, in a complex family system with eight children in the home, the participant identified her nephew, a self-defined sibling in her kinship care setting, as the sibling violence instigator:

He would coordinate fights with all of us... He would get us together and say “Let's play body shots,” so what that means is "Fight!” Fight pair to pair. So he would coordinate like you and you go fight... So it was mainly more so him, than anyone else.

Another participant who was the eldest of five siblings identified one of her younger brothers as the primary instigator:

[Younger half-brother 1] was extremely violent with pretty much everyone. Meaning he would just like, grab [younger half-brother 2] and choke him, pretty much the same stuff my stepdad was doing, like pinch him... or hit my brother or hit my sister... [Later he] started getting more violent by like grabbing knives and trying to stab people while they were sleeping and I would have to tackle him and 
take the knife away from him... my brother was probably the more violent person.

Seven of eight participants identified a primary instigator in the family system, regardless of the number of children in the family. In households with more than two siblings, however, additional abusive sibling dynamics co-occurred along with the primary instigator/retaliator(s) dynamic. In the situation above, two younger children were also instigators. The result was a complex dynamic in which five siblings shifted between instigator and retaliator roles as they engaged in multiple dyadic and triadic patterns of violence.

Finally, Caffaro defines abusive sibling violence perpetrators as motivated by a need for power and control, a characteristic which was supported in the data, along with others. Siblings employed violence to enforce rules and to establish their dominance as decision-makers. One participant used violence to “teach” her sister not to emotionally abuse their neglectful mother. Another overpowered her brother to prevent him from abusing a younger sibling. An older brother beat up his sister to keep her from reporting their lack of parental supervision to adult authorities. In addition to a need for power or control, other instigation drivers were discussed. In some cases, siblings living in impoverished families engaged in violence to obtain scarce resources such as food. Others suggested that instigators’ violent behaviors were due to behavioral, developmental, or mental health challenges. As evidenced by the data, children's motivations for engaging in sibling violence were more nuanced than Caffaro suggests. 
Victim/retaliator perceptions. Extending Caffaro’s definition, Meyers (2017) argued that the phenomenon is also defined by the victim experiencing a sense of terror and powerlessness, along with a perception that the perpetrator's behavior is abusive. The data offered support for this notion, provided by two of eight participants whose older brothers had abused them. One reenacted her 911 call: “I’m scared for my life. I don’t have a parent to support me. My brother is doing this to me every single day.” Another noted that she “didn’t need to be scared all the time” after she was removed to foster care, placed separately from her older brother.

More commonly, the foster care alumni contrasted violent interactions between siblings with adult-perpetrated violence in the home. Participants were exposed to such frequent and extreme adult-perpetrated violence, they were prone to viewing sibling violence as normal. This perception was fortified through social isolation - participants actively hid their home circumstances from outsiders, changed residences frequently due to poverty/eviction, or both. A lack of adult intervention affirmed this perception. In some cases, participants were hesitant to identify the behavior of their instigating siblings as abusive because they had retaliated against the behavior. As one participant recalled, "I did it too. I followed the footsteps. In the back of my mind I knew it was wrong, because it didn't feel good.” The data gathered in the current study suggest that Meyers’ extension of Caffaro's definition is less resonant in the context of child welfare.

My analysis suggests that a refined definition of abusive sibling violence is needed in the context of child welfare that considers the circumstances of child welfareinvolved children’s lives. Specifically, foster children’s exposure to adult-perpetrated 
violence and the lack of adult supervision they receive appears to bear upon children's motivations for engaging in sibling violence and their perspectives about it. While Caffaro argued that a perpetrating sibling is motivated by a need for power and control, participants in the current study offered alternate motivations including a need to secure basic resources and un-/under-addressed behavioral, developmental, and mental health challenges among instigators. Meyers’ additions to the definition were also less resonant with the data in that participants were more apt to perceive sibling violence as normal and to retaliate rather than identify as victims. A refined, nascent definition of abusive sibling violence in the context of child welfare is as follows: a repeated, escalating pattern of violent interactions between/among two or more siblings that results in physical or emotional harm to at least one child, regardless of that child's perception of the violence as it occurs.

Family conditions associated with sibling violence. The extant literature identifies a plethora of family conditions associated with sibling violence in the general population (Caffaro \& Con-Caffaro, 1998; Crick \& Dodge, 1994; Frick \& White, 2008; Kerig \& Stellwagen, 2009; Loeber \& Stouthhamer-Loeber, 1998; Wiehe, 1997). I distilled the conditions into seven codes which were included in the original coding scheme. Table 6 summarizes the data for the sample, displaying the code, definition, and the number of participants who discussed the family condition during their interview. As shown, five or more participants reported that they experienced or were exposed to each one. Individual participants experienced three to seven of the family conditions at the time that sibling violence was happening, with an average of six (data not tabled). 
Table 6

Family Conditions Associated with Sibling Violence

\begin{tabular}{|c|c|c|}
\hline Code & Definition & $\begin{array}{c}\text { Number of } \\
\text { Participants } \\
\quad(n=8)\end{array}$ \\
\hline $\begin{array}{l}\text { Acceptance/ } \\
\text { Modeling of } \\
\text { Violence }\end{array}$ & $\begin{array}{l}\text { Parent(s) communicate(s) that violence is an appropriate } \\
\text { solution to interpersonal problems within the family system by: } \\
\text { - Physical/emotional violence (IPV) between adult } \\
\text { caregivers } \\
\text { - Adult-perpetrated physical/emotional child maltreatment }\end{array}$ & 8 \\
\hline $\begin{array}{l}\text { Parental } \\
\text { Unavailability }\end{array}$ & $\begin{array}{l}\text { Parents are physically and/or emotionally unavailable as a } \\
\text { result of: } \\
\text { - Inability to express love, empathy, caring for the } \\
\text { child(ren) } \\
\text { - } \quad \text { Regular/severe alcohol/drug use } \\
\text { - Chronic/severe mental health challenges } \\
\text { - Chronic/severe physical health challenges }\end{array}$ & 7 \\
\hline $\begin{array}{l}\text { Lack of } \\
\text { Supervision }\end{array}$ & $\begin{array}{l}\text { Parent(s) do(es) not provide expectations for or enforce healthy } \\
\text { child behaviors }\end{array}$ & 7 \\
\hline Siblings Differ & $\begin{array}{l}\text { Sibling qualities that prime perpetrators to enact } \\
\text { physical/emotional violence or predispose victims to receive } \\
\text { abuse: } \\
\text { - Perpetrator Qualities - thinking errors, } \\
\text { cognitive/developmental deficits, lack of impulse } \\
\text { control, lack of empathy, callout-unemotional traits, } \\
\text { narcissism, tendency to inaccurately interpret social cues } \\
\text { - Victim Qualities - genetically determined physical, } \\
\text { emotional, mental characteristics (disabled, } \\
\text { developmentally delayed, exhibit behaviors others } \\
\text { experience as irritating } \\
\text { Large developmental, physical, intellectual, or } \\
\text { social/emotional differences between siblings in a dyad } \\
\text { in which the perpetrator is superior and the victim is } \\
\text { inferior }\end{array}$ & 7 \\
\hline $\begin{array}{l}\text { Differential } \\
\text { Treatment }\end{array}$ & $\begin{array}{l}\text { Parent(s) favor or scapegoat one sibling as compared to } \\
\text { other(s) }\end{array}$ & 6 \\
\hline $\begin{array}{l}\text { Work/ } \\
\text { Financial } \\
\text { Strain }\end{array}$ & $\begin{array}{l}\text { Parent(s) described as experiencing work/financial strain such } \\
\text { that: } \\
\text { - Parent(s) is/are unable to secure stable employment } \\
\text { - Parent(s) work is illegal (e.g., drug dealer) } \\
\text { - Parent(s) work(s) more than full-time to meet basic } \\
\text { needs } \\
\text { - Parent(s) unable to meet family's basic needs due to } \\
\text { un/under-employment }\end{array}$ & 6 \\
\hline $\begin{array}{l}\text { Parentified } \\
\text { Child }\end{array}$ & $\begin{array}{l}\text { One sibling is expected to parent others; caretaking } \\
\text { expectations are developmentally inappropriate given the } \\
\text { child's age/abilities }\end{array}$ & 5 \\
\hline
\end{tabular}


Areas of overlap and alignment among the conditions arose through constant comparison, resulting in a refined set of two primary and two secondary conditions that were directly associated with sibling violence in the data. Primary conditions were strongly resonant in the data, with most participants reporting exposure and directly linking their exposure to sibling violence. Secondary conditions were also prevalent in the data, but linkages to sibling violence were less pronounced. Table 7 presents the final set of family conditions and their definitions along with the initial code(s) each was drawn from. Table 8 displays the number of respondents who reported each family condition, both in their family of origin and in out-of-home care. For those respondents who reported the condition in care, results are also split between participants living in kinship care and those in foster/adoptive care. After the tables, each of the family conditions is discussed in greater detail with example text units drawn from the interviews. 


\section{Table 7}

\section{Final Set of Family Conditions Associated with Sibling Violence in Child Welfare}

\begin{tabular}{|c|c|c|c|}
\hline Initial Code & $\begin{array}{l}\text { Primary/ } \\
\text { Secondary }\end{array}$ & Final Code & $\begin{array}{c}\text { Final Definition } \\
\end{array}$ \\
\hline $\begin{array}{l}\text { - Acceptance/ } \\
\text { Modeling of } \\
\text { Violence } \\
\text { - Lack of } \\
\text { Supervision } \\
\text { - Differential } \\
\text { Treatment }\end{array}$ & $\begin{array}{c}\text { Primary } \\
1\end{array}$ & $\begin{array}{l}\text { Modeling/ } \\
\text { Acceptance of } \\
\text { Violence }\end{array}$ & $\begin{array}{l}\text { Caregivers communicate that violence is an } \\
\text { appropriate solution to interpersonal } \\
\text { problems within the family system: } \\
\text { - Adult-perpetrated physical/emotional } \\
\text { child maltreatment } \\
\text { - Interpersonal violence (IPV) between } \\
\text { adult caregivers } \\
\text { - Caregivers condone sibling/peer } \\
\text { violence } \\
\text { - Parent(s) favor one child (the sibling } \\
\text { violence instigator) }\end{array}$ \\
\hline $\begin{array}{l}\text { - Parental } \\
\text { Unavailability } \\
\text { - Parentified } \\
\text { Child } \\
\end{array}$ & $\begin{array}{l}\text { Primary } \\
2\end{array}$ & $\begin{array}{l}\text { Drugs, } \\
\text { Alcohol, and } \\
\text { Mental Health } \\
\text { Challenges } \\
\end{array}$ & $\begin{array}{l}\text { Caregivers are mentally, emotionally, } \\
\text { and/or physically absent, failing to provide } \\
\text { adequate supervision }\end{array}$ \\
\hline $\begin{array}{l}\text { - Work/Financial } \\
\text { Strain }\end{array}$ & $\begin{array}{l}\text { Secondary } \\
1\end{array}$ & Poverty & $\begin{array}{l}\text { Caregivers fail to meet children's basic } \\
\text { needs }\end{array}$ \\
\hline - Siblings Differ & $\begin{array}{l}\text { Secondary } \\
\quad 2\end{array}$ & $\begin{array}{l}\text { Instigator } \\
\text { Characteristics }\end{array}$ & $\begin{array}{l}\text { Instigators experience behavioral, } \\
\text { developmental, and mental health } \\
\text { challenges }\end{array}$ \\
\hline
\end{tabular}


Table 8

Family Conditions Associated with Sibling Violence Overall and by Placement Type

\begin{tabular}{lccc}
\hline & TOTAL & $\begin{array}{c}\text { Foster/Adoptive } \\
\text { SUBTOTAL }\end{array}$ & $\begin{array}{c}\text { Kinship } \\
\text { SUBTOTAL }\end{array}$ \\
\hline Modeling/Acceptance of Violence & & & \\
\hline Family of origin & 8 & & 2 \\
Out-of-home care & 4 & & \\
\hline Drugs, Alcohol, Mental Health Challenges & & & 1 \\
\hline Family of origin & 6 & & \\
Out-of-home care & 2 & & 2 \\
\hline Poverty & & & \\
\hline Family of origin & 6 & & \\
Out-of-home care & 3 & & \\
\hline Instigator Characteristics & & & \\
\hline Family of origin & 4 & & \\
Out-of-home care & 6 & & \\
\hline
\end{tabular}

Primary family condition 1. Modeling/acceptance of violence. Caregivers

directly and indirectly communicated to participants and their siblings that violence is an appropriate solution to interpersonal problems in the family system. Every participant in the sample experienced some form of adult-perpetrated physical or emotional violence, either directed toward another adult in the home or toward the child(ren). Seven of eight participants were physically abused by an adult caregiver in their family of origin. Four were physically abused or witnessed a sibling being physically abused after removal to out of home care. Among the four, two were in kinship care and two were in foster/adoptive care. Participants and their siblings were beaten with fists, belts, and utensils, choked, thrown into walls, tied up, and force-fed, often for minor transgressions such as talking back, making a mess, or failing to do chores. One participant's father 
"would rather hit me than ground me, because hitting me is just for the day but grounding, then it has to be for weeks.” Another described a kinship caregiver shoving her fingers down her throat to make her eat dinner. A third participant's kinship caregivers:

...hit us a lot with a belt... it was over the littlest, the dumbest things. Like somebody would eat something and we would get in trouble. Or somebody would mess something up and we would get in trouble... the only time they would hit us in the face was when we insulted them.

Emotional abuse was also widespread. Participants and their siblings were shamed and screamed at for "leaving a cup out” or arguing. A particularly cruel example was one mother's repeated accusation that the participant was to blame for her father abandoning the family.

Participants drew direct connections between the adult-perpetrated child maltreatment they experienced in their families of origin and in care, and the physical and emotional violence between siblings. An interview participant who regularly fought physically with her sister stated, "I would hit her and stuff. Probably because my dad was hitting me before, and then I was like, this is how you deal with problems. This is what you do.” In a family where the stepfather was abusive to both the children and their mother, the participant said that her stepdad "would talk down to my sister and call her ugly and fat and all these other things, so my brother followed in his footsteps and said the same things.” When describing a pattern of physically violent interactions with her brother, another participant recalled her mother’s alcohol-induced abuse: “It definitely 
put a strain on me and my brother. Because it happened to us the most, so we kind of did the same to each other.” As evidenced by these comments, the foster care alumni viewed sibling violence as a replication of violent behavior modeled by their caregivers. ${ }^{13}$

In addition to pervasive modeling of violent behavior, caregivers also condoned violence between/among children by allowing, ignoring, or encouraging sibling/peer violence. In an example from early childhood, a participant recalled her father verbally encouraging sibling violence between she and her sister. As a teenager the same participant's mother did not take issue when she told her that she planned to fight a peer after school. The participant connected these exchanges with sibling violence: "Nobody made it not normal... my mom wasn’t like ‘Don’t hit your sister. Don’t go beat this girl up."”

Passive acquiescence was also commonly discussed in the interviews. Six participants described caregivers who had allowed biological or foster siblings to abuse each other in their presence or failed to respond when children reported sibling violence. As stated by one participant, “My mother would just sit back and let it happen.” Another recalled:

I can remember when I was younger my brother just would like, tease me all the time. Call me names and treat me like trash and he would throw things at me and hit me. He was horrible to me. And that was in front of my mom.

\footnotetext{
${ }^{13}$ In addition to adult-perpetrated child maltreatment, all participants disclosed emotional or physical violence (IPV) between adult caregivers in their family of origin or while living in care. There were no direct connections drawn between witnessing IPV and sibling violence, however.
} 
Passive acquiescence was often linked to descriptions of preferential treatment. Five participants described parental favoritism for their male siblings who received more emotional nurturance, were fed first at meals, and received better clothing, toys, and technology than their female siblings. These privileged children could behave violently without consequence. One participant recounted her father standing by as her brother attempted to drown her in a lake. All five participants whose brothers received preferential treatment identified them as the primary sibling violence instigator in the family.

In summary, every participant in the sample received the explicit or implicit message that violence is an appropriate way to address interpersonal problems in the family system. Study participants lived in families where emotional and physical violence were frequently modeled by adult caregivers. When siblings behaved violently, caregivers did not intervene, and in one case verbally encouraged the behavior. Exposure to and acceptance of interpersonal violence in the family system surfaced as a primary family condition for sibling violence in child welfare.

Primary family condition 2. Drugs, alcohol, and mental health challenges. Two of the initial codes (i.e., parental unavailability, parentified child) were combined into a single code describing family systems where parents were mentally, emotionally, and/or physically absent, and as a result failed to provide adequate supervision for children. Parental unavailability was largely due mental health challenges (e.g., PTSD, bipolar disorder, schizophrenia) and/or addiction issues (e.g., alcohol, methamphetamine, crack cocaine, heroin, and prescription drugs). Half reported having a parent with co-occurring 
mental health and addiction challenges. In most cases, caregivers' addiction issues and mental health challenges caused them to leave participants and their siblings unsupervised for lengthy periods of time. When caregivers were physically present, they were described as emotionally or mentally unavailable.

Children in these family situations commonly took on developmentally inappropriate caregiving responsibilities for themselves and their siblings. One participant identified as a "mom” to her siblings and regularly resorted to violence with her brother (i.e., slapping him, pushing him into corners, standing on him) to keep him from harming their younger brother. Another participant "felt like [she] had to be the adult when [her] mom left.” When she attempted to dissuade her older brother from selling drugs, he responded by screaming at her and beating her up. In both instances, interactions of this type were described as a repeated pattern as opposed to one-time incidents and were explicitly linked with children being left alone. When parents who were minimally engaged assigned older children to babysit younger ones, violent dynamics similarly followed. In an adoptive family where an older brother was charged with babysitting four younger siblings, they ganged up on him and beat him up. The younger children also ganged up on their older sister when she was put in charge. Un/under-treated caregiver addiction and mental health challenges resulting in inadequate supervision of children surfaced as another primary family condition for sibling violence in child welfare.

Secondary family condition 1. Instigator characteristics. When describing sibling violence instigators, participants recalled behaviors associated with various 
mental health diagnoses, disabilities, and developmental delays. Examples included motor tics, significantly delayed toilet training, showing no sign of remorse after an aggressive episode, and manipulative, oppositional, and violent behavior directed toward people and animals in a variety of settings. Participants reported that sibling violence instigators had received mental health diagnoses including attention deficit hyperactivity disorder, oppositional defiance disorder, and bipolar disorder. In most cases, participants reported that these challenges were untreated, even after removal to foster care. The data suggest that child welfare-involved children with un-/under-addressed challenges such as these may be prone to physical or emotional sibling violence instigation.

Secondary family condition 2. Poverty. All participants reported living in lowincome families and many lacked adequate access to basic needs such as food, clothing, and stable housing. One participant explicitly connected living in extreme poverty with sibling violence:

Since we were always all over the place, mom could never afford to feed us all, so we were stuck in that survival mode. There were a lot of times when we got in fist fights over things like who was gonna have the last can of green beans or who could have the piece of bread that we had in the cupboard. We've gone to school in the morning with bloody noses, cuts, bruises all over us because we were fighting over food. There's been times when we fought to get the last bit of water, because she couldn't pay for the water bill or electricity a lot of times. If we were running out of water we had to fight over who was gonna get to take the last shower, get a glass of water. It was pretty brutal. 
Although most participants did not link poverty with sibling violence, it is likely that the stress this placed on children was a contributing factor. One participant described arguments with her brother who was selling drugs, a choice that was likely driven by a need for income. Others recalled arguments over shared clothing that escalated into abuse.

Resonance of linear and non-linear theories. The extant sibling violence literature offers both linear and non-linear (i.e., systems-oriented) theories to describe the causal mechanisms that foment family violence. The coding scheme included a code to identify text units associated with components of three linear and one non-linear theory to determine the extent to which they were represented in participants' descriptions. Summarized in Table 9, the codes identified key components of each theory. Codes were assigned to text units describing any aspect of the theory. 
Table 9

Theory Code Descriptions

\begin{tabular}{ll}
\hline Theory/Model & \\
\hline Social & Physical/emotional sibling violence is: \\
Learning & - Learned through observation \\
Theory & - Results in receipt of desired rewards \\
& - Not redirected/does not result in consequences \\
\hline & Physical/emotional sibling violence is described as: \\
Radical & - Justified means for the more powerful person in a dyad/situation to get what they \\
Feminist & want \\
Theory & - Due to a power differential (i.e., physical strength, intellectual/emotional maturity, \\
& level of responsibility) between siblings \\
& - Giving a sibling a sense of control by overpowering another \\
Conflict & - Sibling violence is described as occurring in a setting in which siblings experience: \\
Theory & - Competition - for parental attention \\
& - Parental favoritism - one sibling gets better tangible/emotional resources \\
\hline & Sibling violence is described as occurring in a family system with: \\
Coercive & - Multiple concurrent dynamics among 3+ members \\
Family & - Family members embody stable roles \\
Process & - Mutual training - repeated, cyclical interpersonal reactions reinforce violence \\
& - Feedback loops - emotional, behavioral, or cognitive responses perpetuate violence \\
\hline
\end{tabular}

Linear theories employ reductionist methods to parse a theoretically knowable reality into discrete, measurable variables. Based on Humean causal law, linear theories describe chains of temporally bound relationships (i.e., if event $x$, then event $y$ ). The three linear theories included in the inquiry were social learning theory, radical feminist theory, and conflict theory. After discussing the resonance of the three linear theories with participants' descriptions of sibling violence in the context of child welfare, I will present the study findings related to a non-linear (i.e., systems-oriented) theory of sibling violence, coercive family process.

Social learning theory explains interpersonal violence as a behavior learned through observation that results in receipt of desired rewards and which does not produce 
negative consequences. As discussed in the previous sections on family conditions associated with sibling violence, participants and their siblings experienced considerable adult-perpetrated violence. In addition to learning through experience and observation, children gained a variety of rewards by engaging in sibling violence. Participants instigated violence to gain control of a television remote or an item of clothing, to get to eat the remaining food in the house, to take the last shower before the water was cut off, and to receive a gaming system (a reward one child's grandparents offered to him to encourage him to stop being violent with his sister). Another violent episode was triggered when a foster sister stole the participants' tablet computer. In other examples, children gained a sense of power or control in situations lacking parenting guidance or oversight. Rarely redirected, children were able to behave violently without being held accountable by adult caregivers.

The causal mechanism defined by social learning theory was represented in the data, but given the violent contexts that many child welfare-involved children endure, its primary use is to hone in on children's motivations for engaging in violence. Moreover, the theory does little to inform understanding of sibling violence as a dynamic process between two or more children that is replicated over time within context. Radical feminist theory and conflict theory, discussed next, are subject to similar limitations.

Radical feminist theory identifies patriarchy and the related, pervasive acceptance of the use of power and control to achieve desired aims as the causal mechanisms underlying interpersonal violence. Applied to sibling violence, radical feminism argues that any power differential between siblings such as in physical strength, emotional 
maturity, or assigned level of responsibility could foment violence. Whatever the perspective of the older, bigger, or more powerful sibling, the younger, smaller, less powerful sibling(s) must follow suit or suffer violent consequences.

Among seven of the eight participants interviewed, the primary instigator was older, bigger, or stronger than the sibling(s) they abused. In a situation where a participant's brother was abusive to three younger siblings, the participant related: “...because I was significantly taller than him... he didn’t try [to be violent with me]. But he was also significantly taller than all my other younger siblings... So having that towering effect was beneficial to him in that control over something or some people at least.” Employing her greater size and strength, the participant managed her brother's violent behavior by overpowering him physically. A power differential in age, size, and strength was particularly evident in three interviews where the primary instigator was an older brother who instigated violence with their younger sister. Each sister retaliated, whether verbally or physically, but was ultimately overpowered when their brother employed more extreme acts of violence or used a weapon. One brother destroyed his sister's prized possessions and pulled out clumps of her hair. Another emotionally abused and physically beat up his sister, while the third punched his sister and threatened her with a chainsaw. Across the interviews, the children who instigated or ultimately "won" physically violent exchanges tended to be taller, older, and/or physically stronger than the siblings they engaged in violence with.

As evidenced by the data, within a family configuration radical feminist theory is useful to understand why a child feels empowered to instigate violence, their choice of a 
sibling to target (i.e., one who is smaller/less powerful), and why a child succeeds in overpowering their sibling in an exchange. The theory is less helpful to identify the causal mechanisms underlying a child’s determination to engage in violence, and similar to social learning theory, fails to inform understanding of abusive sibling violence as a dynamic process, especially in multi-sibling families or when the sibling configuration is comprised of children who do not differ markedly (i.e., siblings who are close in age, size, etc.).

Conflict theory positions violence in the family as a reaction to perceived scarcity, assuming that humans are innately self-interested and will utilize any means necessary to obtain desired resources. Conflict theory is discussed in the literature as the causal mechanism underlying sibling jealousy, competition for parental attention, and the expectation that children share valued items. In the current study, the conflict theory code was applied to text units where participants described inadequate access to tangible resources and scarcity of emotional nurturance, including parental favoritism. All text units initially coded for conflict theory were subsumed within the drugs, alcohol, and mental health challenges code and the poverty code - by nature of their involvement in child welfare, every participant in the study was subjected to emotional and/or material scarcity. While conflict theory could prove useful in a general population study with more nuanced experiences of scarcity, it does little to extend understanding of the phenomenon among child welfare-involved youth.

Table 8 maps the linear theories onto the family conditions associated with sibling violence that were represented in the data. The utility of the linear theories to explain 
sibling violence beyond the family conditions would likely depend on the role of the individual or group applying the theory. While a therapist, intervention designer, or researcher could find social learning theory or radical feminist theory useful, a caregiver, case worker, or policy maker might find the primary and secondary family conditions adequate to inform their understanding or guide decision-making in practice.

Table 10

Final Set of Primary and Secondary Family Conditions for Sibling Violence in Child Welfare with Associated Linear Theories

\begin{tabular}{|c|c|c|c|}
\hline $\begin{array}{l}\text { Primary/ } \\
\text { Secondary }\end{array}$ & $\begin{array}{l}\text { Final Family } \\
\text { Condition }\end{array}$ & Final Definition & Linear Theories \\
\hline $\begin{array}{l}\text { Primary } \\
1\end{array}$ & $\begin{array}{l}\text { Modeling/ } \\
\text { Acceptance of } \\
\text { Violence }\end{array}$ & $\begin{array}{l}\text { Caregivers communicate that violence is an } \\
\text { appropriate solution to interpersonal problems } \\
\text { within the family system: } \\
\text { - Adult-perpetrated physical/emotional child } \\
\text { maltreatment } \\
\text { - Interpersonal violence (IPV) between adult } \\
\text { caregivers } \\
\text { - Caregivers condone sibling/peer violence } \\
\text { - Parent(s) favor one sibling (the instigator) }\end{array}$ & $\begin{array}{l}\text { Social learning } \\
\text { theory } \\
\text { Radical feminist } \\
\text { theory }\end{array}$ \\
\hline $\begin{array}{l}\text { Primary } \\
2\end{array}$ & $\begin{array}{l}\text { Drugs, } \\
\text { Alcohol, and } \\
\text { Mental Health } \\
\text { Challenges } \\
\end{array}$ & $\begin{array}{l}\text { Caregivers are mentally, emotionally, and/or } \\
\text { physically absent, failing to provide adequate } \\
\text { supervision }\end{array}$ & Conflict theory \\
\hline $\begin{array}{l}\text { Secondary } \\
1\end{array}$ & Poverty & Caregivers fail to meet children's basic needs & Conflict theory \\
\hline $\begin{array}{l}\text { Secondary } \\
2\end{array}$ & $\begin{array}{l}\text { Instigator } \\
\text { Characteristics }\end{array}$ & $\begin{array}{l}\text { Instigators experience behavioral, } \\
\text { developmental, and mental health challenges }\end{array}$ & N/A \\
\hline
\end{tabular}

After reviewing the linear theories of sibling violence, I examined coercive family process in relation to the data. The analysis focused on the extent to which this non-linear theory of sibling violence, or elements of the theory, could extend 
understanding of the causal mechanisms underlying the phenomenon in the context of child welfare beyond the family conditions and linear theories.

Coercive family process. Combining family systems theory with principles of operant conditioning and negative reinforcement, coercive family process theory employs the key systems concepts of holism, nesting, and non-linearity to examine interpersonal violence in relation to the whole family, including its context. Rather than targeting an individual member as the source of family discord, the theory conceives interpersonal violence to be the product of interactions among every member in the family. Individuals are described as maintaining stable roles within the family system, repeatedly engaging in a narrow set of behaviors. This role stability creates a state of relative equilibrium, producing a family-wide pattern of interaction. The pattern is comprised of multiple coercive processes that produce physical and emotional violence between/among various dyads and triads. Sibling violence results from the collective influence of all members, who are both influenced and constrained by their context.

Holistic analysis via constant comparison between the interviews and the family maps demonstrated substantial resonance between coercive family process theory and the data. All eight participants described multiple, concurrent, stable behavioral interactions among three or more family members that created a repeated pattern of violence among caregivers and children. Four stable roles were represented in the data. Parents and caregivers were modelers and fortifiers, often due to un-/under-treated mental health and addiction challenges. Modelers demonstrated how to behave violently through adultperpetrated child maltreatment, engaging in violence with their adult partner(s), or both. 
Fortifiers condoned sibling violence, either by rewarding children through verbal encouragement or passively allowing the behavior to occur without consequence. Many caregivers embodied both roles.

Children also demonstrated two stable roles. Instigators were the children who initiated violent interactions with their siblings. They were prone to behaviors associated with various mental health diagnoses and disabilities and were typically bigger and more physically powerful than the siblings they initiated violence with. When instigators had multiple siblings, they sometimes served as secondary modelers to younger siblings who then instigated physical or emotional violence with other children in the family system. Retaliators were the children who responded to instigators, typically as an act of selfpreservation. Instigators and retaliators employed violence to rescue other family members from instigator-perpetrated violence.

With regard to families’ community contexts, most lived in low-income communities and some experienced community violence due to high rates of drug use or gang activity. Caregivers who were employed worked in low-wage jobs; many were unemployed and some sold or bartered drugs to supplement their income. Children experienced bullying in their neighborhoods and schools. In the sections that follow, three synthesized typologies of family systems drawn from the most salient findings in the data demonstrate how the four family roles can manifest in child welfare-involved families to produce patterns of sibling violence.

In the family system displayed in Figure 7, two sisters live with their biological father who regularly disciplined them with beatings until he hurt his back at his 
construction job. He is addicted to pain medication and has been out of work for more than a year. The family has been evicted several times and their food stamps do not adequately meet their needs. Between apartments they live out of their car and the sisters are bullied at school for poor hygiene. Weekly, and sometimes more often, Sister 1 becomes overwhelmed by their circumstances, emotionally shaming her father for failing to provide for the family. Sister 2 wants to preserve her father's dignity, so she instigates violence by hitting Sister 1 . This triggers a physical fight that escalates until one or both sisters are physically harmed. Their father, whose physical mobility and mental clarity are compromised by the pain medication, does not intervene. The pattern persists until the sisters are removed to foster care due to neglect and placed separately. Both sisters engage in sibling violence in foster care.

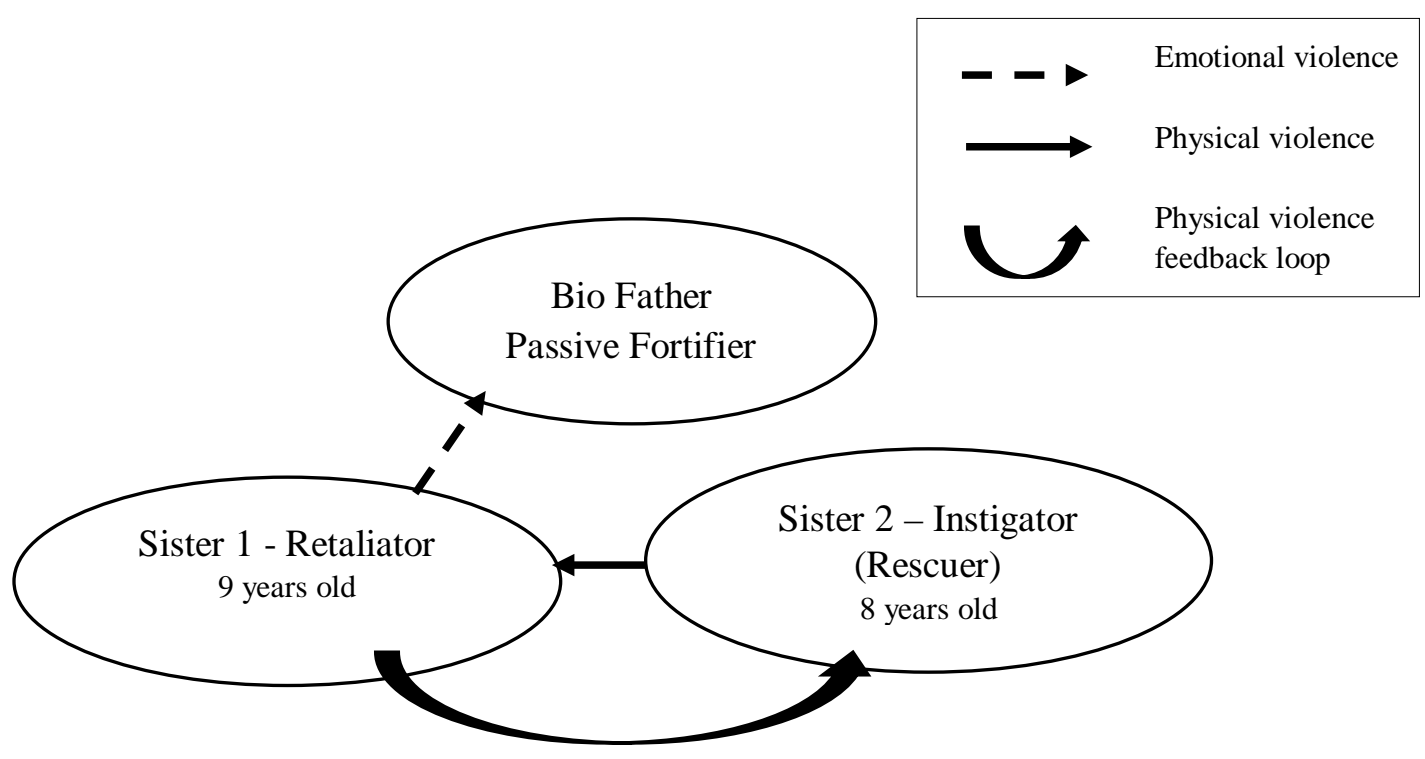

Figure 7. Two biological siblings and their father.

Figure 8 presents a kinship care setting where a foster child has been placed with her aunt, uncle, and their two biological children. Her parents lost custody due to their 
methamphetamine addiction. Before being removed she observed numerous fights between her biological parents and was physically and emotionally maltreated. The foster family lives in an apartment in a low-income community and only has two bedrooms. Brother already slept on the sofa so Sister could have her own room. Sister now shares her room with Foster Sister and takes it out on her by destroying her belongings and shaming her about her parents. Foster Sister responds to Sister's behavior with physical violence. Brother takes Sister’s side, retaliating with physical violence. He’s been getting bullied at school and it feels good to get his anger out. Bio Dad/Uncle works long hours at a factory to support the family. He can hear the noise in the other room but doesn't have the energy to do anything about it. The physical violence between Brother and Foster Sister escalates until Bio Mom/Aunt intervenes with a bribe (e.g., the children can all stay up an hour later if they stop fighting). The pattern of violence persists until Foster Sister's aunt and uncle decide they can’t handle caretaking a foster child - she is removed to a new foster home with five other foster siblings. It is not a good situation but she is about to age out of care and her social worker seems to have other priorities. 


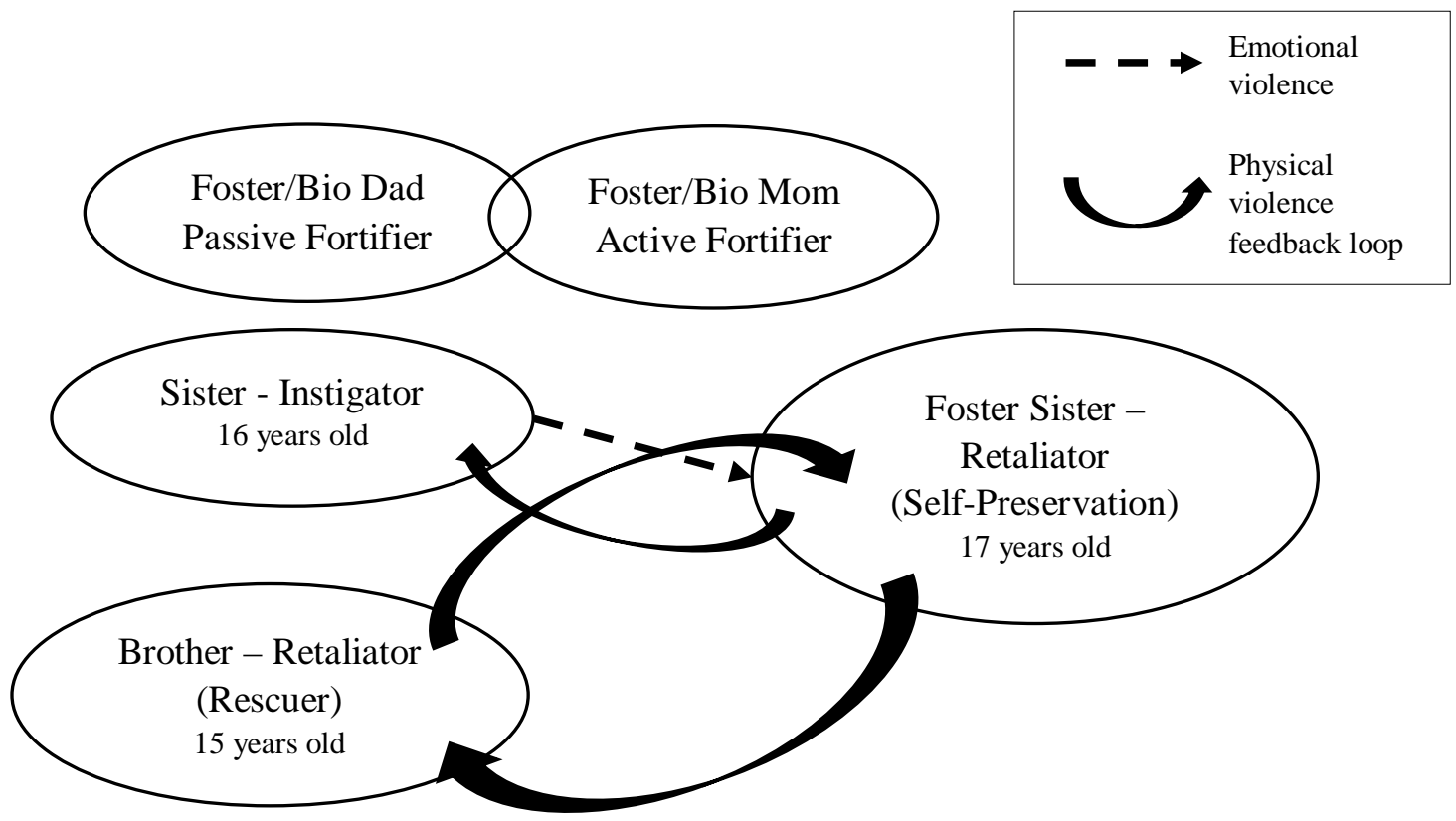

Figure 8. Kinship care setting with two biological siblings and their foster sister.

Figure 9, the final example, presents a biological family system prior to the children being removed to foster care. Dad is in the military and has completed several tours. When he is home he has been increasingly violent with mom, giving her a black eye in their most recent fight. Mom started drinking to manage her stress and she often leaves the children unsupervised. Both mom and dad have used beatings with belts and other objects as a form of discipline over the years. Brother 2 has been violent since he was a toddler, hitting, pinching, and kicking his younger siblings. Mom used to intervene (and so did dad, when he was home), but for the past several years that has been Brother 1's responsibility. Usually he grabs Brother 2 and hits him several times before locking him in the closet - sometimes it takes a very long time for him to calm down and be let out. Brother 3 has tried to retaliate against Brother 2, but he's much smaller and Brother 2 just laughs at him. Brother 3 takes his anger out on Sister with emotional violence. Most 
recently he killed her pet hamster and threw it at her. When she told her mom what had happened, mom told her to heed her brothers - they are the men of the house while dad is away.

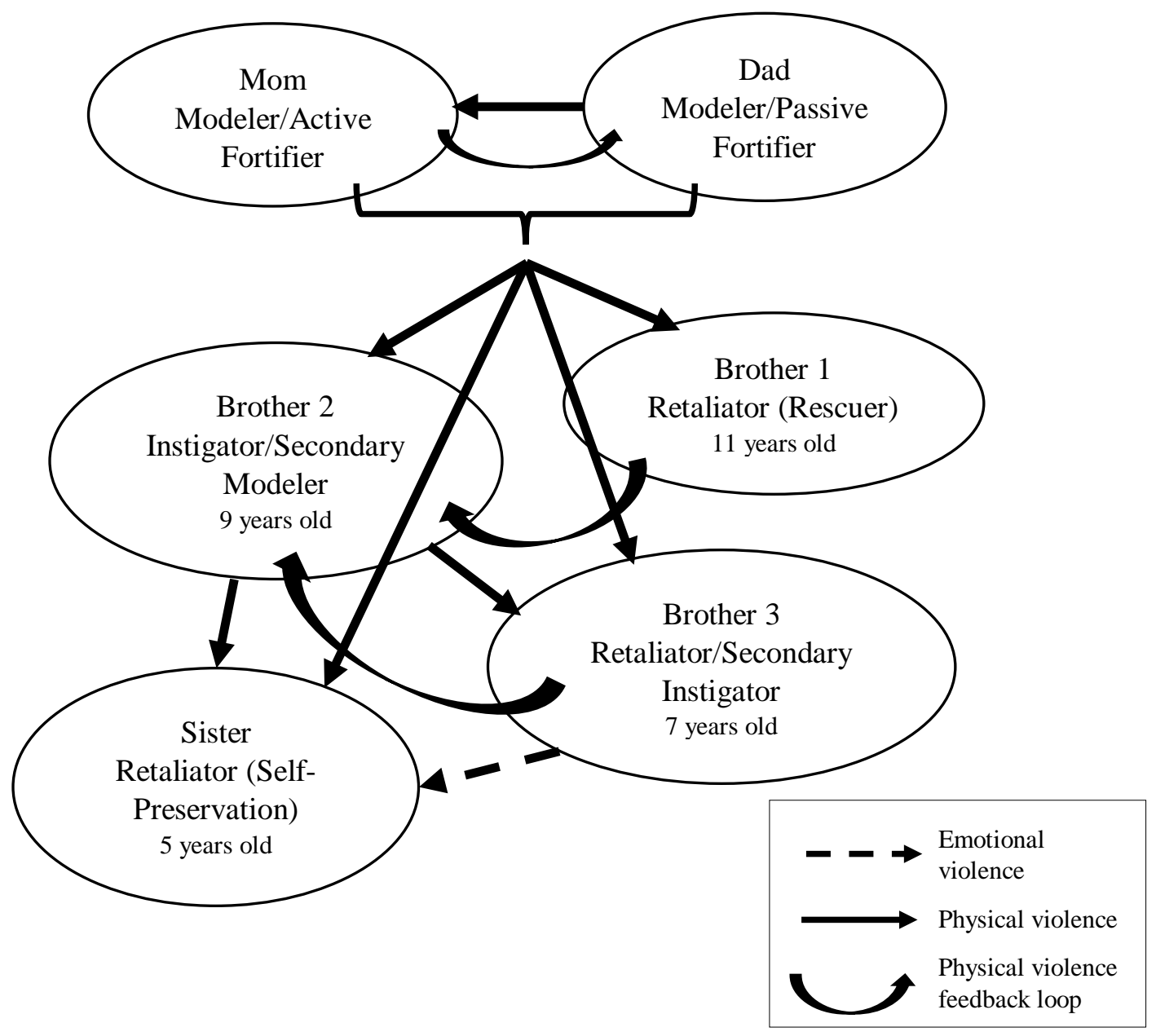

Figure 9. Biological family with four siblings.

As evidenced by these hypothetical family system examples, coercive family process theory is helpful to understand sibling violence as a family-wide pattern of interaction that is influenced by the community context. The theory supports a more holistic analysis of the problem, expanding beyond the family conditions and linear theories to assess how all members in the family system, including key contextual 
factors, contribute to sibling violence. Family system maps that display member characteristics, interpersonal violence, and reinforcing feedback loops are a useful tool to examine how the theory applies, both within and across families.

Research Question 1 sought to elucidate how the foster care alumni experienced sibling violence, and to determine the extent to which their experiences resonated with the family conditions and theories discussed in the general population sibling violence literature. The analysis produced a nascent, refined definition and a reduced set of four key family conditions for sibling violence in the context of child welfare. Moreover, the results underscore the utility of a non-linear theory to understand the phenomenon as a complex, synergistic, and dynamic socio-behavioral process. Coercive family process theory effectively transcends the family conditions and linear theories to holistically incorporate the roles and behaviors of all family members with consideration for the family context. In sum, this non-linear theory offered the most resonant reflection of the causal mechanisms of sibling violence among child welfare-involved families as represented in the data. Subsequent sections present the results for Research Question 2. Research Question 2. From the perspective of foster care alumni, how do adults who care for or work with young people involved in the child welfare system (e.g., foster parents, case workers, mental health providers, kinship caregivers, etc.) respond to sibling violence?

Inadequacy of adult responses to sibling violence in child welfare. Study participants were asked to describe adult responses to sibling violence and their perceptions of the helpfulness of the responses. Just one participant able to recall a 
caregiver who effectively addressed sibling violence. The intervention served to interrupt physical violence between the participant and her sister, but they continued to engage in emotional violence. Participants were more apt to report that the adults in their lives, including mandatory reporters and kinship/foster caregivers, did not intervene into sibling violence when it occurred. Four participants did not recall any adult intervention into their abusive sibling relationships. When caregivers, caseworkers, and law enforcement did respond to sibling violence, their responses were inadequate, failing to ensure the safety of the children. Subsequent sections present study results highlighting the inadequacy of adult responses to sibling violence in the context of child welfare.

Caregiver responses. Among participants who experienced adult intervention into sibling violence, two described ineffectual verbal redirections from caregivers that did not interrupt individual exchanges or the pattern of violence over time. For example, one participant’s mother said, "If you're going to fight go outside.” Another participant was involved in family meetings guided by her adoptive parents that deteriorated into "everybody yelling" and the children being sent to their rooms. A participant who was physically and emotionally abused by her foster siblings reported it to her foster mother who then sided with her siblings.

Just one participant discussed a helpful caregiver response after she and her sister were placed in kinship care:

My aunt, she came home from work that day that we got in a huge fight and said, "You guys may have used to hit each other and that's how you dealt with your problems but that's not how we're going to deal with them here." She just kind of 
talked to us about how hurting each other isn't the way to do it... And since we had so many rules and all this stuff. Our caseworker was always around. I just felt like the rules were way more important... I was just like, “I don't want to mess anything up." ...I didn't want her to have to call the caseworker because we were hitting each other... she had like, a SWAT behind her. It was more impactful. From the perspective of this participant, clear expectations from her aunt, coupled with an engaged caseworker who was perceived as a strong backup, effectively interrupted the sibling violence.

Caseworker responses. Four participants discussed responses to sibling violence after child welfare reports were made. Two participants personally informed their caseworkers that they were being abused by their siblings. After being returned to her biological mother’s care one participant reported her biological brother but her "social workers would literally blame it on [her mom] or blame it on [her].” Another reported her foster siblings and had recordings and pictures as evidence to back up her claim, but "[caseworkers] see no point [in addressing the problem] because I was gonna age out and they... don’t want to go through the paperwork and stuff like that." Caseworker responses to sibling violence reports were limited to two reports that adults filed, and which resulted in sibling separation. One participant was placed in a new foster home while her brother, who had enacted more frequent and extreme acts of violence, remained with their kinship caregivers. Another was glad to have been removed because she was afraid of her brother, but was then forbidden from having any contact with him: 
That was worse than taking me away from my mom. The one person who has been consistent in my life, I can’t even talk to on the phone? I was like, “I understand where you're coming from because I don't want to be abused anymore, but he can’t jump through the phone. If he starts saying stuff all I have to do is hang up." But they were like, "We're not letting you talk to him.” The only respondent who discussed a moderately helpful child welfare intervention attended a family session as a supplement to her sister's individual therapy. She recalled, "I remember liking it. I remember thinking that it was good, and that we should express to each other more,” but never had another opportunity as family therapy was not repeated. Two participants disclosed that they had intentionally avoided disclosure to their caseworkers because they were afraid of being separated from their siblings.

Law enforcement. Three participants discussed police intervention. Two participants, one in kinship care and another in foster care, had an adult caregiver call law enforcement because a sibling was wielding a weapon. In both cases, the response kept siblings safe in the moment, but the children did not receive any further intervention or follow-up. In both cases the violence between siblings continued until the siblings were separated. A third participant who was living alone with her brother called the police during a particularly violent incident. Shortly after arriving the officers determined that there was not an adult in the home and left her alone with him:

I was like, "What is this world? How can you just sit there? That's a danger to my safety.” I was literally crying, 9-1-1. I called 9-1-1. I was like, "My brother is 
beating me up!” It was really bad. I was really upset when they didn’t do anything about it... calling the police should have been a huge game-changer. Before that, I can understand that maybe it wasn't as clear. Maybe the social workers or parents or people involved, outside of us, maybe they didn't see it happening because it was behind closed doors and nobody would know, but once the police have been called it should be intervened... [The officers] literally stayed there for one minute and left.

In this situation the officers did not perceive sibling violence to be a true threat to the child. It is notable that they opted to leave the child in the home with her abuser after she so clearly communicated that she feared for her safety. The officers notified child protective services of the child's living circumstances and she was placed in foster care shortly afterward.

Survivors' recommendations to address the problem. Given the limited response of caregivers, child welfare practitioners, and law enforcement, it is not surprising that participants' recommendations were simple and practical. Two participants called out caregivers for failing to address the problem, recommending that they intervene when siblings are being violent by "actually taking hands into the matter, actually trying to do something" or by "teach[ing] people in general what discipline and consequences are.” Another offered that "Somebody should have said... maybe let's figure out what's going on... what are the factors that are playing into this issue? And who can we get [sibling] connected to, that could offer support?” Four participants 
suggested that improved communication among siblings, facilitated by their caregivers, would be helpful. Another wanted to talk things through with her foster sibling one-onone "to find a solution together." One participant noted that none of her siblings had access to a CASA (Court Appointed Special Advocate) while they were in foster or adoptive care, one of two who recommended youth mentorship as a solution. Mentors were identified as a potential resource outside of the family system to talk with about sibling violence, identify workable solutions, and to advocate for appropriate action. Three participants suggested education about sibling violence for adults who work with and care for children.

The study participants reported little if any adult intervention into sibling violence. Moreover, that which was offered was not effective, especially in the long-term. The only examples that successfully ensured sibling safety included sibling separation, but participants lamented lost contact with their siblings and the lack of follow-up to heal their relationships once separated. Given the inadequacy of adult responses, participants advocated for straightforward solutions: increased attention to the problem, direct action to intervene, and support to maintain and strengthen their sibling relationships. These findings reflect a significant gap in awareness that is negatively impacting children involved in child welfare.

\section{Results of CR Retroduction}

The first two phases of analysis, thematic analysis and abduction, produced three key findings based on the resonance between participants' descriptions of sibling violence and the definitions, family conditions, and theories in the literature: (1) a more 
nuanced definition of abusive sibling violence in the context of child welfare; (2) a refined set of four key family conditions (two primary and two secondary) associated with sibling violence, and; (3) a non-linear theory to explain how the phenomenon manifests within families. These analytic activities also generated information about affected youths' experiences with adult intervention into sibling violence and their recommendations to more effectively address the problem. Collectively, the findings offer insight into sibling violence in relation to existing theoretical frameworks and concepts, with emphasis on the CR “actual” domain of reality that attends to people's motivations for doing things.

To stop analysis here would be an epistemic fallacy, failing to consider the deeper causal structures and mechanisms underlying events observed empirically through the indepth interviews. In the CR process of retroduction, the researcher applies rational judgment to investigate the social conditions under which the causal mechanism(s) of a given phenomenon take(s) effect. The primary goal of retroduction is to modify, support, or reject existing theories to provide the most accurate explanation of reality. Danermark et al. (2002) offer four guiding questions for retroduction, which I revised to apply to the current study: (1) What is fundamentally constitutive for the structures and relations of abusive sibling violence? (2) How is abusive sibling violence possible? (3) What properties must exist for abusive sibling violence to be what it is? (4) What causal mechanisms are related to abusive sibling violence? I applied the questions to assess the extent to which the child welfare system achieves its multi-fold purpose of ensuring the safety, permanency, and wellbeing of children within the broader U.S. political-economic 
context. I built the retroductive analysis from the two primary family conditions associated with sibling violence in the data (i.e., adult modeling/acceptance of violence and un-/under-treated drug, alcohol, and mental health challenges among caregivers). I selected these family conditions because they offered the most accessible in-roads for emancipatory action among child welfare-involved families, an approach well-aligned with the emphasis on critique in $\mathrm{CR}$.

Child maltreatment in political-economic context. For much of modern history child maltreatment lived in the shadows, a phenomenon largely ignored. Then, in the 1960s "battered child syndrome” (i.e., a pattern of multiple fractures in the long bones of very small children) was discovered by pediatric radiologists (Shireman, 2015). This discovery horrified the public and new laws were established to protect children from physical abuse. Passage of the Federal Child Abuse Prevention and Treatment Act of 1974 identified “mandatory reporters” (i.e., working professionals required to notify child protective services of suspected maltreatment) and allocated funding to states to develop child protection programs. This legislation, along with newly developed state laws and media publicity, were highly effective in bringing the issue to light. Child maltreatment reports increased from 416,000 in 1976 to 3.4 million in 2011, an 800 percent increase (Kudashin and Martin, 2009 as cited in Shireman, 2015).

During the same time period, the U.S. experienced two financial crises with substantial political-economic effects. In response to the first crisis in the mid-1970's neoliberal ideology took hold in American politics, fueling economic and social policies 
in support of free market capitalism and rendering substantial cuts to social welfare funding that have persisted to present day. As described by Abramovitz (2014, as cited in Abramovitz and Zelnick, 2015):

...in the 1970s the elite blamed "big government," and especially the welfare state, for their financial woes. Seeking to restore growth and profits by redistributing income upwards and downsizing the state, they sought to undo the New Deal and Great Society programs that they regarded as unwieldy, socially ineffective and too expensive. The now familiar retrenchment tactics included (1) tax cuts, (2) retrenchment of social programs, (3) devolution (shifting social welfare responsibility from the federal government to the states), (4) privatization (shifting social welfare responsibility from the public to the private sector), (5) support for traditional "family values" and a color blind social order and (6) reducing the influence of social movements best positioned to resist this austerity program.

According to neoliberal ideology, social problems are the responsibility of the individuals who experience them and infinite economic growth is paramount to the needs of children and families. Rather than adequately resource the social service system through robust policies that benefit the citizenry, family problems are treated as individual failures deserving the bare minimum of state-funded support. The broader system is structured to benefit the wealthy through policies that privilege capitalist interests over the public good. As evidence of this ideological shift, from 1980 to 2013, federal discretionary 
spending for human services dropped from 5.1 percent to 3.5 percent of GDP

(Congressional Budget Office, 2014 as cited in Abramovitz and Zelnick, 2015). Less

obvious are the many national and international economic policies that funnel resources away from individuals and communities in service to a free market economy.

Neoliberalism has allowed for a systematic dismantling of the social welfare system (Tonry, 1995; Wacquant, 2009; Western, 2006 as cited in Kim, 2013) with substantial implications for child welfare. States have responded to funding shortfalls by narrowing their definitions of what constitutes child maltreatment. Focusing attention on the most serious cases, most financial and human resources are allocated to reactive responses to imminent harm despite research demonstrating that prevention-based interventions are most effective (Shireman, 2015). Many children and families with substantiated maltreatment cases receive no services at all. Among those that do receive services, they are often inadequate to address complex needs (i.e., short-term, focused on a single issue). Training and retaining skilled child protective service caseworkers is also a challenge. Large caseloads and significant emotional labor place considerable stress on caseworkers who are perennially expected to do more with less. As the social service system increasingly rewards efficiency, performance, and accountability, practitioners must dedicate ever more time to tracking outcome data, further increasing workload while detracting from direct service (Abramovitz and Zelnick, 2015). Turnover commonly exceeds 30 percent, further increasing demands and undermining good practice among those who remain (Nissly, MorBaarak, and Levin, 2005 as cited in Shireman, 2015). In addition to undermining family wellbeing, members of the human 
service workforce who are disproportionately comprised of women and people of color suffer low wages, high stress, and burnout (Abramovitz and Zelnick, 2015).

These systemic shortcomings have spanned an era of increasing challenge for American families. Four decades of neoliberal economic policy have produced vast increases in income inequality, stymieing working families’ best efforts to move out of poverty (Rogowski, 2012). A series of national drug epidemics (i.e., crack cocaine, methamphetamine, pharmaceutical/opioid) coupled with a poorly funded behavioral health system have further undermined family wellbeing. Employing CR retroduction to engage critically with the phenomenon, one can logically surmise why child welfare has struggled to address all forms of child maltreatment including abusive sibling violence. By placing the onus on an under-funded and reactive social safety net to solve social problems that are, from a more radical point of view, structural in nature (Mehrotra, Kimball, and Wahab, 2016), neoliberalism operates in an oppressive function while maintaining the false narrative that the citizenry will benefit from upward income redistribution. Figure 10 summarizes the results of the CR retroduction phase of analysis, organizing the three domains of reality with the iceberg metaphor. As shown, the deep causal structures that make violent sibling interactions possible constitute the neoliberal political-economic mechanisms that have gutted the social safety net, including the child welfare system. 


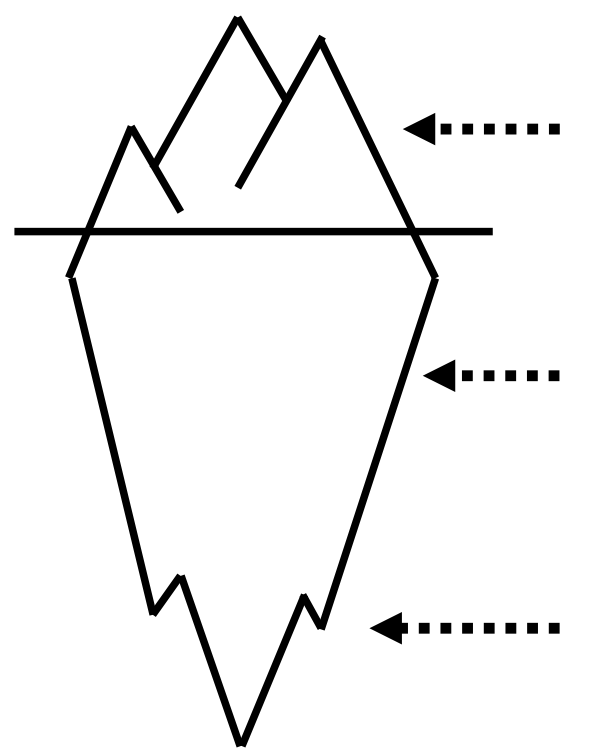

Empirical domain: Interview participants’ descriptions of sibling violence.

Actual domain: Economic disparities and an under-resourced social safety net limit adults’ ability to intervene.

Real domain: Neoliberal political-economic mechanisms drive social and economic policies that privilege capitalist interests over the public good.

Figure 10. Retroduction results summarized in terms of the three domains of reality.

In summary, key findings included a refined, nascent definition of abusive sibling violence, four family conditions associated with sibling violence, and a family systemsbased theory of sibling violence with four stable roles in the context of child welfare. From the perspectives of the foster care alumni interviewed, very little was done to address sibling violence by the caregivers and providers involved in their lives. The final phase of CR analysis, retroduction, identified neoliberal political-economic mechanisms as the deep causal structures that make violent sibling interactions possible. Chapter 5 presents recommendations informed by all three phases of analysis to address sibling violence in the context of child welfare and beyond. 


\section{Chapter 5: Discussion}

As presented through the experiences of the eight foster care alumni who participated in the interviews, abusive sibling violence is a problem worthy of increased attention in the context of child welfare. The participants described living in impoverished families, regularly evicted and without adequate access to basic needs like food and stable housing. Caregivers struggled with serious un-/under-treated drug, alcohol, and mental health challenges, subjecting children to horrific physical and emotional abuse. Without adequate supervision, siblings engaged in patterns of abusive physical and emotional violence within family-wide coercive processes that spanned changing family configurations and years of their young lives. Once removed to out-ofhome care, siblings who were co-placed continued to engage in abusive sibling violence; children who were placed with foster siblings experienced physical and emotional sibling violence in those relationships as well.

Participants' descriptions of sibling violence expose a source of "serious harm" that falls within the federal definition of child maltreatment. ${ }^{14}$ Given that many child welfare-involved youth experience the family conditions associated with abusive sibling violence in the data (i.e., violence modeled by adult caregivers, inadequate supervision due to caregivers' un-/under-treated behavioral health challenges), sibling violence is likely to be common among foster children. The study results support the notion that

\footnotetext{
${ }^{14}$ Child maltreatment is defined as "Any recent act or failure to act on the part of a parent or caretaker which results in death, serious physical or emotional harm, sexual abuse or exploitation; or an act or failure to act, which presents an imminent risk of serious harm” (U.S. Department of Health \& Human Services, 2016, p. viii).
} 
there is a necessary role for social work in addressing physical and emotional sibling violence, yet based on the current sample, child welfare can do much more to protect children from sibling-inflicted abuse. Among the young people interviewed, only extreme acts of physical violence were addressed, and only in some cases. The interventions applied, whether emergency response by law enforcement or therapeutic supports, were inadequate to stop the behavior long-term. The only intervention that effectively interrupted physical sibling violence was separation to different home settings. This was applied without support to maintain or heal the sibling relationship(s), and in some cases emotional sibling violence persisted through long-distance contact.

The lack of adult attention to sibling violence discussed in the interviews is not surprising, given that this form of interfamilial abuse has failed to penetrate discourse on family safety and wellbeing. Despite more than three decades of compelling scholarship demonstrating a variety of deleterious effects among siblings in the general population, "social norms around the acceptability of sibling aggression have likely discouraged interest in [its] prevalence and severity” (Tucker et al., 2013, p. 214). Most states lack specific laws protecting children from their siblings, providing mandated reporters and child welfare caseworkers with little guidance as to how to interpret child abuse statutes in cases of abusive sibling violence (Meyers, 2014). A focus on the parent as the primary point of intervention may further influence caseworkers to overlook harmful sibling relationships.

In cases where abusive sibling violence comes to the attention of a child welfare worker, their ability to provide needed services is hampered by numerous structural 
factors. As a result of the neoliberal economic-political project, child welfare already struggles to respond in a timely or effective manner to adult-perpetrated maltreatment cases. Therapeutic supports are rationed to children with extreme needs and are typically provided to an individual child rather than a sibling group or the whole family. Interventions focused on sibling relationship quality among foster youth are in the early phases of development, leaving workers with few options to support siblings to change behavior or heal from past trauma. Despite these barriers, in recent years, attention to abusive sibling violence has increased in child welfare. Shadik et al. (2013) recommend including discussion of sibling violence in child abuse and neglect parent education curricula, while Perkins and O’Connor (2016) advocate for attention to sibling violence in family-focused interventions. These ideas offer a useful starting point but given the potential for sibling violence to exact harm, additional effort is warranted. The following sections offer recommendations for child welfare.

\section{Raise Awareness and Provide Basic Training for Adults Charged with Ensuring}

\section{Family Safety}

The notion that sibling violence is a form of abuse is a new idea for child welfare. Without understanding what constitutes physical and emotional abuse between siblings, those who are charged with ensuring the safety and wellbeing of children and families (i.e., caregivers, mandatory reporters, caseworkers, crisis service providers, and clinical interventionists) will continue to overlook the problem. The results of the current study offer a starting place for child welfare to begin raising awareness of abusive sibling violence and providing basic tools to intervene. Training on the nascent definition, 
traumatic effects, and primary and secondary family conditions associated with sibling violence could significantly increase the likelihood that caregivers and providers will identify abusive sibling violence when it occurs. Ready contexts for such training include undergraduate and graduate degree programs, new employee onboarding and in-service trainings for direct service practitioners, licensure processes for clinicians, and Foster Parent Training (FPT) programs.

\section{Refine and Adopt a Definition of Abusive Sibling Violence in Child Welfare}

Without a clearly articulated and nationally-adopted definition of what constitutes abusive sibling violence, child welfare workers will have difficulty identifying the problem in the families they work with. It will not be possible to systematically track prevalence data, and sibling violence scholars and researchers will have difficulty bringing the results of individual studies into conversation with one another. The current study offers a nascent definition of abusive sibling violence in the context of child welfare: a repeated, escalating pattern of violent interactions between/among two or more siblings that results in physical or emotional harm to at least one child, regardless of the child's perception of the violence as it occurs. The definition builds from the work of more than three decades of sibling violence research and scholarship in the general population, while adding refinements that take into consideration the contexts of foster children’s lives. A sibling violence working group comprised of experienced caregivers, practitioners, scholars, policy makers, and young people with lived experience could collaboratively refine the definition and facilitate efforts to ensure that it is nationally adopted and universally applied. 


\section{Systematically Assess and Track Abusive Sibling Violence Among Child Welfare- involved Families}

Sibling violence is currently recognized as the most common form of intrafamilial abuse in the general population, with various estimates suggesting that 30 percent or more of children experience severe acts of sibling violence each year (Caffaro, 2014; Finkelhor et al., 2006; Straus et al., 2006; Tucker et al., 2013). Studies have demonstrated that sibling violence commonly co-occurs with adult-perpetrated child maltreatment and interpersonal violence between adult caregivers (Henning et al., 1997; Spaccarelli et al., 1994; Wallace, 1999; Wiehe, 1997). A small number of studies support the notion that maltreated children are likely to engage in sibling/peer violence (Linares et al., 2007; Linares et al., 2015; Shields \& Cincchetti, 1998, 2001), yet the National Child Abuse and Neglect Data System (NCANDS) does not capture sibling abuse rates. To accurately identify cases, determine the scope of the problem, and appropriately allocate resources to prevention and intervention, a sibling violence assessment tool specific to child welfare-involved families should be developed, validated, and systematically incorporated into maltreatment investigations and treatment planning. Informed by the results of the current study, the measure should account for maltreated children’s desensitization to interpersonal violence. Substantiated cases can then be incorporated into state data systems, aggregated nationally, and used to devise national and state policies that support child welfare-involved siblings in developmentally- and culturally-appropriate ways. 


\section{Revisit Child Welfare Co-Placement Policy}

Research has demonstrated that sibling co-placement offers numerous benefits to child welfare-involved youth and current federal child welfare policy recommends that siblings be placed together whenever possible. In the absence of adequate consideration for abusive sibling violence, child welfare is applying an approach to care that appears to be failing to protect children from sibling-inflicted trauma. To ensure that the system provides adequate protections to children in foster care, co-placement policies should be revisited such that cases where co-placement is not warranted are clearly defined and ensure the agency of children to self-determine the level of contact with their siblings. Mandated supports for children who have experienced sibling violence should be incorporated into child welfare policies, undergo pilot testing, and include rigorous, youth-informed evaluation to ensure effectiveness and identify unanticipated outcomes. While sibling violence intervention research is limited, examples of potentially efficacious offerings include individual, sibling, and family therapy, as well as the programs discussed below.

\section{Invest in Programs to Ensure Safe, Strong Sibling Relationships for Child Welfare- Involved Youth}

Sibling relationships are developmentally significant in childhood and across the lifespan. Young children learn social understanding through sibling exchanges and the quality of those exchanges influence adjustment. In early childhood, social and emotional development, identity, and attachment are significantly affected by the sibling relationship (Bank, Burraston, \& Snyder, 2004; Caffaro, 2014; Feinberg et al., 
2013). Robust evidence of linkages between sibling relationship quality and peer acceptance and social competence in childhood exists, as well as school achievement and romantic relationships in adolescence (Feinberg et al., 2012; Feinberg et al., 2013; Pike, Coldwell, \& Dunn, 2005; Richmond, Stocker, \& Rienks, 2005). Supportive sibling relationships can serve a protective function, buffering against stressful life events such as accidents, illnesses, disasters, and parental conflict (Cummings \& Davis, 2002; Gass, Jenkins, \& Dunn, 2005). Participating in moderate sibling conflict and seeing it through to resolution through parent-facilitated mediation can teach children to negotiate and take another's perspective (Siddiqui \& Ross, 2004; Smith \& Ross, 2007).

Sibling relationships, if nurtured, can be the most long-term and consistent interpersonal connections in foster youths' lives. The many instructive and protective functions of healthy sibling relationships make a compelling case for investment in universal sibling supports for children involved in child welfare. Clinical interventions based on coercive family process theory hold promise to support families to remain intact. If out-of-home placement is necessary, sibling-focused interventions may reduce the trauma of separation from caregivers and increase the likelihood that children will maintain meaningful, supportive sibling relationships that last into adulthood. The study participants recommended that child welfare intervene to maintain and strengthen their sibling relationships, with a self-determined level of sibling contact. If separation is required to ensure safety, children should be given agency to choose whether and how to stay in touch with their siblings and, if desired, provided with developmentally- and culturally-appropriate supports to heal and strengthen their sibling relationship(s). 
Interventions should be youth-informed, undergo pilot testing, and include evaluation to build effectiveness and identify unanticipated side-effects among demographic subpopulations.

\section{Inform and Engage the Public to Catalyze Community-Based Solutions}

The recommendations in previous sections focus on the child welfare system (i.e., practitioners, policy makers, and young people who have experienced maltreatment). While it is reasonable to begin addressing sibling violence by leveraging the extensive social welfare infrastructure already in place, the above recommendations will require a substantial, sustained investment from an already strained system. Moreover, it is likely that most sibling violence cases will never be reported to child welfare. American society values family privacy and social norms largely condone sibling violence (Tucker et al., 2013; Wiehe, 1997). Further compounding the issue, many parents and are not knowledgeable of the traumatic effects of physical and emotional sibling violence, dismissing the behavior as a normal demonstration if sibling rivalry that will pass as children mature (Meyers, 2014; Caffaro \& Con-Caffaro, 2005; Wiehe, 1997). Even in cases where a parent believes one child is inflicting abusive acts upon another, to bring the occurrence to the attention of the authorities they must file charges against one child on behalf of the other, a rare occurrence for obvious reasons (Eriksen \& Jensen, 2006).

Given these barriers, a broad-based social movement toward nonviolent sibling interactions could be a more impactful lever for social change. Informing the public with simple messaging about the harms that result from sibling violence and ways to communicate to children that it is not acceptable could reduce sibling violence over time. 
Aligning sibling violence mitigation efforts with anti-bullying campaigns and programs could expedite efforts to increase public awareness and drive collective action.

Incorporating sibling violence into community-driven solutions to interpersonal violence such as those arising from social justice movements could also prove fruitful. Just as interpersonal violence between adults and adult-perpetrated child maltreatment have penetrated public awareness as social problems worthy of attention and intervention, systematic information dissemination coupled with a sustained call for collective action could create a future in which sibling violence is no longer tolerated.

\section{Organize for a More Just, Equitable Society}

Much of sibling violence theorizing in the general population is based on an uncritical acceptance of current economic and social arrangements, focusing on individual, dyadic, and family factors. Yet the CR retroduction phase of analysis for this project and the critical anti-violence literature identify structurally violent social and economic policies as the real causal mechanism underlying actual and observable violent events within families. As demonstrated through CR retroduction, the deep causal mechanism at the root of sibling violence is neoliberal political-economic ideology, blocking individual agency to meet basic economic and behavioral health needs and limiting the capacity of the child welfare system to respond when family violence occurs. In the context of child welfare, efforts to mitigate family violence are also largely based on neoliberal ideology. The child welfare caseworker's intervention toolkit is predominantly focused on the family, devised to interrupt abusive behavior assumed to be due to individual characteristics and factors in the immediate environment. 
Researchers, theorists, and activists are increasingly advocating for systemic solutions to social problems in hopes of creating a more just, equitable society. Recent theoretical frameworks discuss a "crisis of modernity" in which the governing logics of neoliberal democracy have caused rampant human suffering such as the family conditions for sibling violence presented in the results of the current study (Cherry, 2018). ${ }^{15}$ A transdisciplinary community of innovators has proposed a variety of direct actions to confront and dismantle economic and political neoliberalism. In the field of social work, an American New Social Work Left advocates for eliminating engagement with neoliberalism's insidious form of “cruel optimism” (i.e., perpetuation of the fantasy of an achievable American Dream), militantly confronts neoliberalism’s economic and political forms, and encourages creative thinking to imagine an entirely different world (Cherry, 2018). The strength of these emergent strategies is in their acknowledgement of the entanglement of the complex problems we face. Increasing attention to the deep causal structures that produce inequity could ameliorate many of today’s most wicked social problems, including sibling violence.

\footnotetext{
${ }^{15}$ As a current example of the impact of neoliberalism on American life, the United Nations recently determined that the living conditions of the homeless population in San Francisco, one of the most affluent cities in the United States, is a violation of human rights (United Nations General Assembly).
} 


\section{Chapter 6: Conclusions}

Adult-perpetrated child abuse is generally viewed as a well-established social problem and public health concern, the reduction of which is "a moral imperative with clear benefits to children and society” (Lundahl, Nimer, and Parsons, 2006, p. 251). Since coming to the attention of the public in the 1970s, a decades-long process of incremental transformation has shifted perceptions about child maltreatment and significant infrastructure is now in place to protect children from adult-perpetrated harm. While this progress is commendable, physical and emotional sibling violence persist in the shadows, largely ignored. Positioned as the most common form on interfamilial violence, a compelling line of research has demonstrated that children exposed to sibling violence experience trauma symptoms and suffer deleterious effects across the lifespan.

Building on a decades-long line of research and scholarship focused on the general population, a small number of publications have recently implored social work, child welfare, and children's mental health to embrace the notion that sibling violence is a form of child maltreatment and take action to protect children from harm (Meyers, 2014; Perkins \& O’Connor, 2015; Perkins, 2016; Shadik, 2013). These entities have yet to reach agreement on what constitutes physical or emotional abuse between siblings and theorizing about its causes is similarly nascent. To begin to fill gaps in theory, practice and policy in the context of child welfare, I conducted in-depth interviews with eight foster care alumni who self-identified as having experienced physical or emotional sibling violence in their family of origin, or after transitioning into out of home care. The 
study was grounded in critical realism (CR) with the goal of identifying actions to protect children from sibling violence.

The study results offer much guidance to those committed to ensuring the safety and wellbeing of children. As represented in the data, sibling violence manifests differently in the lives of child welfare-involved youth as compared to the general population. The study participants were unique in that they had all experienced extreme physical and/or emotional violence exacted by adult caregivers in their families of origin; many also reported maltreatment in out-of-home care. Participants also lived in circumstances scarce of both instrumental and emotional supports. Building from the work of Caffaro (2011) and Meyers (2017), the interviews informed a refined, nascent definition of abusive sibling violence that reflects the social isolation, instrumental and emotional scarcity, and adult-perpetrated violence so common among child welfareinvolved families: A repeated, escalating pattern of violent interactions between/among two or more siblings that results in physical or emotional harm to at least one child, regardless of that child's perception of the violence as it occurs. The definition places the onus on the adults who care for and work with child welfare-involved youth to effectively inquire into sibling relationship quality and use what they learn to identify supports and guide placement decisions.

The study also examined the extent to which various individual and family conditions associated with sibling violence in the general population were represented in the interviews. Through constant comparison analysis, I identified four family conditions associated with sibling violence in child welfare: (1) modeling/acceptance of violence by 
adult caregivers; (2) un-/under-treated drug, alcohol, and mental health challenges among caregivers; (3) un-/under-treated instigator characteristics associated with various mental health diagnoses, disabilities, and developmental delays, and; (4) poverty. Given the prevalence of these conditions among child welfare-involved families, sibling violence is likely to be common, an idea with preliminary support in the literature (Linares, 2015). Yet data systems are not currently structured to accurately track abusive sibling violence and the rates documented by child welfare are much lower than other nationally representative sources. The study findings highlight a need for data system reform so that child welfare can accurately assess the scope of the problem and allocate resources to support children exposed to this form of abuse.

In addition to offering a definition of abusive sibling violence and identifying four family conditions associated with the phenomenon, the study results present sibling violence as a complex, synergistic, and dynamic socio-behavioral process in the context of child welfare. While the extant literature defines sibling violence in terms of a dyadic, unidirectional exchange with stable victim and offender roles, the study findings resonated most strongly with coercive family process theory. All eight participants described multiple, concurrent, stable behavioral interactions among three or more family members that created a repeated pattern of violence. Within the coercive family processes discussed, there was evidence of four family member roles: (1) adult and child modelers demonstrate how to behave violently; (2) adult fortifiers explicitly or implicitly condone sibling violence; (3) child instigators initiate violent interactions with their siblings, and; (4) child retaliators respond to instigators with reactive violence. Many adult caregivers 
were both modelers and fortifiers. In some cases, children were both instigators and retaliators, taking on different roles depending on the family configuration and contextual factors present at a given point in time. These findings suggest that holistic interventions that engage all family members are apt to be most effective, a notion well-aligned with participants' recommendations to address the problem. Study participants advocated for caregivers (and the adults who work with child welfare-involved youth) to engage in direct action to interrupt physical and emotional violence and support children to maintain and strengthen their sibling relationships.

Finally, CR retroduction exposed neoliberal ideology, and the associated practices and policies that have systematically dismantled the social safety net, as the deep causal structure that produces abusive sibling violence in the empirical domain. By constraining caregiver agency to meet basic needs and address behavioral health challenges and undermining the effectiveness of the child welfare system, the study participants and their siblings were exposed to a variety of harms and challenges and the entities charged with ensuring their safety and wellbeing lacked the fiscal and human resources necessary to meet their needs.

\section{Study Strengths}

The study was strengthened by engaging the perspectives of young people and blending CR with systems thinking.

Youth Perspectives. There is significant evidence that youth engaged in child welfare do not fare well, despite substantial efforts to ensure their safety, permanency, and wellbeing. Most research, scholarship, policy-making, and direct practice is carried 
out in the absence of consultation from the young people whose lives are so significantly impacted by the system. The current study attempted a youth-engaged and youth-guided approach, inviting foster care alumni with lived experience with physical and emotional sibling violence to contribute in a number of ways.

During conceptualization, a group of sibling study advisers from across the country participated in a series of conference calls to offer their recommendations for the research questions, methods, and data collection processes. In response to their guidance, I revised the initial study design to conduct individual interviews rather than focus groups and offered much more background about my own experiences with sibling violence than I had originally intended. I am confident that the data were much richer because of their guidance. I am also hopeful that their recommendations increased the likelihood that the young people who volunteered to be interviewed for the study will be open to contributing to research in the future.

The in-depth interview methods further strengthened the study in that the participants were able to describe their experiences in detail while also providing important contextual information about family and community circumstances they perceived as influencing sibling violence. This approach revealed a dynamic process replicated across family configurations and contexts. Their courageous offerings exposed a significant gap in child welfare that warrants multi-faceted, youth-informed attention and intervention. Their descriptions clearly demonstrate that much more can be done to address abusive sibling violence in child welfare, offering many inroads to facilitate safe, stable sibling relationships. 
Critical Realism. Grounded in a Critical Realist paradigm, the study brought the study participants’ experiences and perspectives into conversation with the linear and non-linear theories discussed in the extant literature. While the more common explanations of sibling violence rely on reductionist linear models (i.e., social learning theory, radical feminism, and conflict theory), the current project suggests that a theory inclusive of intrapsychic, relational, and sociocultural influences (Whitman et al., 2011) offers a closer approximation to the realities of abusive sibling violence in the context of child welfare. Among the families represented in the interviews, coercive family process theory resonated most strongly, a holistic accounting of the contribution of each family member, with consideration for immediate and more distal contextual conditions that influence sibling violence.

Subsequent to abduction, during the retroduction phase of CR I engaged critically with the data with consideration for the historic and political-economic context of the phenomenon. Through this final thought exercise, I was able to identify neoliberalism as the deep causal structure that makes sibling violence possible. From study conception to completion, employing CR enhanced the trustworthiness of the findings by demanding sustained engagement with the data through iterative thought exercises that facilitate critical analysis. This approach also supported me to identify actions for caregivers, practitioners, and policy makers to protect children from abusive sibling violence that span the dyadic to the societal levels of the social ecology.

Systems Thinking. The study was also strengthened by incorporating systems thinking, an emerging paradigm that includes a multitude of models, theories, and 
practices. As a systems-oriented researcher, I developed the study with attention to the key systems concepts of holism, nesting, and non-linearity, and executed data analysis and synthesis with heavy reliance on visual representations. After coding the interviews, I created a series of family system maps that displayed member characteristics, interpersonal violence, and reinforcing feedback loops. During abduction and retroduction, I sketched numerous diagrams representing interactions among socialecological structures discussed in the family violence literature, working back and forth between the theories and data. By thinking systemically, I was able to describe the movement, dynamics, and patterns of sibling violence as represented in the interviews and informed by deep causal analysis. Combining youth engagement with CR and systems thinking, the study offers practical insights and guidance for those invested in the safety and wellbeing of children.

\section{Implications for Future Research}

While there were many strengths in the study design, a key weakness was the lack of “extensive” data (i.e., data on widespread trends, typically gathered with quantitative data) to look for systematic differences across a population (Lennox \& Jurdi-Hage, 2017; Sayer, 2010). It was beyond the scope of a feasible dissertation to include such an approach in the current study, but given the findings of this project, a subsequent phase of extensive data collection is certainly warranted. Informed by the results of the current project, an extensive approach should account for the likelihood that young people may avoid disclosure because they: (1) are afraid of being separated from their siblings; (2) view sibling violence as normal due to their exposure to adult-perpetrated violence, social 
isolation, or failure of adult caregivers to intervene in sibling violence, and; (3)

participated in the violence by retaliating against an instigating sibling. In addition to gathering extensive data, more "intensive" research is needed to build on the results of the current study. The study results suggest that there may be a relationship between the extreme adult-perpetrated violence the participants experienced and their exposure to abusive sibling violence. This is a relationship that would benefit from additional inquiry, both in the context of child welfare and in the general population. Moreover, the current study did not explore the relationship between demographic characteristics such as race, ethnicity, or culture and sibling violence, another important area for future research.

\section{Implications for Social Work}

The current study has demonstrated that abusive sibling violence takes place in the context of child welfare, and those charged with ensuring the safety of children are not responding adequately. Given social work’s “Grand Challenge” to stop family violence (Kulkami, Barth, \& Messing 2016), efforts should be made to build attention to sibling relationship quality into scholarship, practice, and policy-making in social work, child welfare, and children's mental health. Social workers are already a touchstone in the lives of child welfare-involved youth. Though often overextended and underresourced due to a national political-economic context that privileges profit over family safety and wellbeing, even simple actions such as naming the behavior and stating that it is unacceptable could be highly impactful.

Social work would also benefit from a more radical stance on violence, embracing the notion that all forms of violence are harmful and conducting practice and policy with 
the goal of achieving a national culture of nonviolence. In cases of adult-perpetrated maltreatment, an essential component of an investigation is consideration for whether an adult has committed a crime and must be prosecuted in a court of law. The child welfare system has thus dedicated considerable effort to identifying specific violent acts that constitute adult-perpetrated maltreatment, necessitated by its relationship with the legal system. I caution against taking a similar approach to sibling violence, for it is not the extremity of an individual act of physical or emotional violence that impacts a child's brain architecture, but rather, continued exposure to violence in the absence of a supportive adult (Shonkoff et al., 2009). Too much focus on definitional exactitude may limit necessary attention to less extreme forms of violence and could diminish the likelihood of universal access to services for child welfare-involved siblings. Moreover, such an approach could undermine the level of agency the study participants requested, in determining if/how to interact with their siblings when the relationship includes a violent dynamic.

\section{Study Limitations}

All female sample. The study was exploratory and the participants self-selected through convenience sampling methods. While discussion of representativeness is not relevant given the epistemological underpinnings of the inquiry, it is notable that only female participants agreed to participate. There are a variety of reasons why this may have been the case, such as gendered differences in willingness to contribute emotional labor, availability of support for victims of violence, the discourse of violence in policy, practice, and theory, and norms for vulnerability and help-seeking. While it was not 
within the scope of the study to examine gender differences in relation to willingness to talk about sibling violence, the all-female sample has implications for future research. Violence is a gendered phenomenon and the inclusion of male, transgender, and nonbinary voices would likely have influenced the findings. As an example, masculineidentified individuals may be more apt to view sibling violence as normative, or see it as a beneficial skill-building interaction that supports survival with the family or community. Going forward, it will be important to identify ways to add male, transgender, and additional non-binary voices to research on sibling violence in the context of child welfare.

Individual perspectives. I conducted the interviews with foster care alumni who identified as having experienced sibling violence before and during foster care. In the exploratory spirit of the study, the only constraints I placed on the sampling criteria were to ensure that participants were over the age of 18 and spoke English at the time of the interview. The study findings are limited to the perspectives of the individuals interviewed, discussing what appears to be a family-wide coercive process of multiple dynamics involving children and caregivers. Gathering the perspectives of family members involved in a violent sibling dynamic would surely enrich understanding of the phenomenon, another area for future research.

Investigator limitations. There were many aspects of the study that I was attempting for the first time. While I began the project with experience conducting interviews, these were on a far more sensitive topic and covered significantly more 
breadth and depth than any I had done previously. As I transcribed the interviews and reviewed the transcripts, I noted missed opportunities to probe for additional clarification, and in some cases failed cover every question in the protocol. Every study has trade-offs; I compromised detail in order to cover more ground. Despite these shortcomings, the protocol successfully covered all the study questions. More importantly, participants appeared to be glad to have the opportunity to share their stories within a minimal structure.

This was also my first attempt executing a study grounded in critical realism. The CR literature was helpful to develop the methodology for the enquiry, but I found little guidance about how to carry out the retroduction phase of analysis and few articles where CR researchers discussed their process in enough detail for me to replicate it.

Retroduction blends analysis and interpretation, a tricky endeavor for any researcher. I felt least confident in this phase of analysis, consistently wondering if my own values were exacting too much influence on the results. I was fortunate to have the opportunity to dialogue (by email) about retroduction with a CR researcher in Canada who is currently publishing on the "nuts and bolts how to" of CR. Based on my exchanges with her, as well as the recommendations from my committee chair, I believe that I was ultimately able to complete the process in alignment with the spirit of the approach. 


\section{References}

Abramovitz, M. \& Zelnick, J. (2015). Privatization in the human services: Implications for direct practice. Clinical Social Work, 43, 283-293.

Administration for Children and Families, Division of Health and Human Services. (2016). The child abuse prevention and treatment act. https://www.acf.hhs.gov/sites/default/files/cb/capta2016.pdf

Allen, K.A. (2013). Understanding bullying in an affluent, academically rigorous U.S. high school: A grounded theory analysis. Journal of human Behavior in the Social Environment, 23, 413-436.

Archer, M.S. (1995). Realist social theory: The morphogenetic approach. Cambridge: Cambridge University Press.

Archer, M.S. (2010). Morphogenesis versus structuration: On combining structure and action. The British Journal of Sociology, 225-252.

Bandura, A., Ross, D. \& Ross, S. (1963). Vicarious reinforcement and imitative learning. Journal of Abnormal and Social Psychology, 63, 575-582.

Bank, L., Burraston, B., \& Snyder, J. (2004). Sibling conflict and ineffective parenting as predictors of adolescent boys' antisocial behavior and peer difficulties: Additive and interactional effects. Journal of Research on Adolescence, 14(1), 99-125.

Bank, L., Snyder, J., \& Prescott, A. (2002). Sibling relationship intervention in the prevention and treatment of antisocial behavior: Rationale, description, and advantages. Unpublished manuscript, Oregon Social Learning Center, Eugene, OR. 
Bank, L., \& Kothari, J. (2013). Sibling intervention for conduct-problem children: Benefits for both older and younger siblings. Manuscript submitted for publication.

Bates, S.R. (2006). Making time for change: On temporal conceptualizations within (critical realist) approaches to the relationship between structure and agency, Sociology, 20(1), 143-161.

Bhaskar, R. (1979). The possibility of naturalism: A philosophical critique of the contemporary human sciences. Atlantic Highlands, NJ: Humanities Press.

Bhaskar, R. (1998). Philosophy and scientific realism. In M. Archer, R. Bhaskar, A. Collier, T. Lawson, \& A. Norrie (Eds.), Critical realism: Essential readings (pp. 16-47). London: Routledge.

Bronfenbrenner, U. (1979). The ecology of human development: Experiments by nature and design. Cambridge, MA: Harvard University Press.

Brown, L. \& Strega, S. (2005). Research as resistance: Critical, indigenous, and antioppressive approaches. Toronto: Canadian Scholars’ Press/Women’s Press.

Butler-Kisber, L. (2010). Qualitative inquiry: Thematic, narrative and arts-informed perspectives. Thousand Oaks, CA: Sage Publications Inc.

Button, D.M., \& Gealt, R. (2010). High risk behaviors among victims of sibling violence. Journal of Family Violence, 25, 131-140.

Caffaro, J.V. (2011). Sibling violence and systems-oriented therapy. In J. Caspi (Ed.), Sibling development: Implications for mental health practitioners (pp. 245-272). New York, NY: Springer Publishing Company. 
Caffaro, J.V. (2014). Sibling abuse trauma: Assessment and intervention strategies for children, families, and adults, Second Edition. New York, New York: Routledge.

Caffaro, J.V., \& Conn-Caffaro, A. (1998). Sibling abuse trauma: Assessment and intervention strategies for children, families, and adults. Binghamton, NY: The Haworth Maltreatment and Trauma Press.

Caffaro, J.V., \& Conn-Caffaro, A. (2005). Treating sibling abuse in families. Aggression and Violent Behavior, 10, 604-623.

Caspi, J. (2008). Building a sibling aggression treatment model: Design and development research in action. Research on Social Work Practice, 18, 575-585.

Caspi, J. (2012). Sibling aggression: Assessment and treatment. New York: Springer.

Centers for Disease Control and Prevention, Division of Violence Prevention, National Center for Injury Prevention and Control (2014). Connecting the dots: An overview of the links among multiple forms of violence. Retrieved from http://www.cdc.gov/violenceprevention/pdf/connecting_the_dots-a.pdf

Cherry, K. (2018). Critical thoughts on American social work and the crisis of modernity: Lessons from theory and current events. Journal of Progressive Human Services, 29(1), 40-60.

Child Welfare Information Gateway (2013). Sibling issues in foster care and adoption. Washington DC: U.S. Department of Health and Human Services, Children’s Bureau. 
Cohn, M. (2008). Sibling placement: The importance of the sibling relationship for children in foster care. National Resource Center for Permanency and Family Connections Information Packet, New York, New York.

Courtney, M.E., Piliavin, I., Grogan-Kaylor, A., \& Nesmith, A. (2001). Foster youth transitions to adulthood: A longitudinal view of youth leaving care. Child Welfare Journal, 80, 685-717.

Cranley, L.A., Doran, D.M., Tourangeau, A.E., Kushniruk, A., \& Nagle, L. (2012). Recognizing and responding to uncertainty: A grounded theory of nurses' uncertainty. Worldviews on Evidence-Based Nursing, Third Quarter, 149-158.

Crick, N.R., \& Dodge, K. (1994). A review and reformulation of social informationprocessing mechanisms in children’s social adjustment. Psychological Bulletin, 115(1), 74-101.

Crosbie-Burnett, M., \& Klein, D.M. (2009). The fascinating story of family theories. In Bray, J. H. and Stanton, M. (Eds.), The Wiley-Blackwell handbook of family psychology (37-52). Malden, MA: Wiley-Blackwell.

Cummings. E.M. \& Davis, P.T. (2002). Effects of martial conflict on children: recent advances and emerging themes in process-oriented research. Journal of Child Psychology and Psychiatry, 43(1), 31-63.

Danermark, B., Ekström, M., Jakobsen, L., \& Karlsson, J.C. (2002). Explaining society: An introduction to critical realism in the social sciences. London: Routledge. 
Eriksen, S., and Jensen, V. (2006). All in the family? Family environmental factors in sibling violence. In H. Williams (Ed.), Child abuse (pp. 54-64). Farmington Hills, MI: Greenhaven Press.

Feinberg, M.E., Solmeyer, A.R., \& McHale, S.M. (2012). The third rail of family systems: Sibling relationships, mental and behavioral health, and preventative intervention in childhood and adolescence. Clinical Child and Family Psychology Review, 15, 43-57.

Feinberg, M.E., Sakuma, K., Hostetler, M., \& McHale, S.M. (2013). Enhancing sibling relationships to prevent adolescent problem behaviors: Theory, design and feasibility of Siblings are Special. Evaluation and Program Planning, 26, 97-106.

Finkelhor, D., Ormrod, R., Turner, H., \& Hamby, S.L. (2005). The victimization of children and youth: A comprehensive, national survey. Child Maltreatment, 10(1), 5-25.

Finkelhor, D., Turner, H., \& Ormrod, R. (2006). Kid's stuff: The nature and impact of peer and sibling violence on younger and older children. Child Abuse \& Neglect, 30, 1401-1421.

Finlay, L. (2002). “Outing” the researcher: The provenance, process, and practice of reflexivity. Qualitative Health Research, 12(4), 531-545.

Fletcher, A.J. (2017). Applying critical realism in qualitative research: methodology meets method. International Journal of Social Research Methodology, 20(2), 181194. 
Frick, P., \& White, S.F. (2008). The importance of callous-unemotional traits for developmental models of aggressive and antisocial behavior. Journal of Child Psychology and Psychiatry, 29(4), 359-375.

Gass, K., Jenkins, J., and Dunn, J. (2007). Are sibling relationships protective? A longitudinal study. Journal of Child Psychology and Psychiatry, 48(2), 167-175.

Gelles R.J. \& Steinmetz, S.K. (2006). Behind closed doors: Violence in the American family. New Brunswick, N.J.: Transaction Publishers.

Gil, D.G. (1996). Preventing violence in a structurally violent society: Mission impossible. American Journal of Orthopsychiatry, 66(1), 77-84.

Graham-Bermann, S.A., Cutler, S.E., Litzenberger, B.W., \& Schwartz, W.E. (1994). Perceived conflict and violence in childhood sibling relationships and later emotional adjustment. Journal of Family Psychology, 8(1), 85-97.

Grannic, I. \& Patterson, G.R. (2006). Toward a comprehensive model of antisocial development: A dynamic systems approach. Psychological Review, 113(1), 101131.

Guest, G., Bunce, A., \& Johnson, L. (2006). How many interviews are enough? An experiment with data saturation and variability. Field Methods, 18(1), 59-82.

Gustavsson, N.S., \& MacEachron, A.E. (2010). Sibling connections and reasonable efforts in public child welfare. Families in Society, 91, 39-44

Hamby, S., \& Grych, J. (2013). The web of violence: Exploring connections among different forms of interpersonal violence and abuse. New York, London: Springer. 
Hegar, R.L. (2005). Sibling placement in foster care and adoption: An overview of international research. Children and Youth Services Review, 27(7), 717-739.

Hegar, R.L., \& Rosenthal, J.A. (2011). Foster children placed with or separated from siblings: Outcomes based on a national sample. Children and Youth Services Review, 33(7), 1245-1253.

Henning, K., Leitenberg, H., Coffey, P., Bennet, R., \& Jankowski, M. (1997). Long-term psychological adjustment to witnessing interparental physical conflict during childhood. Child Abuse \& Neglect, 21, 501-515.

Hoffman, K.L., \& Edwards, J.N. (2004). An integrated theoretical model of sibling violence and abuse. Journal of Family Violence, 19(3), 185-200.

Hoffman, E. (2007). Open-ended interviews, power, and emotional labor. Journal of Contemporary Ethnography, 36, 318-346.

Hoffman, K.L., Kiecolt, K.J., \& Edwards, J.N. (2005). Physical violence between siblings: A theoretical and empirical analysis. Journal of Family Issues, 26(8), 1103-1130.

Horwath, J., Kalyva, E., \& Spyru, S. (2012). “I want my experiences to make a difference” promoting participation in policy-making and service development by young people who have experienced violence. Children and Youth Services Review, 34, 155-162.

Houston, S. (2001). Beyond social constructionism: Critical realism and social work. British Journal of Social Work, 31, 845-861. 
Hyde, J. \& Kammerer, N. (2009). Adolescents’ perspectives on placement moves and congregate settings: Complex and cumulative instabilities in out-of-home care. Children and Youth Services Review, 31, 265-273.

Keddell, E. (2011). Reasoning processes in child protection decision making: Negotiating moral minefields and risky relationships. British Journal of Social Work, 41, 1251-1270.

Kennedy, D.E. \& Kramer, L. (2008). Improving emotion regulation and sibling relationship quality: The More Fun with Sisters and Brothers Program. Family Relations, 57, 567-578.

Kerig, P.K. \& Stellwagen, K.K. (2009). Roles of callous-unemotional traits, narcissism, and Machiavellianism in childhood aggression. Journal of Psychopathology and Behavioral Assessment, 32, 343-352.

Kim, M.E. (2013). Challenging the pursuit of criminalization in an era of mass incarceration: The limitations of social work responses to domestic violence in the USA. British Journal of Social Work, 43,1276-1293.

Kiselica, M.S., \& Morrill-Richards, M. (2007). Sibling maltreatment: The forgotten abuse. Journal of Counseling and Development, 85, 148-160.

Kominkiewicz, F. B. (2004). The relationship of child protection service caseworker discipline-specific education and definition of sibling abuse: An institutional hiring impact study. Journal of Human Behavior and the Social Environment, 9(1-2), 69-82. 
Kothari, B.H., McBeath, B., Lamson-Siu, E., Webb, S.J., Sorenson, P., Bowen, H. ... \& Bank, L. (2014). Development and feasibility of a sibling intervention for youth in foster care. Evaluation and Program Planning, 47, 91-99.

Kothari, B.H., McBeath, B., Sorenson, P., Bank, L., Waid, J. Webb, S.J., \& Steele, J. (2017). An intervention to improve sibling relationship quality among youth in foster care: Results of a randomized clinical trial. Child Abuse \& Neglect, 63, 1929.

Kramer, L. (2004). Experimental interventions in sibling relations. In R.D. Conger, F.O. Lorez, and K.A.S. Wickrama (Eds.), Continuity and change in family relations: Theory, methods and empirical findings (pp. 345-380). Mahway, NJ: Erlbaum.

Kramer, L. \& Bank, L. (2005). Sibling relationship contributions to individual and family well-being: Introduction to the special issue. Journal of Family Psychology, 19(4), 483-485.

Kuhn, T. (1962). The structure of scientific revolutions. Chicago: University of Chicago Press.

Kulkarni, S.J., Barth, R.P., \& Messing, J.T. (2016, September). Policy recommendations for meeting the Grand Challenge to Stop Family Violence (Grand Challenges for Social Work Initiative Policy Brief No. 3). Cleveland, OH: American Academy of Social Work \& Social Welfare.

Lennox, R. \& Jurdi-Hage, R. (2017). Beyond the empirical and the discursive: The methodological implications of critical realism for street harassment research. Women's Studies International Forum, 60, 28-38. 
Lenz-Rashid, S. (2004). Employment experiences of homeless young adults: Are they different for youth with a history of foster care? Children and Youth Services Review, 28, 235-259.

Linares, L.O. (2008). The sibling bonds project. Unpublished manuscript. NYU Child Study Center, New York University, New York, NY.

Linares, L.O., Jimenez, J., Nesci, C., Pearson, E., Beller, S., Edwards, N., \& LevinRector, A. (2015). Reducing sibling conflict in maltreated children placed in foster homes. Prevention Science, 16, 211-221.

Linares, L.O., Li, M.M., Shrout, P.E., Brody, G.H., \& Pettit, G.S. (2007). Placement shift, sibling relationship quality and child outcomes in foster care: A controlled study. Journal of Family Psychology, 21, 736-743.

Loeber, R. \& Stouthamer-Loeber, M. (1998). Development of juvenile aggression and violence. American Psychologist, 53(2), 242-259.

Lopez, P., \& Allen, P.J. (2007). Addressing the health needs of adolescents transitioning out of foster care. Pediatric Nursing, 33, 345-356.

Maxwell, J.A. (2012). A realist approach to qualitative research. Los Angeles: Sage Publications, Inc.

Mayring, P. (2000). Qualitative content analysis. Forum: Qualitative Social Research, 1(2).

McBeath, B., Kothari, B.H., Blakeslee, J., Lamson-Siu, E., Bank, L., Linares, L.O.... \& Shlonsky, A. (2014). Intervening to improve outcomes for siblings in foster care: 
SIBLING VIOLENCE AND CHILD WELFARE

Conceptual, substantive, and methodological dimensions of a prevention science framework. Children and Youth Services Review, 39, 1-10.

McDonald, C. \& Martinez, K. (2016). Parental and others' responses to physical sibling violence: A descriptive analysis of victims' retrospective accounts. Journal of Family Violence, 31, 401-410.

Mehrotra, G. R., Kimball, E., and Wahab, S. (2016). The braid that binds us: The impact of neoliberalism, criminalization, and professionalization on domestic violence work. Journal of Women and Social Work, 31(2), 153-163.

Meyers, A. (2014). A call to child welfare: Protect children from sibling abuse. Qualitative Social Work, 13(5), 654-670.

Meyers, A. (2017). Lifting the veil: The lived experience of sibling abuse. Qualitative Social Work, 16(3), 333-350.

Milevsky, A. (2011). Sibling relationships in childhood and adolescence. New York: Columbia University Press.

Miller, L.E., Grabell, A., Thomas, A., Bermann, E., \& Graham-Bermann, S.A. (2012, February 13). The associations between community violence, television violence, intimate partner violence, parent-child aggression, and aggression in sibling relationships of a sample of preschoolers. Psychology of Violence. Advance online publication. doi: 10.1037/a0027254

Morris, T. (2006). Social work research methods. Thousand Oaks, CA: Sage Publications. 
Morse, J.M. (1995). The significance of saturation. Qualitative Health Research, 5(2), 147-149.

Nagel, T. (1989). The view from nowhere. Oxford: Oxford University Press.

National Scientific Council on the Developing Child (2005/2014). Excessive stress disrupts the architecture of the developing brain: Working paper No. 3. Updated edition. Retrieved from www.developingchild.harvard.edu.

Nicoletti, A. (2007). Perspectives on pediatric and adolescent gynecology from the allied health professional. Journal of Pediatric Adolescent Gynecology, 20, 205-206.

Noland, V., Liller, K., McDermott, R., Coulter, M., \& Seraphine, A. (2004). Is adolescent sibling violence a precursor to college dating violence? American Journal of Health Behavior, 28, S13-S23.

Oakley, A. (1981). Interviewing women: A contradiction in terms. In H. Roberts (Ed.), Doing feminist research (pp. 30-61). London: Routledge and Kegan Paul.

O’Rielly, M. \& Parker, N. (2012). ‘Unsatisfactory saturation’: A critical exploration of the notion of saturated sample sizes in qualitative research. Qualitative Research, 13(2), 190-197.

Parr. S. (2015). Integrating critical realist and feminist methodologies: Ethical and analytical dilemmas. International Journal of Social Research Methodology, 18(2), 193-207.

Patterson, G.R. (1982). Coercive family process. Eugene, OR: Castalia. 
Perkins, N.H. (2014). Perceptions and experiences of physical and emotional violence between siblings: A mixed-methods, comparative case study (Doctoral dissertation). Virginia Commonwealth University, Richmond, Virginia.

Perkins, N.H., \& O’Connor, M.K. (2016). Physical and emotional sibling violence: A necessary role for social work. Social Work, 61(1), 91-93.

Perkins, N.H., \& Stoll, A.J. (2016). Practical considerations of physical and emotional sibling violence in foster families: A summary of the current literature. Journal of Family Social Work, 19(5), 407-419.

Pike, A., Coldwell, J., \& Dunn, J.F. (2005). Sibling relationships in early/middle childhood: Links with individual adjustment. Journal of Family Psychology, 19(4), 523-532.

Pinel-Jacquemin, S., Cheron, J., Favart, E., Dayan, C., \& Scelles, R. (2013). Violence among siblings and joint placement: A review of the literature. Early Child Development and Care, 183(7), 963-980.

Randolph, W., \& Viswanath, K. (2004). Lessons learned from public health mass media campaigns: Marketing health in a crowded media world. Annual Review of Public Health, 25, 419-437.

Reid, W.J., \& Donovan, T. (1990). Treating sibling violence. Family Therapy, 17(1), 4959.

Reilly, T. (2003). Transition from care: Status and outcomes of youth who age out of foster care. Child Welfare, 82, 727-746. 
Richmond, M.K., Stocker, C.M., \& Rienks, S.L. (2005). Longitudinal associations between sibling relationship quality, parental differential treatment, and children’s adjustment. Journal of Family Psychology, 19(4), 550-559.

Riebschleger, J., Day, A., \& Damashek, A. (2015). Foster care youth share stories of trauma before, during, and after placement: Youth voices for building traumainformed systems of care. Journal of Aggression, Maltreatment, \& Trauma, 24, $339-360$.

Rogowski, S. (2012). Social work with children and families: Challenges and possibilities in the neo-liberal world. British Journal of Social Work, 42, 921-940.

Rowntree, M. (2007). Responses to sibling sexual abuse: Are they as harmful as the abuse? Australian Social Work, 60(3):347-361.

Ross, K. (2017). Making empowering choices: How methodology matters for empowering research participants. Forum: Qualitative Social Research, 18(3), Art. 12.

Sayer, A. (1992). Methods in social science: A realist approach. London: Routledge. Sayer, A. (2010). Method in social science: A realist approach, revised ( $2^{\text {nd }}$ ed.). New York: Routledge.

Schonkoff, J. P., Boyce, W. T., \& McEwen, B. S. (2009). Neuroscience, molecular biology, and the childhood roots of health disparities: building a new framework for health promotion and disease prevention. JAMA, 301(21), 2252-2259.

Schwandt, T.A. (1994). Handbook of qualitative research. Thousand Oaks, CA: Sage. 
Shadik, J.A., Perkins, N.H., \& Kovacs, P.J. (2013). Incorporating discussion of sibling violence in the curriculum of parent intervention programs for child abuse and neglect. Health and Social Work, 38(1), 53-57.

Shireman, J.F. (2015). Critical issues in child welfare, second edition. New York, New York: Columbia University Press.

Shields, A., \& Cicchetti, D. (1998). Reactive aggression among maltreated children: The contributions of attention and emotion dysregulation. Journal of Clinical Child Psychology, 27(4). 381-395.

Shields, A., \& Cicchetti, D. (2001). Parental maltreatment and emotion dysregulation as risk factors for bullying and victimization in middle childhood. Journal of Clinical Child \& Adolescent Psychology, 30(3). 349-363.

Siddiqui, A., \& Ross, H. (2004). Mediation as a method of parent intervention in children’s disputes. Journal of Family Psychology, 18(1), 147-159.

Smith, S.R. \& Hamon, R.R. (2012). Exploring family theories ( ${ }^{r d}$ Ed.). New York: Oxford University Press.

Smith, J. \& Ross, H. (2007). Training parents to mediate sibling disputes affects children's negotiation and conflict understanding. Child Development, 78(3), 790805.

Smith, J.D., Dishion, T.J., Shaw, D.S., Wilson, M.N., Winter, C.C., \& Patterson, G.R. (2014). Coercive family process and early-onset conduct problems from age 2 to school entry. Development and Psychopathology, 26, 917-932. 
Solomon, D.T., Niec, L.N., \& Schoonover, C.E. (2017). The impact of Foster Parent Training on parenting skills and child disruptive behavior: A meta-analysis. Child Maltreatment, 22(1), 3-13.

Spaccarelli, S., Sandler, I., and Roosa, M. (1994). History of spouse violence against mother: Correlated risks and unique effects in child mental health. Journal of Family Violence, 9, 79-95.

Spielfogel, J.E., Leathers, S.J., Christian, E., \& McMeel, L.S. (2011). Parent management training, relationships with agency staff, and child mental health: Urban foster parents’ perspectives. Children and Youth Services Review, 33, 2336-2374.

Staff, I. \& Fein, E. (1992). Together or separate: A study of siblings in foster care. Child Welfare, 71(3), 257-270.

Straus, M. A. (1979). Measuring intrafamily conflict and violence: The conflict tactics (CT) scales. Journal of Marriage and Family, 41, 75-88.

Straus, M. A., Gelles, R. J., \& Steinmetz, S. K. (2006). Behind closed doors: Violence in the American family. New York, NY: Anchor Press/Doubleday.

Strolin-Goltzman, J., Kollar, S., \& Trinkel, J. (2010). Listening to the voices of children in foster care: Youths speak out about child welfare workforce turnover and selection. Social Work, 55(1), 47-53.

Swaim, R.C. \& Kelly, I. (2008). Efficacy of a randomized trial of a community and school-based anti-violence media intervention among small-town middle school youth. Prevention Science, 9, 202-214. 
Thomas, B.W. \& Roberts, M.W. (2009). Sibling conflict resolution skills: Assessment and training. Journal of Child and Family Studies, 18, 447-453.

Tucker, C.J., Finkelhor, D., Shattuck, A.M., \& Turner, H. (2013). Prevalence and correlates of sibling victimization types. Child Abuse \& Neglect, 37, 213-223.

Tudge, J.R.H., Mokrova, I., Hatfield, B.E., \& Karnik, R.B. (2009). Uses and misuses of Bronfenbrenner's bioecological theory of human development. Journal of Family Theory \& Review, 1, 198-201.

U.S. Department of Health \& Human Services (2015). Children's Bureau focus areas. [Web content]. Retrieved from http://www.acf.hhs.gov/programs/cb/focusareas/child-abuse-neglect

U.S. Department of Health \& Human Services. (2016). Child maltreatment 2016. Washington DC: Administration of Children and Families. Retrieved from https://www.acf.hhs.gov/sites/default/files/cb/cm2015.pdf

United Nations General Assembly (2018). Report of the special rapporteur on adequate housing as a component of the right to an adequate standard of living, and on th eirhg to non-discrimination in this context. Retrieved from http://www.undocs.org/A/73/310/rev.1

Wakefied, M. A., Loken, B., \& Hornik, R. C. (2010). Use of mass media campaigns to change health behavior. The Lancet, 376, 1261-1271.

Walker, L.E. (1986). Psychological causes of family violence. In Lystad, M. (ed.), Violence in the Home: Interdisciplinary Perspectives (pp. 71-98), New York, NY: Brunner/Mazel. 
Walker, A.J., Allen, K.R., \& Connidis, I.A. (2005). Theorizing and studying sibling ties in adulthood. In Bengtson, V. L., Acock, A. C., Allen, K. R., Dilworth-Anderson, P., and Klein, D. M. (Ed.). Sourcebook of family theory \& research (pp. 167-190). Thousand Oaks, CA: Sage.

Wallace, H. (1999). Family violence: Legal, medical, and social perspectives. Needham Heights, MA: Allyn \& Bacon.

Washington, K. (2007). Research review: Sibling placement in foster care: a review of the evidence, Child and Family Social Work, 12, 426-433.

Whiteman, S. D., McHale, S. M., \& Soli, A. (2011). Theoretical perspectives on sibling relationships. Journal of Family Theory and Review, 3(2), 124-139.

Wiehe, V. R. (1997). Sibling abuse: Hidden physical, emotional, and sexual trauma. Thousand Oaks, CA: Sage Publications, Inc.

Wiehe, V. R. (1998). Understanding family violence: Treating and preventing partner, child, sibling, and elder abuse. Thousand Oaks, CA: Sage Publications, Inc.

Wright, K. (2011). Reality without scare quotes: Developing the case for critical realism in journalism research. Journalism Studies, 12(2), 156-171.

World Health Organization (2002). World report on violence and health. Retrieved from http://whqlibdoc.who.int/publications/2002/9241545615_eng.pdf?ua=1

World Health Organization (2009). Changing cultural and social norms that support violence. Retrieved from http://www.who.int/violence_injury_prevention/violence/norms.pdf 
Wojciak, A., McWey, L. M., \& Helfrich, C. M. (2013). Sibling relationships and internalizing symptoms of youth in foster care. Children and Youth Services Review, 35(7), 1071-1077.

Wulczyn, F. \& Zimmerman, E. (2005). Sibling placements in longitudinal perspective. Children and Youth Services Review, 27, 741-763.

Zwick, M. (2015). Elements and relations: Aspects of a scientific metaphysics. Manuscript in preparation. 


\title{
Appendices
}

\author{
Appendix A: Recruitment Flyer
}




\section{Do you have experience with foster care? \\ Did you experience physical or emotional violence \\ with a sibling?}

A research study is seeking foster care alumni to learn more about physical and emotional sibling violence.

Your participation may help improve child welfare services for others.

\section{You will get $\$ 20$ for your participation.}

You are eligible if:

- You are 18-24 years old

- You have a history of involvement in foster care

- You have at least one sibling

- You were a perpetrator or victim of physical or emotional sibling violence before or during your involvement in child welfare

Physical violence includes hitting, punching, kicking, biting, or using a weapon like a knife or a gun against a sibling. Emotional violence can include humiliating a sibling, using words or threats to make a sibling feel unsafe, destroying a prized possession or harming a pet. These are just examples; there are lots of other ways siblings are violent with each other.

Your participation in the study will include:

- A face-to-face interview with the researcher - Katie will work with you to arrange a meeting location that is convenient for you

- Filling out a background information form

If you are interested in participating, please contact the researcher:

Katie Winters, M.A.

Ph.D. Student, Portland State University

k.winters@pdx.edu

Cell phone: (503) 956-6432

Foster Care alumni who have worked with Katie are also available if you would like to ask them about their experiences:

Tim Dennis (Knoxville, TN): tburns58@gmail.com (865) 256-1391

Ashley Strange (Washington, D.C.): ashleystrange@outlook.com (202) 468-8041

Ke'Onda Johnson (West Palm Beach, FL): keondaj14@gmail.com (561) 572-7141 
Appendix B: Participant Informed Consent Document 


\section{Sibling Violence Study - Consent to Participate}

Please sign and return one copy of this consent form. Keep the other for your records.

\section{What is this research study about?}

A PhD student at Portland State University named Katie Winters is interested in learning about sibling violence among child welfare-involved youth. You are being asked to be in this study because you have past experience with the child welfare system and sibling violence.

You are eligible if:

- You are 18-24 years old

- You have a history of involvement in the child welfare system

- You have at least one sibling

- You were a perpetrator or victim of physical or emotional sibling violence before or during your involvement in child welfare

What will I be asked to do?

If you decide to be in this study, you will be asked to do the following:

1. Participate in a 90-minute interview with the researcher

2. Fill out a background information form

The interview will be used to talk about your experiences with sibling violence. Physical violence includes hitting, punching, kicking, biting, or using a weapon like a knife or a gun against a sibling. Emotional violence can include humiliating a sibling, using words or threats to make a sibling feel unsafe, destroying a prized possession or harming a pet. These are just examples; there are lots of other ways siblings are violent with each other. You will be asked to talk about:

- Your relationship(s) with your sibling(s)

- Your relationships with your other family members, and their relationships with each other

- The community where you were living when you experienced sibling violence

- The things that adults such as your case worker, counselor, or foster parent(s) did (or didn't do) to address the violence between you and your sibling(s)

- Your ideas to help siblings who are experiencing violent interactions

These discussions will be audio-recorded, with your permission.

What will I get in return?

$\checkmark$ You will receive a $\$ 20$ to thank you for your participation 
Satisfaction of knowing your participation may help improve child welfare services for other youth who experience sibling violence

\section{What are the risks and benefits?}

Talking about your experiences with sibling violence can be very personal. Some of the questions may be sensitive for you and you may feel uncomfortable, angry, sad, guilty, or embarrassed. You do not have to answer any questions that you're not comfortable with and can stop whenever you'd like. If you are upset after the interview and need to talk with someone, I encourage you to use the resources below.

- 211 info - Bi-lingual: By dialing 211 on your phone or going to 211 info.org, you will receive confidential assistance to access roughly 3,000 agencies and over 50,000 low cost and free programs to help people in Oregon.

- Oregon Coalition Against Domestic Violence: 503-230-1951

- National Alliance of Mental Illness Oregon Chapter: 503-230-8009

- National Suicide Prevention LifeLine: 1-800-273-8255

There is also a small risk that your information will be seen by somebody other than Katie and her research supervisor. However, she will follow strict rules to protect your confidentiality. Steps she will take to protect you are listed in the next section. There are no direct benefits for participating in this study.

\section{Mandatory Reporting}

It is the investigator's legal obligation to report child abuse, child neglect, elder abuse, harm to self or others or any life-threatening situation to the appropriate authorities, and; therefore, your confidentiality will not be maintained.

\section{What are you doing to protect me?}

Your confidentiality is very important. Katie will do many things to protect you:

- She won't tell anyone if you take part in this study or not.

- What you share will be kept confidential. Your name and any information about you will be kept confidential. By "kept confidential" I mean that the names of people in the study will not be given to anyone else and, when I write or talk about what I learned in this study, I will do my best to make it so no one will be able to tell who I am talking about.

- I will store all information you give me in a locked briefcase, a locked cabinet, or on a password-protected computer and/or secure server.

\section{Participation is Voluntary}

It is up to you if you want to be in this study. If you choose to be in the study, you do not have to answer any questions you don't want to and you can stop at any time. If you 
decide not to be in the study, or to drop out, you may do so without it affecting any services you receive.

\section{Alternative to Being in the Study}

The alternative to being in this study is to choose not be in the study. Your participation is voluntary. Your choice to participate will NOT have an impact on ANY of the services you receive now or in the future.

\section{Who to Call with Questions}

If you have any concerns about the research study, you may contact Stephanie Wahab at (503) 725-5083. She is the person who directs the study. If you have any concerns about your rights in the study, you may contact the PSU Office of Research Integrity, 1600 SW 4th Ave., Market Center Building, Ste. 620, Portland, OR 97201; phone (503) 725-2227 or 1 (877) 480-4400.

\section{If I sign the form, what does it mean?}

This is a consent form. Your signature below means that:

1. You have read and you understand what this form says.

2. You are willing to be in the study.

3. You know that you do not have to be in this study and you can change your mind and stop at any time.

4. You know that being in this study has nothing to do with any of the services you receive.

5. You keep a copy of this form.

I have read this form and agree to be in this study.

First Name

Signature
Last Name

Date

\section{Audio Recording}

In order to ensure that I can accurately document responses to the questions, I am asking for your permission to audio-record the interview. The audio-recording will be kept confidential and stored in a password-protected file. The recordings will be destroyed no earlier than three years after the completion of the study. You have the right to stop the recording at any time during the interview or your optional follow-up interview without penalty. You also have the right to agree to participate in the study without being audio-recorded. Your signature below means that:

- You have read and you understand what this form says. 
- You are giving permission to be audio-recorded. 
Appendix C: Data Collection Instruments: Interview Protocol and Background Form 


\author{
Interview Protocol \\ Foster Care Alumni Perspectives on Abusive Sibling Violence
}

\title{
Introduction
}

Welcome! Before we get into any of this, I first want to thank you for your willingness to talk with me today. This is an important topic, and it can also be a tender topic, so I want to acknowledge your courage first thing.

I think it's also important for me to let you know about my experience with sibling violence, to give you a bit of understanding about where I'm coming from. I have a brother who is two years older than me, and who was very violent with me when we were growing up [provide examples]. Those interactions affected different parts of my life in powerful ways, and so l've chosen to focus on learning about siblings in my graduate school program.

There have been some big studies about violent sibling relationships, and I would say that there is strong evidence that it's a pretty common problem. None of the studies I have come across have included the voices of foster care alumni, so I would like to use my research project to hear young people's perspectives on sibling violence. It's my hope that this research will help case workers, therapists, foster parents... really anybody who works with young people involved in child welfare to have information about sibling relationships and what to do if siblings are having trouble.

So today we'll be using the time to hear your perspectives on the topic of sibling violence. By violence I mean physical violence and emotional violence. Physical violence includes hitting, punching, kicking or biting, or using a weapon like a knife or a gun against a sibling. Emotional violence can include humiliating a sibling, using words or threats to make a sibling feel unsafe, destroying a prized possession or harming a pet. These are just examples, and there are lots of other ways that siblings are violent with each other. I'd like to keep this conversation focused on physical and emotional sibling violence, so if you have experiences with sexual violence, please try to keep your sharing focused on physical and/or emotional violence.

This conversation will be confidential. What I mean by confidential is that I won't share your comments with anyone else.

Do you have any questions for me before we begin? [Respond to any questions posed by the interview participant]

Would it be okay for me to audio-record our conversation? I won't share the recording with anyone- it's just to ensure that I accurately capture the information you share 
during the interview. I can take notes instead of recording if that is your preference. [If yes, begin recording. If no, use paper/pencil to take notes during the interview.]

OK, that's enough from me.

\section{Interview Questions}

1. I'd like to begin by having you tell me about your biological family (your family of origin). While we talk l'd like to work together to draw a map of the people in your family system (here's an example). This will help me to understand the family members who were involved in your life when you were experiencing sibling violence (show example).

a. What was/were your relationship(s) like with each of the people in your family system before you became involved with child welfare?

b. What were their relationships like with each other? Was there physical or emotional violence between other people in your family?

i. Were there sources of stress in your family that affected the relationships you've described?

1. Did your family have financial struggles?

2. Did members of your family have problems with drugs or alcohol?

3. Did family members have mental health challenges?

2. I'd also like to hear about the community where you lived, when you lived with your biological family.

a. What was your neighborhood like? Did it feel like a safe place to live?

b. What kinds of families lived in your neighborhood? What were your neighbors like? Did you know your neighbors? How was your relationship with them?

c. What was your school like? How did you feel when you were at school? Were there problems at your school with drugs or violence?

3. Now l'd like to have you tell me about the physical and or emotional violence between you and your sibling(s).

a. What did your interactions look like when you weren't getting along?

i. Could you please describe a specific example of a physically and or emotionally violent exchange?

ii. From your perspective, what usually lead up to (or caused) physical or emotional violence with your sibling?

iii. Was one person usually the perpetrator and another person usually the victim?

iv. What would happen afterward? 
v. How often did these kinds of exchanges happen?

vi. When this was happening, did you see it as abusive?

vii. How did your parents/caregivers respond when you and your sibling(s) were being physically or emotionally violent with each other?

1. How helpful were the things they did to support your sibling relationship?

2. Can you think of other things they could have done that might have worked better?

viii. Were there other adults in your life that tried to help you and your sibling(s) to have a better relationship at that time?

1. How helpful were the things they did?

2. Can you think of other things they could have done that might have worked better?

ix. Thinking about the ways that adults intervened (or didn't), how has that shaped your perspective about adults or authority?

4. Now l'd like to talk about your relationship with your sibling(s) after you went into care.

a. Did you live together or apart?

b. What was/were your relationship(s) like with your siblings during the time you were in foster care? How would you compare your relationship at that time, to when you were living with your biological family?

5. During that time, when you were in foster care, what kinds of things did adults in your life, such as your caseworker, foster parents, counselors, or others do that were focused on your relationship(s) with your sibling(s)?

a. What kinds of things did they do to help you and your sibling(s) have a good relationship?

b. How helpful were the things they did to support your sibling relationship?

c. Did they do anything that made your relationship with your sibling(s) worse?

d. Can you think of other things they could have done that might have worked better?

e. What do you recommend to address sibling violence?

6. What helped you to get through those tough times with your sibling(s)?

a. Were there things that you did to keep yourself safe?

b. Can you think of qualities about yourself that helped you through those experiences? 
c. Were there any other sources of support or resilience that you can think of?

7. What is/are your relationship(s) with your sibling(s) like now?

a. Did you rekindle or heal the relationship? How? What supports were helpful?

b. What are your wishes for the future of your relationship(s)?

Thank the study participant. Complete the Background Information Form. 


\section{Participant Background Information}

1. Age in years:

2. Gender:

$\square$ Female

$\square$ Genderqueer/Androgynous

$\square$ Intersex

$\square$ Male

$\square$ Transgender

Transsexual

Cross-dresser

FTM (female-to-male)

MTF (male-to-female)

Other (please specify):

Prefer not to answer

3. Do you consider yourself to be:

$\square$ Heterosexual or straight

$\square$ Gay or lesbian

Bisexual

$\square$ Other

Prefer not to answer

4. What is your ability status? (please check all that apply):

Deaf or have serious difficulty hearing

Blind or have serious difficulty seeing even when wearing glasses

Because of a physical, mental, or emotional condition, I have serious difficulty concentrating, remembering, or making decisions

Serious difficulty walking or climbing stairs

Have difficulty dressing or bathing 
Because of a physical, mental, or emotional condition, I have difficulty doing errands alone such as visiting a doctor's office or shopping

$\square$ Other:

$\square$ None/Prefer not to answer

5. What is your race or ethnicity? (Please check all that apply)

$\square$ Alaska Native

American Indian

Asian

Black/African American

Hispanic, Latino/-a, or of Spanish origin

Middle Eastern

Native Hawaiian/Other Pacific Islander

$\square$ White

Other:

Unknown/Prefer not to answer

6. Would you be willing to have another conversation with Katie about sibling violence?

$\square$ Yes

$\square$ No

If yes, please provide your contact information below

Name:

Telephone Number:

Email Address: 
Appendix D: Final Coding Scheme 


\begin{tabular}{|c|c|c|}
\hline Code & Definition & Coding Rule(s) \\
\hline $\begin{array}{l}\text { D1. Caffaro \& } \\
\text { Meyers' definitions } \\
\text { supported }\end{array}$ & $\begin{array}{l}\text { Supports any aspect of the definition of } \\
\text { abusive sibling violence put forward by } \\
\text { Caffaro and/ or Meyers: } \\
\text { A repeated pattern of violent } \\
\text { interactions } \\
\text { An escalating pattern of violent } \\
\text { interactions } \\
\text { Stable victim/ offender roles } \\
\text { Perpetrator motivated by a need for } \\
\text { power and control } \\
\text { Victim experiences a sense of terror } \\
\text { Victim experiences a sense of } \\
\text { powerlessness } \\
\text { Victim perceives perpetrator's behavior } \\
\text { as abusive }\end{array}$ & $\begin{array}{l}\text { Any single or multiple } \\
\text { aspects of the } \\
\text { definition is/ are } \\
\text { supported }\end{array}$ \\
\hline $\begin{array}{l}\text { D2. Caffaro \& } \\
\text { Meyers' definitions } \\
\text { challenged }\end{array}$ & $\begin{array}{l}\text { Any single or multiple aspects of the } \\
\text { definition is/are challenged (i.e., } \\
\text { opposite description is provided): } \\
\text { One-time events } \\
\text { Stable pattern that does not escalate } \\
\text { Victim/ offender roles are not clear } \\
\text { and/ or shift over time } \\
\text { Perpetrator motivation is something } \\
\text { other than a need for power or control } \\
\text { Victim is not afraid of the perpetrator } \\
\text { Victim feels powerful in the face of } \\
\text { perpetrator's aggressions/ responds in- } \\
\text { kind } \\
\text { Victim minimizes perpetrator's } \\
\text { behavior or perceives it as normal/ } \\
\text { typical/ acceptable }\end{array}$ & $\begin{array}{l}\text { Code if any aspect of } \\
\text { the definition is } \\
\text { challenged }\end{array}$ \\
\hline $\begin{array}{l}\text { FC1. Family } \\
\text { condition - } \\
\text { parental } \\
\text { unavailability }\end{array}$ & $\begin{array}{l}\text { Parents are physically and/ or } \\
\text { emotionally unavailable as a result of: } \\
\text { Inability to express love, empathy, } \\
\text { caring for the child(ren) } \\
\text { Regular/severe alcohol/ drug use } \\
\text { Chronic/ severe mental health } \\
\text { challenges } \\
\text { Chronic/ severe physical health } \\
\text { challenges }\end{array}$ & $\begin{array}{l}\text { Any single or multiple } \\
\text { aspects of the } \\
\text { definition is/ are } \\
\text { supported }\end{array}$ \\
\hline
\end{tabular}




\begin{tabular}{|c|c|c|}
\hline $\begin{array}{l}\text { FC2. Family } \\
\text { condition - lack of } \\
\text { supervision }\end{array}$ & $\begin{array}{l}\text { Parent(s) do(es) not provide } \\
\text { expectations for or enforce healthy } \\
\text { child behaviors }\end{array}$ & $\begin{array}{l}\text { Must co-occur in the } \\
\text { data along with/be } \\
\text { described as resulting } \\
\text { from parental } \\
\text { unavailability (FS1) }\end{array}$ \\
\hline $\begin{array}{l}\text { FC3. Family } \\
\text { condition - } \\
\text { parentified child }\end{array}$ & $\begin{array}{l}\text { One sibling is expected to parent } \\
\text { others; caretaking expectations are } \\
\text { developmentally inappropriate given } \\
\text { the child's age/ abilities }\end{array}$ & $\begin{array}{l}\text { Must co-occur in the } \\
\text { data along with/ be } \\
\text { described as resulting } \\
\text { from parental } \\
\text { unavailability (FS1) }\end{array}$ \\
\hline $\begin{array}{l}\text { FC4. Family } \\
\text { condition - } \\
\text { differential } \\
\text { treatment }\end{array}$ & $\begin{array}{l}\text { Parent(s) favor or scapegoat one sibling } \\
\text { as compared to other(s) }\end{array}$ & $\begin{array}{l}\text { Favoritism/ } \\
\text { scapegoating must be } \\
\text { a stable, long-term } \\
\text { pattern of interaction; } \\
\text { not a one-time event }\end{array}$ \\
\hline $\begin{array}{l}\text { FC5. Family } \\
\text { condition - } \\
\text { work/financial } \\
\text { strain }\end{array}$ & $\begin{array}{l}\text { Parent(s) described as experiencing } \\
\text { work/ financial strain such that: } \\
\text { Parent(s) is/are unable to secure stable } \\
\text { employment } \\
\text { Parent(s) work is illegal (e.g., drug } \\
\text { dealer) } \\
\text { Parent(s) work(s) more than full-time } \\
\text { to meet basic needs } \\
\text { Parent(s) unable to meet family's basic } \\
\text { needs due to un-/ under-employment }\end{array}$ & $\begin{array}{l}\text { Any single or multiple } \\
\text { aspects of the } \\
\text { definition occur } \\
\text { immediately prior to } \\
\text { and/ or at the same } \\
\text { time as sibling } \\
\text { violence }\end{array}$ \\
\hline $\begin{array}{l}\text { FC6. Family } \\
\text { condition - } \\
\text { acceptance/ } \\
\text { modeling of } \\
\text { violence }\end{array}$ & $\begin{array}{l}\text { Parent(s) communicate(s) that violence } \\
\text { is an appropriate solution to } \\
\text { interpersonal problems within the } \\
\text { family system by: } \\
\text { Encouraging/ allowing/ ignoring } \\
\text { sibling } \\
\text { physical/ emotional violence (SEE } \\
\text { FS2) } \\
\text { Physical/ emotional violence (IPV) } \\
\text { between adult caregivers } \\
\text { Adult-perpetrated physical/ emotional } \\
\text { child maltreatment }\end{array}$ & $\begin{array}{l}\text { Physical abuse } \\
\text { includes: hitting, } \\
\text { kicking, biting, } \\
\text { beating up, use of a } \\
\text { weapon } \\
\text { Emotional abuse } \\
\text { includes: ridiculing, } \\
\text { insulting, threatening, } \\
\text { belittling, destruction } \\
\text { of personal property, } \\
\text { harming a pet } \\
\text { Also code if } \\
\text { participant describes } \\
\text { behavior as "abuse"/ } \\
\text { "abusive" }\end{array}$ \\
\hline
\end{tabular}




\begin{tabular}{|c|c|c|}
\hline $\begin{array}{l}\text { FC7. Family } \\
\text { condition - siblings } \\
\text { differ }\end{array}$ & $\begin{array}{l}\text { Sibling qualities that prime perpetrators } \\
\text { to enact physical/ emotional violence or } \\
\text { predispose victims to receive abuse: } \\
\text { Perpetrator Qualities: thinking errors, } \\
\text { cognitive/ developmental deficits, lack } \\
\text { of impulse control, lack of empathy, } \\
\text { callout-unemotional traits, narcissism, } \\
\text { tendency to inaccurately interpret } \\
\text { social cues } \\
\text { Victim Qualities: genetically } \\
\text { determined physical, emotional, mental } \\
\text { characteristics (disabled, } \\
\text { developmentally delayed, exhibit } \\
\text { behaviors others experience as } \\
\text { irritating } \\
\text { Large developmental, physical, } \\
\text { intellectual, or social/ emotional } \\
\text { differences between siblings in a dyad } \\
\text { in which the perpetrator is superior and } \\
\text { the victim is inferior }\end{array}$ & $\begin{array}{l}\text { Description of a } \\
\text { sibling(s) experiencing } \\
\text { physical/ emotional } \\
\text { abuse embody any of } \\
\text { the traits listed }\end{array}$ \\
\hline $\begin{array}{l}\text { SLT1. Social } \\
\text { Learning Theory }\end{array}$ & $\begin{array}{l}\text { Sibling violence described as resulting } \\
\text { from social learning. Physical/ } \\
\text { emotional violence is... } \\
\text { Learned through observation } \\
\text { Results in receipt of desired rewards } \\
\text { (e.g., gaining control of an object, } \\
\text { parental attention, the pleasurable } \\
\text { experience of power from a sibling's } \\
\text { fearful response) } \\
\text { Not redirected/ does not result in } \\
\text { consequences (SEE FS2) }\end{array}$ & $\begin{array}{l}\text { Any single or multiple } \\
\text { aspects of the theory } \\
\text { is/ are supported }\end{array}$ \\
\hline $\begin{array}{l}\text { RFT1. Radical } \\
\text { Feminist Theory }\end{array}$ & $\begin{array}{l}\text { Sibling violence described as... } \\
\text { Justified means for the more powerful } \\
\text { person in a dyad/ situation to get what } \\
\text { they want (SEE FS2) } \\
\text { Due to a power differential (i.e., } \\
\text { physical strength, intellectual/ } \\
\text { emotional maturity, level of } \\
\text { responsibility) between perpetrator and } \\
\text { victim (SEE FS7) } \\
\text { Giving the perpetrator a sense of } \\
\text { control by overpowering another }\end{array}$ & $\begin{array}{l}\text { Either or both aspects } \\
\text { of the theory is/ are } \\
\text { supported }\end{array}$ \\
\hline
\end{tabular}




\begin{tabular}{|c|c|c|}
\hline $\begin{array}{l}\text { CT1. Conflict } \\
\text { Theory }\end{array}$ & $\begin{array}{l}\text { Sibling violence is described as } \\
\text { occurring in a setting in which siblings } \\
\text { experience... } \\
\text { Scarcity - Lack of access to emotional } \\
\text { or tangible resources perceived as } \\
\text { scarce (SEE FS5, FS1) } \\
\text { Competition - for parental attention } \\
\text { Parental favoritism - One sibling gets } \\
\text { better "stuff", whatever the stuff is } \\
\text { (SEE FS4) }\end{array}$ & $\begin{array}{l}\text { Any single or multiple } \\
\text { aspects of the theory } \\
\text { is/ are supported }\end{array}$ \\
\hline $\begin{array}{l}\text { CFP1. Coercive } \\
\text { family process }\end{array}$ & $\begin{array}{l}\text { Sibling violence is described as } \\
\text { occurring in a family system with... } \\
\text { Multiple concurrent dynamics between } \\
\text { 3+ members } \\
\text { Family members embody stable roles } \\
\text { Mutual training - Repeated, cyclical } \\
\text { interpersonal reactions reinforce } \\
\text { violence } \\
\text { Feedback loops - Responses support } \\
\text { perpetuation of violence } \\
\text { Emotional, behavioral, or cognitive } \\
\text { responses perpetuate violence }\end{array}$ & $\begin{array}{l}\text { Any single or multiple } \\
\text { aspects of the theory } \\
\text { is/ are supported }\end{array}$ \\
\hline $\begin{array}{l}\text { SEM1. Social } \\
\text { Ecological Model }\end{array}$ & $\begin{array}{l}\text { Interactions across community and } \\
\text { family contexts produce/ support } \\
\text { violence (i.e., "open systems" } \\
\text { conception of reality). Focus is on } \\
\text { community (school, neighborhood, } \\
\text { etc.) factors that interact with the } \\
\text { family level of the ecology to produce/ } \\
\text { support interpersonal violence. }\end{array}$ & $\begin{array}{l}\text { Community factors } \\
\text { include poverty, } \\
\text { crime, and community } \\
\text { violence }\end{array}$ \\
\hline $\begin{array}{l}\text { I1. Intervention - } \\
\text { Real Time - } \\
\text { Helpful }\end{array}$ & $\begin{array}{l}\text { Description of helpful adult } \\
\text { intervention into sibling violence: } \\
\text { Verbal, physical, or other efforts to } \\
\text { intervene into violent exchanges in real } \\
\text { time }\end{array}$ & $\begin{array}{l}\text { Code any real-time } \\
\text { intervention effort } \\
\text { described as helpful to } \\
\text { halt/ reduce sibling } \\
\text { violence }\end{array}$ \\
\hline $\begin{array}{l}\text { I2. Intervention - } \\
\text { Real Time - NOT } \\
\text { Helpful }\end{array}$ & $\begin{array}{l}\text { Description of unhelpful adult } \\
\text { intervention into sibling violence: } \\
\text { Verbal, physical, or other efforts to } \\
\text { intervene into violent exchanges in real } \\
\text { time }\end{array}$ & $\begin{array}{l}\text { Code any real-time } \\
\text { intervention effort } \\
\text { described as unhelpful } \\
\text { to halt/ reduce sibling } \\
\text { violence }\end{array}$ \\
\hline
\end{tabular}




\begin{tabular}{|c|c|c|}
\hline $\begin{array}{l}\text { I3. Intervention - } \\
\text { Formal - Helpful }\end{array}$ & $\begin{array}{l}\text { Description of helpful adult } \\
\text { intervention into sibling violence: } \\
\text { Preventative or reactive formal } \\
\text { interventions - therapy, programs }\end{array}$ & $\begin{array}{l}\text { Code any formal } \\
\text { intervention effort } \\
\text { described as helpful to } \\
\text { halt/ reduce sibling } \\
\text { violence }\end{array}$ \\
\hline $\begin{array}{l}\text { I4. Intervention - } \\
\text { Formal - NOT } \\
\text { Helpful }\end{array}$ & $\begin{array}{l}\text { Description of unhelpful adult } \\
\text { intervention into sibling violence: } \\
\text { Preventative or reactive formal } \\
\text { interventions - therapy, programs }\end{array}$ & $\begin{array}{l}\text { Code any formal } \\
\text { intervention effort } \\
\text { described as unhelpful } \\
\text { to halt/ reduce sibling } \\
\text { violence }\end{array}$ \\
\hline $\begin{array}{l}\text { I5. Intervention - } \\
\text { Recommendations }\end{array}$ & $\begin{array}{l}\text { Participant-generated recommendations } \\
\text { to intervene into sibling violence }\end{array}$ & $\begin{array}{l}\text { Code any participant- } \\
\text { generated } \\
\text { recommendations to } \\
\text { intervene }\end{array}$ \\
\hline $\begin{array}{l}\text { PSV Origin. } \\
\text { Physical Sibling } \\
\text { Violence in Family } \\
\text { of Origin }\end{array}$ & $\begin{array}{l}\text { Hitting, kicking, biting, beating up, use } \\
\text { of a weapon }\end{array}$ & $\begin{array}{l}\text { Any single or multiple } \\
\text { physical sibling } \\
\text { violence types are } \\
\text { reported in family of } \\
\text { origin }\end{array}$ \\
\hline $\begin{array}{l}\text { PSV Foster. } \\
\text { Physical Sibling } \\
\text { Violence in Foster } \\
\text { Care }\end{array}$ & $\begin{array}{l}\text { Hitting, kicking, biting, beating up, use } \\
\text { of a weapon }\end{array}$ & $\begin{array}{l}\text { Any single or multiple } \\
\text { physical sibling } \\
\text { violence types are } \\
\text { reported in foster care }\end{array}$ \\
\hline $\begin{array}{l}\text { ESV Origin. } \\
\text { Emotional Sibling } \\
\text { Violence in Family } \\
\text { of Origin }\end{array}$ & $\begin{array}{l}\text { Ridiculing, insulting, threatening, } \\
\text { belittling, destruction of personal } \\
\text { property, harming a pet }\end{array}$ & $\begin{array}{l}\text { Any single or multiple } \\
\text { emotional sibling } \\
\text { violence types are } \\
\text { reported in family of } \\
\text { origin }\end{array}$ \\
\hline $\begin{array}{l}\text { ESV Foster. } \\
\text { Emotional Sibling } \\
\text { Violence in Foster } \\
\text { Care }\end{array}$ & $\begin{array}{l}\text { Ridiculing, insulting, threatening, } \\
\text { belittling, destruction of personal } \\
\text { property, harming a pet }\end{array}$ & $\begin{array}{l}\text { Any single or multiple } \\
\text { emotional sibling } \\
\text { violence types are } \\
\text { reported foster care }\end{array}$ \\
\hline $\begin{array}{l}\text { Break1. Stop-point } \\
\text { of Sibling } \\
\text { Violence }\end{array}$ & $\begin{array}{l}\text { The point at which sibling violence } \\
\text { ends }\end{array}$ & $\begin{array}{l}\text { Code the final stop- } \\
\text { point- may include } \\
\text { physical separation or } \\
\text { end to violence while } \\
\text { cohabitating }\end{array}$ \\
\hline
\end{tabular}


R1. Resilience

Sources of resilience that support subjects to navigate sibling violence
Code reply to interview question: What helped you get through it? 
Appendix E: Family Map Example 


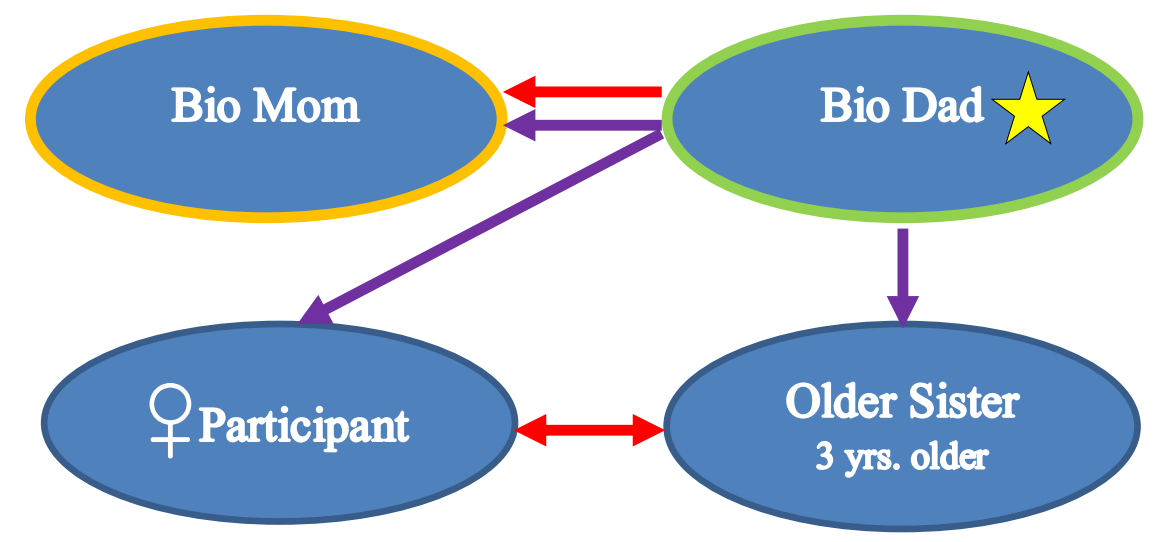

Map 1. Participant 0-5 years old

- Dad was a drug dealer and user. Bipolar - diagnosed and medicated.

- Dad was verbally and physically violent with mom (e.g., controlling, choked her, threw her up against the wall). "You could tell my mom was afraid of my dad.”

- Mom abused alcohol and described as "paranoid.”

- Mom was a teen parent to participant and older sister.

- Dad was “controlling” of participant and sister

- Participant and older sister fought over toys; Dad verbally reinforced that violence was an appropriate way for siblings to resolve disagreements.

- Dad was incarcerated for attempt to do bodily harm $\rightarrow$ Map 2

Physical violence
Emotional violence
Drug abuse
Alcohol abuse
Mental health challenges




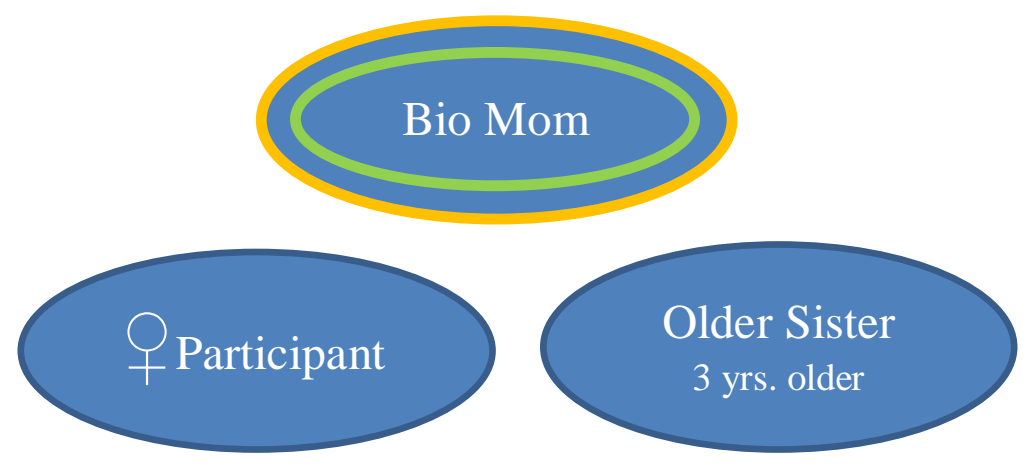

Map 2. Participant 5-9 years old

- Mom "was a mess" (heavy user of alcohol and meth) and "not around much."

- Sister was away a lot - started having sex "because no one was around... all the time trying to be gone,” ... "we didn't have a relationship almost.”

- Mom went to jail for meth $\rightarrow$ Map 3

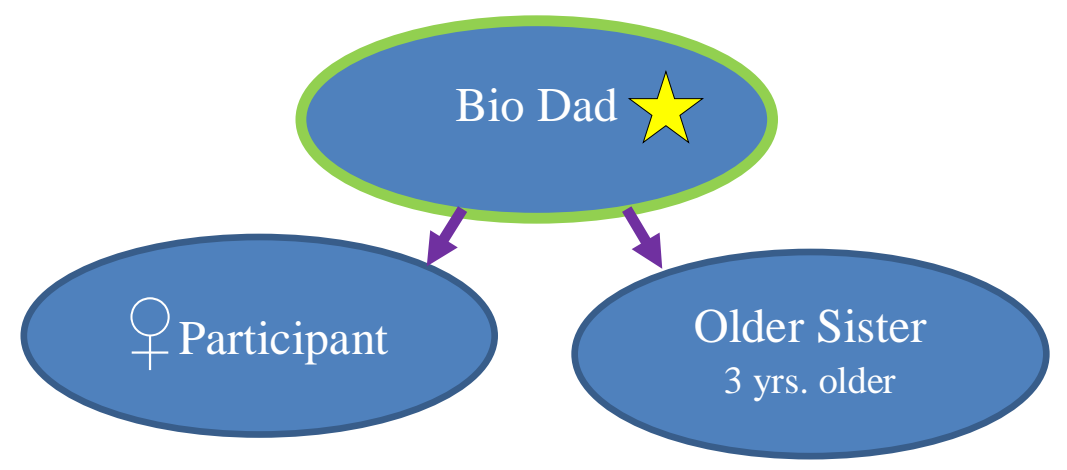

Map 3. Participant 9 years old

- Brief family formation.

- Dad "liked to have control” and sister didn’t like it. Sister opted to move in with mom $\rightarrow$ Map 4 


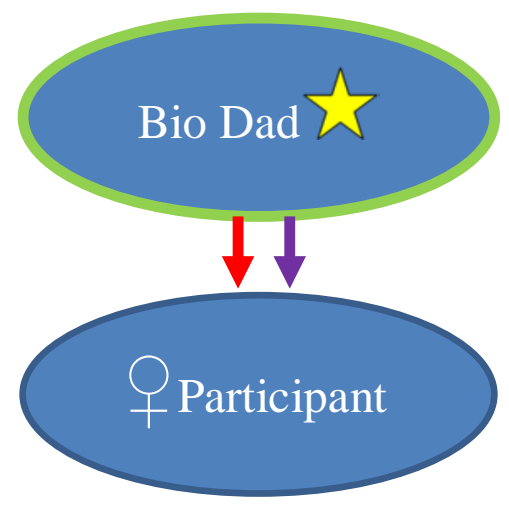

Map 4. Participant 9-12 years old

- Sister lived separately, with mom.

- Dad was physically abusive. Hitting that left marks. Also "scaring you" and "trying to be in control" by "having a screaming feud."

- Noteworthy that dad's physical violence followed his time in prison (likely a highly violent environment).

- $\quad$ Dad went to prison again for selling drugs $\rightarrow$ Map 5 


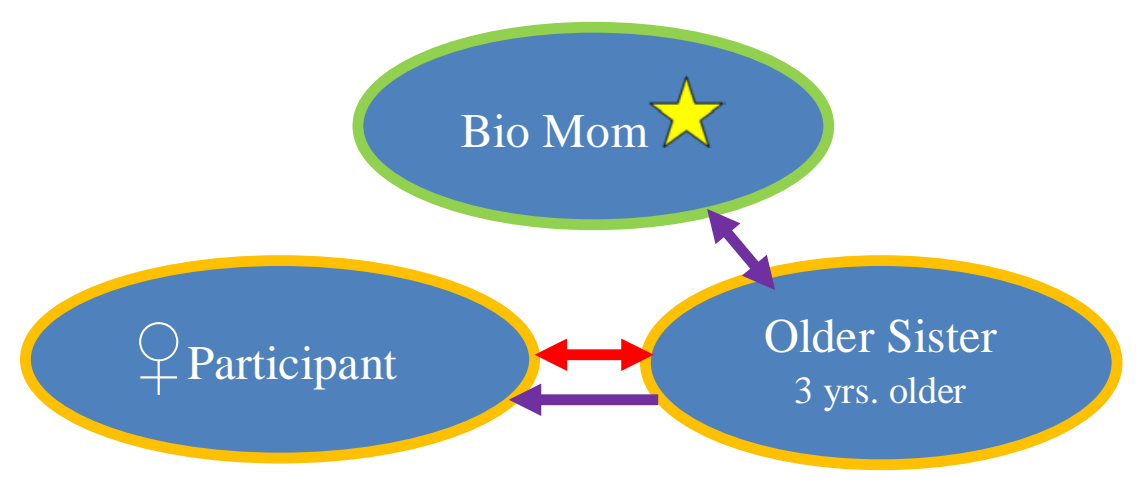

Map 5. Participant 12-13 years old

- Most pronounced sibling violence (i.e., weekly)

- Mom was depressed (meth use side-effect)

- Sibling Violence Patterns:

o Sister would be "really mean" to mom (response to differential treatment?) $\rightarrow$ Participant would then hit sister to "set her straight"

o Sister "would instigate it... she will abuse you verbally until you do something about it" $\rightarrow$ Participant would retaliate against verbal abuse with physical violence.

- Sister would physically fight back (lay on her back and kick).

- $\quad$ Mom and boyfriend have an intense drug episode $\rightarrow$ Map 6 


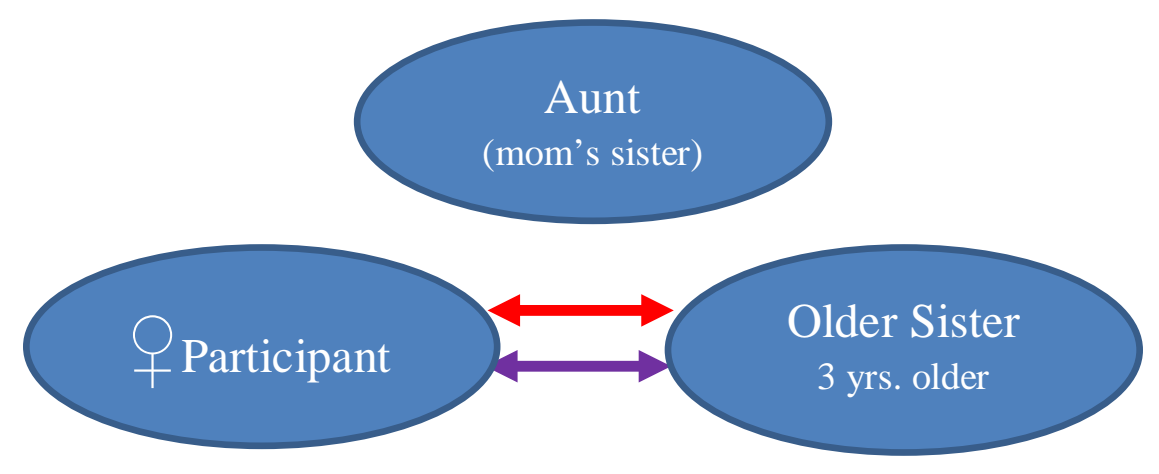

Map 6. Participant 13-14 years old

- Adoptive home

- Sibling physical and emotional violence until aunt intervened. Emotional violence continued until older sister moved out.

- Sister went to “juvi”, residential home, and participant never lived with her again. 


\section{Theory Synthesis}

Caffaro \& Meyers - Definitions of Abusive Sibling Violence

SUPPORTED - repeated escalating pattern, stable victim/offender roles (sister initiates conflict with emotional violence, participant responds with physical violence - stable instigator/retaliator roles)

[Participant] She would know. I would literally just look at her and she would know and she would run... that's what she does. She runs and then she does this thing where she falls on her back. She would like, kick, so you can't hit her. This one time she was doing that and she kicked me hard, and I flew all the way down the stairs. [Interviewer] How often was that?

[Participant] Probably every week or something... Not always her kicking me down the stairs or me punching her five times in the head, but just like, we would fight.

She would instigate it. She knew that was what I would turn to, physical violence. She was more like, verbal. Like she would abuse you verbally until you do something about it.

If my sister said something really mean to my mom, on multiple occasions it happened, I would hit her. I would run after her, wherever she would go, and just hit her wherever I could. And so that was typical... I would usually hit her on places like her head so you could never see it. She'd just be like "My head hurts, I have a big knot now." "Well, you shouldn't have said that. You shouldn't have done that." That's what I would say.

NOT SUPPORTED - no evidence of need for power/control, perception of perpetrator's behavior as abusive, victim sense of terror, or victim sense of powerlessness

\section{Social Learning Theory}

SUPPORTED - participant learned and then replicated physical violence from bio dad. This occurred in the absence of redirection. The "reward" was a sense of accomplishment for protecting mom

We really started fighting, like being physical toward each other, after I lived with my dad. I think if I was never really like, introduced to that, I wouldn't be hitting her.

I would hit her and stuff. Probably because my dad was hitting me before, and then I came and I was like, "This is how you deal with problems. This is what you do." Because that's what [dad] does. He hits people, and so, that's the way to do things.

\section{Radical Feminist Theory}


SUPPORTED - General acceptance of violence to meet desired ends is supported by bio dad (modeling) and bio mom (failure to intervene)

She used to take my toys from me all the time, and then she would hit me (giggles). And I would hit her with my toys. Like I specifically remember a time she took this phone away from me. We both had our own phones, but she took mine. I took it back from her and I hit her on the head. And I will never forget it. And my parents were like 'Don't take her stuff', and I felt pretty cool. I was like, you learned a lesson, right?

My mom was fine with it. I said, "Mom, I'm gonna fight this girl tomorrow, so be prepared to pick me up" and she was like "Okay." She was like, "I'll be waiting at work for you to give me a call." I was like, "Okay, cool."... you see, nobody made it not normal. It happened to me, so it was normal, from my dad. And then my mom wasn't like "Don't hit your sister. Don't go beat this girl up."

\section{Conflict Theory}

SUPPORTED - Poor family, parents are drug dealers with addiction and mental health problems, siblings have differential access to fashionable clothes, good food, clear demonstrations of parental favoritism

I was eating all these cool things [from our food stamps] at the table and then my sister came to get something to eat... and my mom comes out there like "What do you think you're doing?" and my sister was like, "Getting some food," and my mom was like "No. You can eat bread and butter for all I care." ...I always felt bad when my mom would be really mean to my sister, because she was so nice to me, and that obviously hurt my sister... I can't be out here eating a platter of all these different great foods we just bought and you be like "You can eat bread and butter for all I care" to my sister, while she's watching me eat whatever I want.

\section{Coercive Family Process}

SUPPORTED - Triad of mom, sister, and participant creates a patterned dynamic in which sister initiates through verbal abuse, to either mother or sister. Participant then retaliates with physical violence (replicated from abuse received from father), and sister responds with physical violence

[Participant] She would like, be really mean to my mom, like make my mom cry, and I was like "I have to straighten her out," that's what I thought.

[Interviewer] Straighten her out?

[Participant] Yeah, like I would hit her and stuff. 
I feel like my mom put us in that situation. So like, what could she have done? Nothing. She was putting me in the situation, so if she was like "Don't hit her," I would have been like, "I'm hitting her for you."

\section{Social Ecological Model}

SUPPORTED - community violence, “drug” communities, school bullying

We always lived in the same type of town... drug communities. Where I'm from meth is huge. That's like, normal, not a big deal, honestly. People being on drugs, like pills, and that kind of stuff... a lot of kids in foster care.

Fourth grade was the first time I experienced being bullied... I feel like rules were not implemented. It was not a good school. I was bullied on the bus, I was bullied in school... then in 5th grade, 6th and 7th grade I lived with my dad... I also experienced bullying there... I was learning how to be really mean in school. Because I had to be... I just feel like everyone did it... I got in a fist fight [in middle school] and got suspended. Middle school I was bullying people, people were bullying me. 
Appendix F: Human Subjects Application to IRB 


\section{IRB APPLICATION for EXPEDITED / FULL REVIEW}

IMPORTANT: PSU faculty and students must submit any research plan involving Human Subjects to the IRB for review. Use this application to request Expedited or Full review human subjects' research approval. If you believe the activities are Exempt, you may use the IRB Exempt Application. If you believe the activities do not meet the definition of "human subjects research" complete the Review Not Required Form and submit to hsrrc@pdx.edu. See Instructions page of this application for more details. Important: (1) Hard-copy submissions will not be accepted; submit electronically. (2) All questions must be answered, please enter N/A for questions that do not apply. (3) If the research is funded, a copy of the research proposal must be submitted to complete the application.

\section{Section I: Investigator's Assurance}

$\square$ This is a new protocol submission

$\bigotimes$ This is a revised initial review protocol submission with requested modifications

This is an amendment submission

Indicate which Sections are revised: (Check each applicable section and include all protocol revisions in red text or use track changes - see Instructions on Pg. 3)

$\square$ Section I: $\square$ Section II (indicate which parts: A-T): $\square$ Section III (indicate changed attachments/addendums):

Principal Investigator (or faculty advisor for students): Stephanie Wahab, Ph.D. (faculty advisor) E-Mail: wahabs@pdx.edu

Co-Principal Investigator: E-Mail:

Other Personnel (GA, Project Mgr., etc.): $\quad$ E-Mail:

Department: School of Social Work Campus Mail Code: SSW Preferred Phone \#: (503) 4753442

Title of Protocol: Study Examining Foster Care Alumni Perspectives on Abusive Sibling Violence Mailing Address: P.O. Box 751-SSW, Portland, OR 97207-0751

Proposed Duration of Project (months/years): 1 year Anticipated Start Date: February, 2018

Is this project funded? $\square$ Yes $\square$ Not yet (Application has been submitted) $\bigotimes$ No

Type of Funding: $\square$ Federal $\square$ State $\square$ Foundation $\square$ Other $\quad$ Funding Agency:

PIAF \#:

NOTE: If this is a funded project, a copy of the research proposal must be submitted. 
STUDENTS ONLY:

Master's Thesis $\quad$ PhD/EdD Dissertation (Approval Date:) $\square$ Other:

Under advisement from the above faculty member, I verify that I will conduct this research in accordance with PSU's Human Subjects Research Review Policy.

Student Name: Katie Winters, M.A. (type in your name and email electronic copy to your PSU mentor)

PSU Student ID \#: 925034915 Email: k.winters@pdx.edu Date: January 12, 2018

Investigator's Responsibilities and Assurances:

(Mark each box with an $\boldsymbol{\otimes}$ when understood/agreed/certified)

I understand PSU's policies concerning research involving human subjects and:

1. I I understand that I have ultimate responsibility for the protections of the rights and welfare of human participants, the conduct of this study, and the ethical performance of this research.

2. \I will maintain IRB related documents (including signed consent forms, as applicable) for a minimum of three years after the completion of the study.

3. I understand that it is my responsibility to ensure that all study personnel receive the mandatory human subjects' research protection education (either $\mathrm{CITI}$ or $\mathrm{NIH}$ ) and to maintain a training documentation file.

I agree to:

4. Comply with all PSU/IRB policies, decisions, conditions and requirements.

5. Х Obtain prior approval from the IRB before amending or altering the research protocol or changing the approved consent/assent form.

6. $\bigotimes$ Notify the Office of Research Integrity of the development of any financial interest not already disclosed.

7. $\bigotimes$ Notify the Office of Research Integrity for all adverse events and unanticipated problems as soon as possible. In case of DHHS supported activities, I will also report these problems to the Department of Health and Human Services (through the respective granting office).

I certify that:

8. $\bigotimes$ The time and resources are available to complete this project.

9. $\bigotimes$ The equipment, facilities, and procedures to be used in this research meet recognized standards for safety.

10. $\$ New information that may affect the risk-benefit assessment for this research will be reported to the Office of Research Integrity.

11. I I agree to ensure adequate supervision of all research study personnel and to meet with the investigator(s), if different then myself, on a regular basis to monitor progress. 
12. $\bigotimes$ The information provided in this application and all attachments is complete and correct.

Signature of Principal Investigator or Faculty Advisor:Stephanie Wahab

Date: $1 / 12 / 18$

(Type in name and submit by email to hsrrc@pdx.edu )

\section{Instructions-IRB Application for Expedited/Full Review}

\section{Application Requirements:}

- The IRB application for Expedited/Full Review has three parts:

1. Investigator's Assurance cover sheet (Section I)

2. Project Narrative (Section II)

3. Appendices (Section III)

- All questions must be answered. Please enter N/A for questions that do not apply.

- Consent documents must be written in at least 12 pt. font.

- Applications must be page numbered, including Appendices.

- Submit complete applications by email, to hsrrc@pdx.edu. Only Microsoft Word of Adobe PDF files will be accepted.

- IRB amendment submissions: Amendments to protocols initially submitted on or after May 1, 2014 must use this form. Include new information in red text or Track Changes.

- The Investigators Assurance serves as the researcher's contact information page and signature of assurance. This form must be filled out completely and accompanied by proper signatures. Electronic signatures will be accepted from $@$ @dx.edu email accounts.

- Information for student research only:

1. Graduate/undergraduate students cannot function as Principal Investigators (PIs).

2. Application must be signed and submitted by the advisor/PI (i.e., the faculty advisor must complete and sign the Investigator's Assurance as PI).

3. The student must sign the "Students Only" box on the bottom portion of the Investigator Agreement and provide their PSU ID number.

4. Graduate Studies requires PhD students to have committee approval of their dissertation prior to IRB submission (contact GSE for more details).

5. Student investigators may not include themselves as a human participant in their research. Also, recruitment of human participants from their immediate family, friends and associates should be avoided.

\section{‘Human Subjects' Definition and Resources:}


'Human subjects' is a legally defined term. In this document the terms participant, respondent and human subject or subject are all referring to the legally defined term "Human subject."

Information on activities meeting the definition of "human subjects' research" can be found on the "Review Not Required Form." Additionally, there are two areas researchers often ask about:

The following MEET the definition of human subjects' research:

1. NSF human subjects' activities, including performance data shared with NSF. (NSF retains all shared data in a data repository for future research purposes.)

2. Data collection about live humans that involves maintaining this data in a repository for future research purposes.

\section{How to "Unprotect" Application to Insert Red Text or Use Track Changes:} In Microsoft Word 2010 or 2013, click the "Restrict Editing" icon on the Developer Tab. In the sidebar, click "Stop Protecting." No password is required. Text editing in the form should be now allowed. For other versions of Word, or if you have any difficulties in removing document protections, please contact ORI at hsrrc@pdx.edu or 725-2227.

\section{Section II: Project Narrative (complete sections below)}

\section{A. Research Description:}

1. Explain why, what, how, who and when.

i. Why: (i.e., describe specific study aims, research questions to be studied, study goals and a brief description of the scientific background

After decades of incremental transformation, western society no longer condones adult-perpetrated child abuse, nor interpersonal violence between adult family members. While this progress is commendable, violence between siblings remains conspicuously absent from discourse on family safety and wellbeing. Labelled with trivializing terms such as "sibling rivalry" or dismissed as an innocuous phenomenon that children will simply outgrow, research offers compelling evidence to the contrary; child victims suffer numerous deleterious effects across the lifespan (Hoffman, Kiecolt, and Edwards, 2005, Kramer and Bank, 2005, Finkelhor et al., 2006, Button and Gealt, 2010, Graham-Bermann and Cutler, 1992, as cited in Caffaro, 2011, Feinberg et al., 2012). These effects are of great concern, given that sibling violence is now widely recognized as the most common form of intra-familial abuse; various estimates garnered from the general population suggest that 30 percent or more of children experience severe acts violence inflicted by a sibling each year (Finkelhor and Dziuba-Leatherman, 1994; Finkelhor, Ormrod, Turner, and Hamby, 2005; Straus and Gelles, 1990). 
Numerous studies have drawn linkages between a child's exposure to violence and their propensity to inflict violent acts upon others. Children who witness domestic violence between their parents are more likely to engage in violent behavior with their siblings and peers; sibling abuse is also more prevalent in families in which both spousal and child abuse are present (Button and Gealt, 2009; Henning et al., 1997; Spaccarelli, Sandler, and Roosa, 1994; Wallace, 1999, Wiehe, 1997). Co-occurrence of family violence types suggests that sibling violence is common among families served by the child welfare system, yet child welfare caseworkers, with their focus on interventions to mitigate harms perpetrated by adult caregivers, may miss indicators of sibling abuse. In cases where sibling relationship problems are noted, case workers may neglect to intervene because adult harms take precedence when family issues are triaged for intervention.

The proposed study will employ interview methods to gather qualitative data from foster care alumni who have experienced physical and emotional sibling violence. The research questions guiding the study are: (1) How do young people age 18-26 with a history of involvement in foster care describe their experiences with physical and emotional sibling violence? (1.a.) To what extent are theories of sibling violence represented in their descriptions? (1.b.) To what extent do the young people perceive the violence as abusive? (2) How do adults who care for or work with young people involved in the child welfare system (e.g., foster parents, case workers, mental health providers, kinship caregivers, etc.) respond to sibling violence? (2.a.) To what extent were responses perceived as helpful? (2.b.) What do foster care alumni recommend to address sibling violence?

ii. What \& How: (i.e., describe what the researchers and the participants will be doing and how these activities will be accomplished.)

Study participants will be comprised of a convenience sample recruited through FosterClub (https://www.fosterclub.com/_allstars/article/about-all-stars), New Avenues for Youth, and Portland State University Better Futures. Recruitment will begin with dissemination of the Recruitment Flyer (included as an attachment). The flyer will be distributed by each of the agencies listed. Foster care alumni who are willing to participate in the project will contact the researcher directly to learn more about the study. They will also receive the contact information of three foster care alumni who served as advisers for this study if they would like to hear about their experiences working with me prior to contacting me about the study.

The interview data will be collected in-person, at a location determined by each interview participant. I will only interview participants within a 1-day drive of Portland, OR and will work with each respondent to identify a location at is safe and private for the interview. Each interview will begin with the consent process, discussed in subsequent sections. After completing the consent process, each study participant will participate in an individual interview with the researcher, including completion of the family system map (included as an attachment). 
Upon conclusion of the interview, each participant will be asked to complete the Background Information form.

Who: (i.e., describe who the participants are and how they will be identified.)

Study participants will be recruited to meet the following criteria: (1) foster care alumni ages 18-26 years old with a history of involvement in the Child Welfare system; (2) with at least one (self-defined) sibling; (3) and for whom the study participant describes their sibling relationship as having been physically or emotionally violent in the period leading up to or during their involvement in foster care. The researcher will recruit participants via a convenience sampling process through agencies that serve foster care alumni.

iii. When: (i.e., describe the order of research activities in a timeline.)

Recruitment will begin in February 2018 (pending study approval). Interview(s) will occur from February through July 2018. The project will be complete 12months following the project start date.

\begin{tabular}{|l|l|}
\hline \multicolumn{1}{|c|}{ Activity } & \multicolumn{1}{c|}{ Dates } \\
\hline Recruitment - distributes recruitment flyers & February-June, 2018 \\
\hline Interviews & February-July, 2018 \\
\hline Data Analysis \& Synthesis & March-November, 2018 \\
\hline Study Completion - Notify PSU IRB & December, 2018 \\
\hline
\end{tabular}

\section{B. Study Design \& Setting}

1. Describe the study design:

The dissertation study will investigate abusive sibling violence among youth involved in the child welfare system via in-depth interviews that include completion of a family system map and completion of a background information form which will capture basic demographic information. The study is grounded in a critical realism (CR) philosophy of science, and is designed with the goal of building theory of abusive sibling violence in the context of child welfare. by generating emergent themes describing research participants' attitudes and experiences. With participant permission, the interview(s) will be recorded to accurately capture the dialogue which takes place. I will transcribe qualitative data from the interview(s) for review and analysis.

The data analysis process will be researcher and theory-driven, including three key steps: (1) identification of demi-regularities; (2) abduction, and; (3) retroduction (Fisher, 2017). The process is non-linear, moving from the concrete, to the abstract, and then returning to the concrete (Sayer, 1992). Specifically, I will employ Mayring's (2000) deductive category application process, which works with theoretically derived codes to organize textual data. Theories discussed in the sibling violence literature will be the categories for the initial coding scheme, as will 
the key critical realism concepts of structure, agency, and open systems. The categories will be continuously refined through a constant comparison analysis approach which will occur over the course of data collection. The codes that are most prevalent (i.e., dominant) in the data will comprise the demi-regularities.

Once the demi-regularities have been identified, I will engage in abduction and retroduction, thought exercises serving to elucidate meaningful causal theory that incorporates not only underlying structures, but also the human actions which fortify or dismantle them. Abduction will consist of a cross-walk between the demiregularities and the previously developed theories and CR concepts with the goal of uncovering causal mechanisms of abusive sibling violence. I will use retroduction to explore the contextual conditions necessary for a particular causal effect to manifest at the empirical level. Retroduction focuses on theorizing about the social, cultural, and/or historical conditions in which a causal mechanism takes effect (Fletcher, 2017; Lennox \& Jurdi-Hage, 2017).

To establish trustworthiness I will maintain an audit trail throughout the study such that it will be possible to follow the process of data analysis and synthesis back to the original transcripts. I will engage a member of members of my dissertation committee to review examples from the audit trail for guidance about data reduction as needed. My committee will also serve as a panel of auditors who will review the initial deductive categories, definitions, examples, and coding rules I develop to guide the initial phase of analysis (i.e., identification of demi-regularities). At appropriate junctures over the course of the data collection and analysis process I will again engage the members of my committee to review the categories as they are expanded and refined. Specifically, I will do this whenever I substantially revise the initial categories or add numerous and highly divergent additional categories to the analysis framework. Finally, I will carry out reflexive memoing throughout the data collection and analysis phases to explore how my own conceptions bear upon the process of interpretation. I will debrief with my academic adviser and student peers to discuss the issues that arise in the memos in order to grow as a researcher and to garner emotional support to engage with this sensitive topic.

2. Identify the sites or locations where the research/data analysis will be conducted: To be determined

3. Describe the Principal Investigator's experience conducting research at study site(s) (or similar sites) and familiarity with populations and communities: The student researcher has experience conducting in-depth interviews with pregnant women and new mothers receiving home visiting services for lowincome women who self-report risk factors including IPV, drug/alcohol problems, a history of abuse/neglect including Adverse Childhood Experiences. For the study I conducted interviews with women in their homes throughout the state of Oregon. In addition to this interviewing experience, I have experience working with foster care alumni through two past projects implemented in collaboration with FosterClub. First, I 
conducted a pilot of this study with FosterClub interns (i.e., foster care alumni participating in a leadership development program). Second, I worked with four foster care alumni who served as "sibling study advisors" providing consultation on this study via a series of conference calls. Finally, as a mid-career evaluator, I have been involved in many evaluations of health and human service programs including school readiness, child maltreatment prevention, public health, and out of school time programs, among others. These projects have included site visits and face-to-face interviews and focus groups with a variety of program stakeholders including parents, children, and students.

4. Is the research conducted outside the United States? $\square$ Yes $\square$ No

a. If yes, describe site-specific regulations or customs affecting the research, local scientific and ethical review structure: N/A

5. Are there any permissions that have been, or will be, obtained from cooperating institutions, community leaders, or individuals, including approval of an IRB or research ethics committee? $\square$ Yes $\square$ No

a. If yes, provide a list of the permissions (also include copies with the application, if available): Permission has been obtained via email communication from Celeste Bodner, FosterClub Chief Executive Director, Founder, Non-Voting Board Member. I will seek approval from New Avenues for Youth and the PUS RTC for Pathways to Positive Futures once this amendment is approved.

6. Does the research require approval from other PSU compliance committees?

(e.g., Radiation Safety Committee (RSC), Institutional Animal Care and Use Committee (IACUC), and Institutional Biosafety Committee (IBC), etc.) $\square$ Yes $\square$ No

If yes, the $\mathrm{PI}$ is responsible for seeking approval from the other committees required for this research. Work cannot start until final approval is received from all

appropriate committees. List each compliance committee review required: N/A

7. Provide an approximate number of subjects to be enrolled and justify the sample size: Interview participants will count 6-12 foster care alumni living within a 1-day round-trip drive from Portland, OR. The sample size is small, per the CR philosophy and constructivist epistemology grounding the study. In addition, this is an unfunded dissertation project and so is subject to resource constraints.

(Provide information for each subject group, as defined in the sections $8 \mathrm{~A}$ and $8 \mathrm{~B}$ below. For example, minors' \#, crime victims' \#s, etc.):

8. Approximate total number of subjects to be recruited: 6-12

a. Please identify subjects that will be recruited by checking all that apply in $\mathbf{8 A}$ and $8 \mathrm{~B}$. Submit additional materials as required.

A. Children or Adult: Check all that apply 


\begin{tabular}{|l|l|}
\hline$\square$ Birth to 3 years & Parental Permission Form \\
\hline$\square$ 4-7 years & $\begin{array}{l}\text { Parental Permission Form and Verbal } \\
\text { Child's Assent }\end{array}$ \\
\hline$\square$ 8-17 years & $\begin{array}{l}\text { Parental Permission Form and Child's } \\
\text { Written Assent }\end{array}$ \\
\hline$\square 18$ \& over & Written Consent \\
\hline
\end{tabular}

B. Potentially Vulnerable Populations: If potentially vulnerable populations will be recruited, identify these groups by checking below.

$\square$ Neonates/Fetuses

$\square$ Children (Complete $\underline{\text { Addendum } 4}$ and include in application.)

$\square$ Prisoners (Complete Addendum 5 and include in application. If using prisoner data sets collected for other than research purposes complete Addendum $5 \mathrm{a}$ and include in application.)

$\square$ Pregnant women

$\square$ Decisionally impaired (for groups not already identified on this list)

$\square$ HIV/AIDS patients

$\square$ Native American Tribes

$\square$ Crime victims

$\square$ Substance abusers

$\square$ Persons living outside the U.S.

$\square$ Non-English speaking

$\square$ Terminally ill

$\square$ Institutionalized individuals

$\square$ College Students

$\bigotimes$ Other: Young adults who have aged out of the foster care system

9. Are there groups of people purposefully being excluded? $\square$ Yes $\square$ No

A. If yes, identify the groups that are being excluded [Check all that apply in 9A and explain the reasons for exclusion in $9 B$ below]:

$\square$ Ethnic/racial groups $\$ Non-English speaking

$\square$ Adults 65 or older $\square$ Sexual orientation

$\square$ Children (under 18) $\square$ Marital status

$\square$ Pregnant women $\square$ Religion

$\square$ Males $\quad \square$ Other: 
Females

B. Explain the reasons for the exclusion criteria identified in \#9A: I am mono-lingual so cannot conduct interviews in languages other than English. The pilot is not funded so does not include budget for language interpretation services.

\section{Describe safeguards to protect the rights and welfare of vulnerable populations:}

Participants will represent a 'vulnerable' population. Considerations for sense of safety are therefore paramount to ensuring a positive participant experience and obtaining meaningful data. I will address these key social dynamics in a number of ways which are informed by the literature and the guidance of the sibling study advisors. First, I have built information about myself into the data collection instrument and I will use this rapport-building process to foster a two-way relationship that models a save level of self-disclosure about my own experiences with sibling violence and may serve to disrupt the research-participant power imbalance. Second, I will explicitly convey that the interviewee holds the power to guide the process in that they can decide where we meet, which questions to answer, and that they can stop participating at any time. Third, throughout my engagement with each participant I will emphasize an ethic of care that privileges empathy and mutual respect over capturing data. For example, if a participant demonstrates a desire to discuss a topic unrelated to the focus of the inquiry, I will allow time and space for this as a demonstration that their needs are important, valid, and are equal to my own.

The alumni who participate in the research face a risk of psychological distressthis could occur during the interview(s), or after data collection is complete. I understand that talking about personal experiences can make some people feel uncomfortable, angry, sad, guilty, or embarrassed. I will work to mitigate these sources of discomfort by emphasizing the importance of avoiding over-disclosure and to not say anything that they are not comfortable sharing. Study participants will be reminded that their participation is voluntary and that they can take a break, not respond to some questions, or choose not to continue with the pilot at any time. I will interact in a calm, respectful manner and I will be alert to instances of distress. If needed, I will pause the interview and inquire about their desire to continue (or need for a break) if it appears that any participant is becoming distressed.

There is also a small risk that information shared during data collection will be seen by those other than me. During the consent process I will emphasize the following points which will be included in the consent form:

1. I will not talk to anyone about individuals who participate in the study

2. Participant information will be kept private including names or other potentially identifying information 
3. All study information will be stored in locked cabinets and on passwordprotected computers

4. Recordings will be transported in a locked briefcase and uploaded onto a secure server

5. I (Katie Winters) and my dissertation supervisor are the only people who will see participant information

In addition to these risks, by participating in the alumni will be at increased risk of being subject to mandatory reporting if they share that they plan to hurt themselves or others, or report that they are in imminent danger. In such case I will call the appropriate authorities. I will provide detailed information about my role as a mandatory reporter during the consent procedures.

(See Additional Requirements for Research with Vulnerable Populations for guidance regarding children, prisoners and participants who become incarcerated after enrolling. Contact ORI for guidance regarding human fetuses and neonates.)

\section{Data Collection Methods}

Check all method(s) to be used (Include copies of all the data collection methods checked in Survey/Questionnaire or Interview sections below, including translations, if applicable.):

1. $\triangle$ Survey/Questionnaire - Identify modality(ies)

\In person $\square$ Web-based $\square$ E-mail $\square$ Postal mail $\square$

Telephone $\square$ Other:

2. $\bigotimes$ Interview - Identify modality(ies) $\bigotimes$ One-on-one $\square$ focus group $\square$ Oral history $\square$ other:

3. $\square$ Observation of Public Behavior - Identify modality(ies) $\square$ Classroom $\square$ Public meetings $\square$ other:

4. $\square$ Examination of Archived Data/Secondary or Records Briefly describe the records to be examined:

5. $\square$ Taste Evaluation $\square$ Wine/alcohol $\square$ *Non-wholesome food $\quad \square$ Genetically altered food *Wholesome food may meet Category 6 exemption. Fill out Exempt form.

6. $\square$ Examination of Human Pathological or Diagnostic Tissue Specimens (e.g., blood, bodily fluids) 
7. $\square$ Unproven or Untested Procedures

$\square$ Biomedical $\square$ Psychological $\square$ Other:

If any checked, describe:

8. $\bigotimes$ Recordings - Identify type(s)

$\triangle$ Voice $\square$ Video $\square$ Photograph/Image

$\begin{array}{lll}\text { Check Method of recording: } & \square \text { Analog } & \square \text { Digital } \\ \text { Check the purpose of the recordings: } & \square \text { For transcription } & \square \text { Other }\end{array}$

If checked 'Other' explain: (For example, recorded for speech pattern analysis, archiving purposes, presentation at the meetings, etc.)

9. $\square$ Internet:

10. $\square$ Social Media:

11. $\square$ Other:

\section{Recruitment Methods}

Does the study involve the recruitment of participants? $\quad$ Yes $\square$ No

1. Describe recruitment/advertising methods:

Participants will be initially recruited through the FosterClub, New Avenues for Youth, and the PSU RTC for Pathways to Positive Futures, which will disseminate the recruitment flyer with study information through their networks. Those who are interested in learning more will have the opportunity to hear about the purpose and procedures for the project directly from the researcher prior to opting in to the project, as well as to talk to sibling study advisers who have agreed to serve as foster care alumni references for the study. Recruitment will be, at minimum, a two-step process. Potential participants will express interest with the recruitment flyer. The consent process will serve as the second step in the recruitment process.

Check all that apply and attach all recruitment materials that will be used:

$\begin{array}{ll}\square \text { Person to person } & \square \text { Media (TV, newspaper, radio, Web site) } \\ \square \text { Phone } & \square \text { Social Media } \\ \square \text { Postal mail } & \square \text { Other: } \\ \square \text { E-mail } & \end{array}$

2. How will potential subjects be identified and how will potential subjects be approached 
to participate? (Answer for each subject group)

Explain in detail: Potential subjects will include foster care alumni who are connected to FosterClub, New Avenues for Youth, and the PSU RTC for Pathways to Positive Futures The agencies will disseminate the recruitment flyer information through their networks.

3. Who will obtain consent/assent and when will that be done? (Answer for each subject group) Katie Winters, M.A.

Explain in detail: I will obtain consent on the day that the interview occurs. I will provide a hard copy of the consent form and verbally review it in detail.

4. What screening procedures or tools will be used? (Answer for each subject group)

Explain in detail: The consent process will occur on the day that the interview is conducted. I will provide a consent form to the potential study participant which specifies what the participant will be asked to do, how the data will be used, associated risks and protections, and that participation is voluntary. I will review the consent form in its entirety and answer questions that participant has about the form or study procedures. I will emphasize that the participant can revoke consent at any time throughout the pilot process. I will ask permission for the discussion(s) to be recorded. I will describe the purpose of audiorecording, including the added ability to capture accurate information when the recording is transcribed, and to be able to practice respectful and active listening during the discussion(s). Participants may refuse to be recorded. In this case, I will respect this decision and take notes during the discussion(s).

For each participant who opts to sign the consent form and proceed with the pilot, I will retain a signed copy which will be kept in a locked file cabinet throughout the study period. I will provide a participant copy to each participant who opts in.

\section{E. Consent Process}

Choose all that apply and attach appropriate forms to this application. (See Informed Consent or Waiver of Consent Checklists for guidance.)

1. $\bigotimes$ Adult(s) $\square$ Children $\square$ Parent(s) $\square$ Guardian(s)/legally authorized representatives

\begin{tabular}{|l|l|}
\hline$\square$ Written & $\begin{array}{l}\text { A consent, assent, or permission form that contains } \\
\text { all of the required elements of informed consent. }\end{array}$ \\
\hline $\begin{array}{l}\text { Alteration of } \\
\text { Informed }\end{array}$ & $\begin{array}{l}\text { Requesting IRB approval for waiver of some or all } \\
\text { of the elements of informed consent, assent, or }\end{array}$ \\
\hline
\end{tabular}




\begin{tabular}{|c|c|}
\hline $\begin{array}{l}\text { Consent/Assent } \\
\text { process }\end{array}$ & $\begin{array}{l}\text { permission (i.e. medical record review, deception } \\
\text { research, or collection of biological specimens). } \\
\text { If checked, complete Addendum } 1 \text { and submit with } \\
\text { the application. }\end{array}$ \\
\hline $\begin{array}{l}\text { Waiver of } \\
\text { Documentation } \\
\text { of Informed } \\
\text { Consent/Assent }\end{array}$ & $\begin{array}{l}\text { Requesting IRB approval for waiver of the } \\
\text { requirement for documentation of informed } \\
\text { consent, assent, or permission (i.e. telephone } \\
\text { survey or mailed survey, internet research, or } \\
\text { certain international research). } \\
\text { If checked, complete Addendum } 2 \text { and submit with } \\
\text { the application. }\end{array}$ \\
\hline $\begin{array}{l}\text { Waiver of } \\
\text { Informed } \\
\text { Consent/Assent } \\
\text { Process }\end{array}$ & $\begin{array}{l}\text { Requesting IRB approval for waiver of the } \\
\text { requirement for the informed consent, assent, or } \\
\text { permission process (i.e. medical record review, } \\
\text { deception research, or collection of biological } \\
\text { specimens). } \\
\text { If checked, complete Addendum } 3 \text { and submit with } \\
\text { the application. }\end{array}$ \\
\hline
\end{tabular}

2. What steps have been taken to prevent potential coercion or undue influence in recruiting subjects and obtaining consent or assent? (For example, if the project involves students of the PI or a product developer who will be testing the product, a neutral third party must be engaged in these processes.) Explain in detail: The first phase of recruitment will be carried out by FosterClub, New Avenues for Youth, and the PSU RTC for Pathways to Positive Futures in that they will disseminate the recruitment flyer through their networks. Interested participants will have the option of talking/emailing/texting with a sibling study adviser to hear the perspective of a peer about their experiences working with me. Interested participants will then contact me by telephone or email to schedule a study screening telephone call in which I will share more about the study and confirm that they have direct experience with physical and/or emotional sibling violence. I will emphasize the voluntary nature of the study during the screening call and again during the face-toface consenting process. For those who agree to be interviewed, the final phase of the consent process will occur face-to-face prior to the interview. The participants will receive a \$20 gift card to Amazon.com, as an expression of appreciation for their contribution to the study.

\section{F. Study Procedures}

1. Describe any study procedures that have not been described elsewhere: 
2. Does the study involve the collection of data/specimens (including the use of existing data/specimens)? $\square$ Yes $\square$ No

a. If yes, indicate how, when, where and from whom specimens or data will be obtained and what data or specimens will be collected: N/A

3. Is there a data and safety monitoring plan (required for greater than minimal risk studies)? $\square$ Yes $\square$ No

a. If yes, describe the plan: All data collection procedures will be HIPAAcompliant. Data will be stored on a password-protected computer and locked file cabinet. Any breach of participant data will be reported to the IRB immediately.

4. Are there any anticipated circumstances under which participants will be withdrawn from the research without their consent? $\square$ Yes $\square$ No

a. If yes, describe the circumstances, as well as any associated procedures to ensure orderly termination: N/A

\section{G. Risks/Benefits}

1. Potential risks to participants (check all that apply):

$\bigotimes$ Invasion of privacy to the subject or family

$\bigotimes$ Breach of confidentiality

Physical harm or discomfort

$\bigotimes$ Psychological/emotional discomfort or distress

$\square$ Psychological effect that is more than discomfort or distress

$\square$ Social stigmatization

$\square$ Economic (e.g., employment, insurability)

$\square$ Legal

$\bigotimes$ Any study related activity which subjects might consider sensitive, offensive, threatening, or degrading?

Withholding standard care and procedures

Significant time or inconvenience

Other:

2. Does the study pose risk to individuals other than the participants?

Explain in detail: N/A

3. Indicate the risk category that most accurately describes the risk level for the risks identified in Section G, questions 1 \& 2 above: 
$\bigotimes$ Not greater than minimal risk ${ }^{16}$

$\square$ Greater than minimal risk, but presenting the prospect of direct benefit to individual subjects

$\square$ Greater than minimal risk, no prospect of direct benefit to individual subjects, but likely to yield generalizable knowledge about the subject's disorder or condition

Research not otherwise approvable which presents an opportunity to understand, prevent, or alleviate a serious problem affecting the health or welfare of subjects

4. How will these potential risks be minimized in order to protect subjects' rights and welfare? (See Additional Requirements for Research with Vulnerable Populations for guidance regarding children, prisoners and participants who become incarcerated after enrolling. Contact ORI for guidance regarding human fetuses and neonates.)

Explain in detail: Great care will be taken to minimize risk to participants who choose to engage in the research. Participants will be encouraged to skip questions that they do not want to answer, to take breaks if needed, and will be told that they can leave the conversation at any time, and for any reason. To further reduce the potential that participants will experience emotional distress during the discussions, I will closely monitor participant affect and if any participant appears upset or agitated, I will check in with them about their wellbeing.

5. In the event that any of these potential risks occur, how will it be handled (e.g. compensation, counseling, etc.)?

Explain in detail: Participants demonstrating discomfort during the interview(s) will be encouraged to take a break or discontinue participation. All participants will receive general assistance information which will be included on the consent form (e.g., 211 info number). Breaches of participant confidentiality will be reported to the PSU IRB and any recommended actions will be executed immediately to remedy harm done through the breach.

6. Is it probable that a subject's previously unknown physical or psychological condition will be discovered (e.g. disease, depression, genetic predisposition, illegal activity etc.) as a result of the study activities? $\square$ Yes $\bigotimes$ No

a. If yes, what would types of conditions could be discovered and how will

\footnotetext{
${ }^{16}$ Minimal risk" means that the probability and magnitude of harm or discomfort anticipated in the research are not greater in and of themselves from those ordinarily encountered in daily life or during the performance of routine physical or psychological examination or tests. 45 CFR 46.102 (i)
} 
these situations be handled?

Explain in detail:

7. Describe the expected benefits of this project (NOTE: compensation is not considered a benefit):

a. To the individual subjects:

Explain in detail: Study participants may benefit from the knowledge that others have also experienced sibling violence, and so they are not alone in that regard.

b. To society:

Explain in detail: Society will benefit from increased knowledge of a common, yet understudied and poorly understood phenomenon.

8. Explain how, in your assessment, benefits of this study outweigh the risks. (e.g. risk/benefit ratio): Previous studies of sibling violence have not included youth voice. By engaging youth in conversations about their experiences with sibling violence, the study has far-reaching potential to inform child welfare practice and policy on a national scale.

\section{H. Available Resources}

1. Are there research staff members, in addition to the Principal Investigator/Student Investigator?

$\bigotimes$ No (If no, skip to 3)

$\square$ Yes

a. If yes, outline training plans to ensure that research staff members are adequately informed about the protocol and study-related duties: N/A

2. If necessary to the research, describe the minimum qualifications for each research role (e.g., RN, social worker), their experience in conducting research, and their knowledge of study sites and culture(s): N/A

3. Briefly describe how the research facilities and equipment at the research site(s) support the protocol's aims (e.g., private rooms available for interview, etc.): I will work with each participant to agree on a private location for the interview.

4. Are there provisions for medical and/or psychological support resources (e.g., in the event of incidental findings, research-related stress)? $\triangle$ Yes $\square$ No $\square$ N/A (not needed)

a. If yes, describe the provisions and their availability: All participants will receive general assistance information which will be included in the consent form (e.g., 211 info number).

\section{Reportable Events}


Outline plans for communicating reportable events (e.g. adverse events or unanticipated problems involving risks to participants or others, breach of confidentiality, child abuse, and suicidal ideation): Adverse events or unanticipated problems such as loss of data files or extreme emotional responses to participation in the pilot will be reported as soon as possible to the PSU IRB with the Unanticipated Problems/Adverse Event Report Form. Any mandatorily reportable events will be reported to the appropriate authorities.

\section{J. Research Related Injuries}

1. Does this research involve greater than minimal risk to participants? $\square$ Yes $\square$ No

2. If yes, are there provisions for medical care and compensation for research-related injuries?

$\square$ Yes $\bigotimes$ No

a. If yes, outline these provisions (Medical treatment should be available including first aid, emergency treatment and follow-up care as needed. If the research plan deviates from this policy, provide appropriate justification. Compensation for physical injuries that result from study participation is not generally required): N/A

\section{K. Participant Privacy}

Describe provisions to protect participants' privacy (their desire to control access of others to themselves, e.g., the use of a private interview room) and to minimize any sense of intrusiveness that may be caused by study questions or procedures.

In addition to carrying out the interview(s) in a private room, participants will be strongly encouraged to avoid over-disclosure. The primary purpose of the study is to learn about child welfare-involved youth's experiences with sibling violence. Participants will be encouraged to focus on these aspects of their experiences and to disclose the details of their violent interactions only to the extent that they feel will helpful to understanding the circumstances surrounding their experience.

\section{Data Confidentiality}

1. Will the information obtained be recorded in such a manner that participants can be identified, either directly or through identifiers linked to the participants?

$\triangle$ Yes $\square$ No

2. Will data be made public? $\square$ Yes $\square$ No

a. If no, describe provisions to maintain confidentiality at each phase of the data in the research. If engaging in internet or social media research, provide copies of the sites privacy policy and include an explanation of how approval is obtained for performing research activities that include these sites or explain why approval is not required: During travel to/from the program site, all study materials will be kept with the interviewer at all times. Upon return to Portland, I will transfer any identifiable paper documents to a locked cabinet. I will download recordings to a password protected computer, make a back-up copy on a USB flash 
drive (which I will keep in a locked cabinet), and then delete the recording from the digital recorder. All data will be maintained in a fashion that is in compliance with HIPAA regulations.

b. If yes, verify by checking "yes" that participants will be informed of what data will be public and this information is included in the consent/assent form/processes.

$\square$ Yes

\section{Confidentiality of Data Collection Instruments}

Instructions: List all data collection instruments covered in this IRB application. For each instrument, enter the letter designating the level of confidentiality for this instrument at each data stage. Use the following Confidentiality codes:

$A=$ Anonymous (No identifiers that link the data to a specific subject)

$U=$ Unlinked-Confidential (Collected with identifier or code, but all identifiers \& codes are removed)

$\boldsymbol{C}=$ Coded-Confidential (Linked to a specific subject by a code, not by a direct identifier)

I=Intentionally Identified (Personal identifiers and research data are stored together in one file)

\begin{tabular}{|c|c|c|c|c|}
\hline \multirow[b]{2}{*}{ Instrument } & \multicolumn{4}{|c|}{ Data Stage } \\
\hline & Collection & Analysis & Storage & Dissemination \\
\hline Example: Teacher Survey & $\mathrm{A}$ & $\mathrm{A}$ & $\mathrm{A}$ & $\mathrm{A}$ \\
\hline Example: Teacher Interview & 1 & C & C & A \\
\hline 1. Interview Protocol & $\mathrm{A}$ & A & A & $\mathrm{A}$ \\
\hline $\begin{array}{l}\text { 2. Participant Background } \\
\text { Information }\end{array}$ & I & 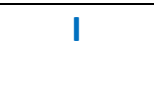 & I & $\mathrm{U}$ \\
\hline
\end{tabular}

4. Method(s) of protection and location of data storage: (Check all that apply)

$\bigotimes$ Locked office

$\bigotimes$ Locked cabinet

$\square$ Coded to a master list

$\square$ Other:

When coded to a master list, check the appropriate description of how the master list will be kept separate from the data: 


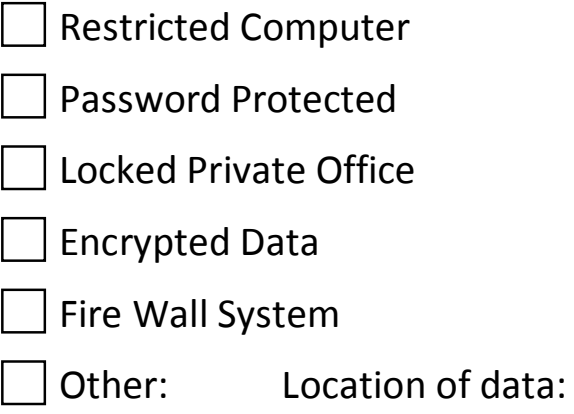

Building and room number: 1924 SE $11^{\text {th }}$ Ave., \#7, Portland, OR 97214

Electronic storage location: 1924 SE $11^{\text {th }}$ Ave., \#7, Portland, OR 97214

5. How long will research materials be stored, and when will they be destroyed, including voice/video/digital/images? (PSU guidelines require all research materials (consent forms, surveys etc.) to be kept for a minimum of three years after completion of the study.) The research materials will be kept for three years and then will be destroyed.

6. Will the data be transmitted? $\square$ Yes $\square$ No

a. If yes: i. How long will data be transmitted and stored? N/A

ii. What are the plans for the data at the end of the storage period (how will it be destroyed, or will it be returned to data provider)? Paper forms will be shredded. Digital recordings will be deleted.

7. How will research team members and/or other collaborators have access to information about study participants? I (Katie Winters) and my dissertation supervisor are the only people who will need access to the information about study participants. It will not be shared.

\section{Costs and Payments}

1. Identify any costs that participants may incur during the study, including transportation, costs, childcare, or other out-of-pocket expenses: None.

2. Will subjects be compensated for these costs? $\square$ Yes $\bigotimes$ No

a. If yes, what is the compensation, how much will the subject be offered, and how will they receive it? (i.e., money or gift certificate, extra credit, etc.) N/A

3. Are there any OTHER payments, compensations or reimbursements that participants may receive during the study that are not related to participant incurred costs?

$\bigotimes$ Yes $\square$ No

If yes, specify the amount, method and timing of disbursements: Participants will each receive a \$20 Amazon gift card to thank them for their contribution to the study.

4. Will compensation be extra credit?

$\square$ Yes $\bigotimes$ No

a. If yes, students must be able to complete an alternative assignment for extra credit, should they choose not to participate in the research. This assignment must 
be comparable, with respect to time and effort, as the participation in research.

Describe the alternative assignment: N/A

5. When will the participants be compensated?

$\bigotimes$ Before the study $\quad \square$ Installments during the study

$\square$ Withdraw/complete the study

\section{N. Multi-site Study Management}

1. Does the study involve multiple sites? $\square$ Yes $\square$ No

a. If yes, describe plans for communication among sites regarding adverse events, interim results, protocol modifications, monitoring of data, etc.: N/A

\section{O. Investigational Drug, Biologic or Device}

1. Does the study does involve an investigational Drug, Biologic or Device? $\square$ Yes $\bigotimes$ No

2. Identify and describe the drug/biologic/device (e.g., marketing status): N/A

3. Is there an IND/IDE, classification of a device as significant vs. non-significant risk?

$\square$ Yes $\square$ No

4. Describe its administration or use: N/A

5. Compare the research drug/biologic/device to the local standard of care: N/A

6. Describe plans for receiving, storage, dispensing and return (to ensure that they will be used only for participants and only by authorized investigators): N/A

7. If proven beneficial, describe anticipated availability and cost to participants poststudy, and plans (if applicable) to make available: N/A

\section{P. HIPAA Privacy Protections}

1. Are HIPAA privacy protections required? $\square$ Yes $\square$ No

(Protected Health Information obtained from a Covered Entity [e.g. a hospital or community health center] requires these protections. PSU is not a Covered Entity.)

If yes, fill out the HIPAA Application Supplemental form.

If unsure, refer to the HIPAA Application Supplemental form for guidance, or call ORI for assistance.

\section{Q. Human Data and Human Specimen Banking}

(These are repositories established by PSU investigators for the purpose of storing data and/or specimens for future research purposes. Data banking includes electronic data files and databases.)

1. Does the study include Specimen Banking? $\square$ Yes $\bigotimes$ No

2. Does the study include Data Banking? $\square$ Yes $\triangle$ No

3. Identify what will be collected and stored, and what information will be associated with the specimens: N/A 
4. Describe where and how long the data/specimens will be stored and whether participants' permission will be obtained to use the data/specimens in other future research projects: N/A

5. Identify how and who may access data/specimens: N/A

6. Will specimens and/or data be sent to OR from research collaborators outside of PSU?

$\square$ Yes $\bigotimes$ No

a. If yes, describe the plan: N/A

\section{R. Sharing Study Results}

1. Is there a plan to share study results with individual participants? $\square$ Yes $\square$ No a. If yes, describe the plan:

2. Is there a plan to disseminate aggregate results to the community where the research is conducted? $\square$ Yes $\bigotimes$ No

a. If yes, describe the plan:

\section{S. Disclosure of Financial Interests}

Does the PI, Co-PI, or any other person responsible for the design, conduct, or reporting of this research have an economic interest in, or act as an officer or director of, any outside entity whose financial interest would reasonably appear to be affected by the results of the study? $\square$ Yes $\bigotimes$ No

If yes, complete below:

a. Name of the person with a potential financial conflict of interest (COI): N/A

b. Explain the potential financial conflict of interest: N/A

c. Explain how the potential financial conflict of interest will be managed: (If the financial interest is a "significant financial interest" as defined in PSU's Financial Conflict of Interest Policy, submit the management plan established with the Financial Conflict of Interest Committee.) N/A

\section{T. Regulatory Compliance}

This section is for documenting compliance with other regulatory requirements.

1. Are student records being used? $\square$ Yes $\square$ No a. If yes, describe how compliance will be maintained with the Family Educational Rights and Privacy Act (ㅌRPA): N/A

2. Does this project have funding from any of the following federal agencies? (Check all that apply) 
$\square$ Department of Defense (DOD)

$\square$ Department of Education

Department of Energy

Department of Justice

Department of Navy

Environmental Protection Agency (EPA)

$\square$ National Institute of Health

National Science Foundation (NSF)

If any of the above are checked, describe the plan to comply with the regulations required by that agency: (See Regulatory Compliance Required by Federal Funding

Agencies for a list of these regulations.) N/A

\section{Section III: Appendices}

\section{a. Informed Consent/Assent/Permission forms}

(See Informed Consent or Waiver of Consent Checklists for guidance.)

\section{b. $\quad$ Training and Experience}

All staff engaged in human subjects' interaction and intervention, or working with identifiable human data or private information about live human subjects activities are required to complete training. The submission packet must include documentation of training for all personnel listed in the protocol, including student investigators and PI's. It is the PI's responsibility to ensure that all other staff (not listed on the protocol) complete this training and keep documentation. The IRB may request documentation of training at any time as part of a post approval monitoring activities.

IRB applications received without training certificates are considered incomplete. The effective application receipt date will be when the complete application (including training) is received by ORI.

Training is available online through the Collaborative Institutional Training Initiative (CITI): https://www.citiprogram.org/. When signing up for the training, please select the Social \& Behavioral Research Investigators learner group and complete either the Social \& Behavioral Research - Basic/Refresher course OR the Social and Behavioral Responsible Conduct of Research course. Submit a copy of the completion certificate electronically to the IRB office. Alternatively, a completion certificate of the National Institute of Health's Protecting Human Research Participants course may be submitted. Please note, we are unable to verify NIH training electronically, so completion documentation must be provided directly to the IRB at hsrrc@pdx.edu.

In addition to the CITI or NIH training, please describe any specialized training, education, or experience that would help to minimize the risks, particularly if working 
with vulnerable populations and/or sensitive topics. If the researcher will be advised by an expert or on-site mentor, note this information in the application.

c. Recruitment Materials (Posters, Flyers, Scripts)

d. Data Collection Instruments (Interviews, Surveys, Focus Group Questions)

e. $\quad$ Expedited Checklist (optional)

The IRB makes the final determination of whether a non-exempt project is eligible for review under expedited or full board review. If you believe that the research is nonexempt and eligible for expedited review, you may fill out the expedited checklist and attach to this application.

f. Addendums as appropriate

Please submit completed applications by email to hsrrc@pdx.edu DATA COLLECTION CANNOT BEGIN UNTIL IRB APPROVAL IS GRANTED. 